\title{
Immunthrombozytopenie - aktuelle Diagnostik und Therapie: Empfehlungen einer gemeinsamen Arbeits- gruppe der DGHO, ÖGHO, SGH, GPOH und DGTI
}

\author{
Axel Matzdorffa ${ }^{\mathrm{O}}$ Oliver Meyer ${ }^{\mathrm{b}}$ Helmut Ostermann ${ }^{\mathrm{c}}$ Volker Kiefel $^{\mathrm{d}}$ Wolfgang Eberl $^{\mathrm{e}}$ \\ Thomas Kühne ${ }^{f}$ Ingrid Pabinger ${ }^{g}$ Matthias Rummel ${ }^{\mathrm{h}}$ \\ ${ }^{a}$ Asklepios Klinikum Uckermark, Schwedt/Oder, Deutschland; \\ ${ }^{b}$ Institut für Transfusionsmedizin, Universitätsmedizin Berlin - Campus Benjamin Franklin, Berlin, Deutschland; \\ ${ }^{\mathrm{c}}$ Medizinische Klinik und Poliklinik III, Klinikum der Universität München, München, Deutschland; \\ dInstitut für Transfusionsmedizin, Universitätsmedizin Rostock, Rostock, Deutschland; \\ ${ }^{\text {e}}$ Klinik für Kinder- und Jugendmedizin, Klinikum Braunschweig, Braunschweig, Deutschland; \\ f Onkologie/Hämatologie, Universitäts-Kinderspital beider Basel, Basel, Schweiz; \\ ${ }^{9}$ Klinische Abteilung für Hämatologie und Hämostaseologie, Universitätsklinik für Innere Medizin I - Medizinische Universität Wien, \\ Wien, Österreich; \\ ${ }^{\text {h} M e d i z i n i s c h e ~ K l i n i k ~ I V ~(H a ̈ m a t o l o g i e), ~ U n i v e r s i t a ̈ t s k l i n i k u m ~ G i e ß e n, ~ G i e ß e n, ~ D e u t s c h l a n d ~}$
}

\section{Einleitung}

Die Immunthrombozytopenie (ITP) ist eine seltene Erkrankung («orphan disease») und die Expertise im Umgang mit diesen Patienten ist nicht «breit gestreut». Die folgenden Empfehlungen sollen Ärzte, Zahnärzte und Angehörige anderer Gesundheitsberufe, die nicht häufig Umgang mit ITP-Patienten haben, bei ihren Entscheidungen unterstützen.

Im Jahr 1996 publizierte die American Society of Hematology (ASH) ihre erste ITP-Leitlinie [1]. Diese sogenannte ASH-Leitlinie war viele Jahre lang richtungsweisend für die Behandlung der ITP. Die ASH-Leitlinie von 1996 wird häufig als erste Leitlinie zur ITP genannt. Tatsächlich datiert die erste ITP-Leitlinie jedoch 4 Jahre früher [2]. Sie beschränkte sich jedoch auf die pädiatrischen ITP und erreichte deshalb keinen vergleichbaren Bekanntheitsgrad. Die bisher letzte deutschsprachige ITP-Leitlinie wurde im Jahr 2014 publiziert [3]. Aufgrund zahlreicher neuer Erkenntnisse ist eine Aktualisierung notwendig geworden. Die folgenden Empfehlungen einer interdisziplinären Arbeitsgruppe von Fachexperten der Deutschen Gesellschaft für Hämatologie und Medizinische Onkologie (DGHO), der Österreichischen Gesellschaft für Hämatologie und Medizinische Onkologie (ÖGHO), der Schweizerischen Gesellschaft für Hämatologie (SGH), der Gesellschaft für pädiatrische Onkologie und Hämatologie (GPOH) und der Deutschen Gesellschaft für Transfusionsmedizin und Immunhämatologie (DGTI) berücksichtigen alle relevanten Publikationen bis November 2017. Abstracts werden nur zitiert, wenn sie in den Jahren 2015 und folgende auf Kongressen vorgestellt wurden.

\section{Terminologie und Definition}

Empfehlungsgrad EK

ITP steht für «Immunthrombozytopenie». Der Begriff «idiopathische thrombozytopenische Purpura» soll nicht mehr benutzt werden.

Eine ITP soll nur diagnostiziert werden, wenn die Thrombozytenzahl wiederholt unter $100 \times 10^{9} / 1$ liegt.

Das Akronym ITP steht für «Immunthrombozytopenie» und hat nach internationaler Übereinkunft den Begriff «idiopathische thrombozytopenische Purpura» abgelöst, weil man die ITP nicht mehr als idiopathisch (griech. ídios páthos = Erkrankung ohne fassbare Ursache) bezeichnen kann, seit man weiß, dass ihr eine Dysregulation des Immunsystems zugrunde liegt [4]. Außerdem zeigt fast ein Drittel der neu diagnostizierten ITP-Patienten keine Purpura, sondern nur niedrige Thrombozytenwerte $[5,6]$.

Von einer ITP spricht man - ebenfalls nach internationaler Übereinkunft - nur, wenn die Thrombozytenzahl wiederholt unter $100 \times 10^{9} / 1$ liegt [4]. Dies ist niedriger als die übliche untere Normbereichsgrenze für die Thrombozytenzahl (meist um $150 \times 10^{9} / 1$ ). Das Risiko von Personen mit Thrombozytenwerten zwischen 100 $\times 10^{9} / 1$ und $150 \times 10^{9} / 1$, im weiteren Verlauf eine ITP zu entwickeln, ist sehr gering $(<1 \% / \mathrm{Jahr})$.

In Tabelle 1 sind die Ursachen für eine Thrombopenie aufgeführt. Bei der ITP unterscheidet man eine primäre Form, bei der

\section{KARGER}

(c) 2018 S. Karger GmbH, Freiburs 
Tab. 1. Einteilung der Thrombozytopenien

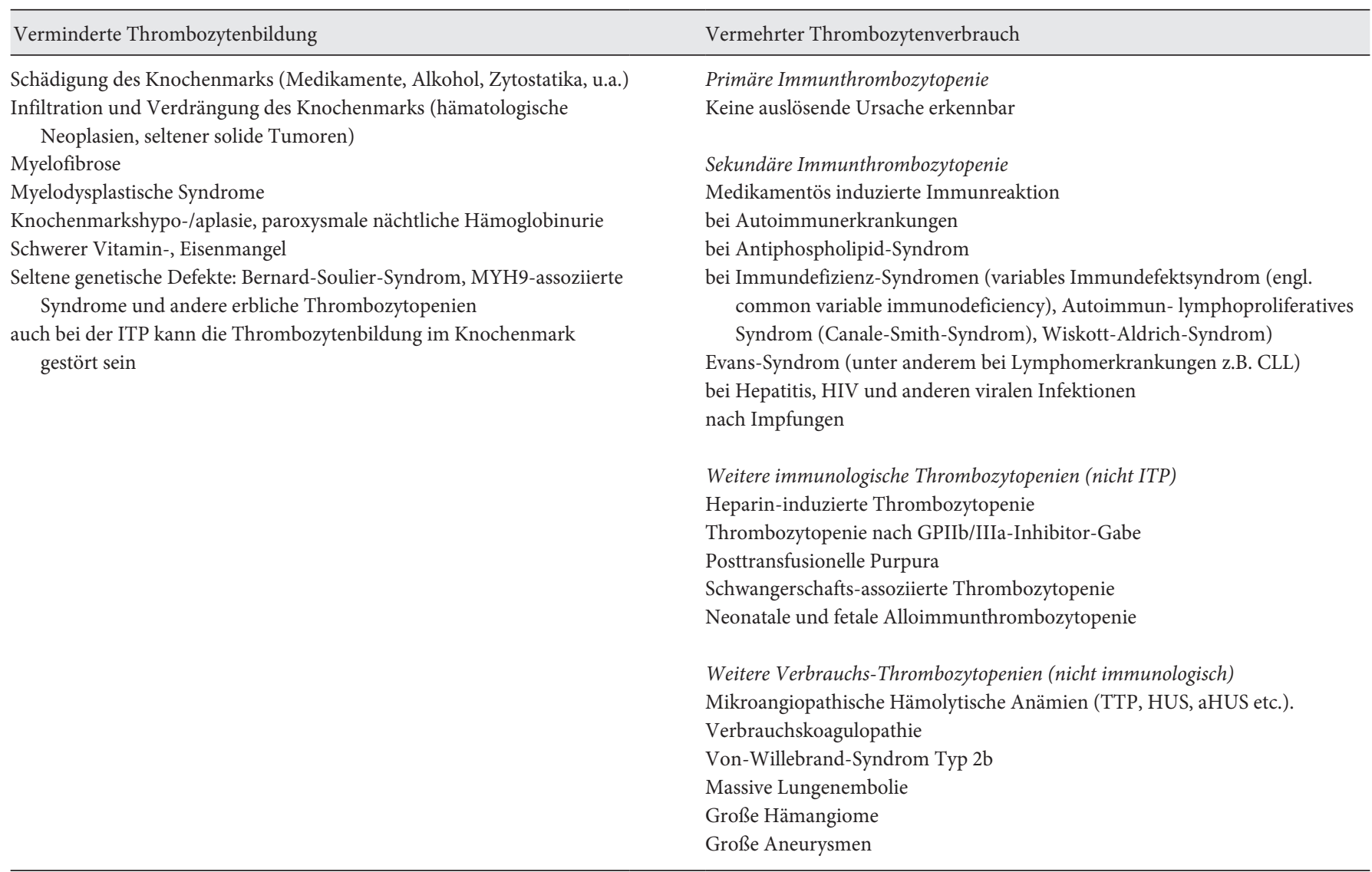

Andere Thrombozytopenien

Thrombozytopenie bei Milzvergrößerung

Thrombozytenverlust bei massiver Blutung

Thrombozytopenie bei schweren Infektionen

Probleme der Laboranalytik

EDTA-induzierte Pseudothrombozytopenie

keine auslösende Ursache erkennbar ist, von sekundären Formen, bei denen die ITP durch Medikamente oder andere Erkrankungen ausgelöst wird (etwa $80 \%$ primär, $20 \%$ sekundär) [7, 8].

\section{Historie}

Ein weit verbreitetes Eponym für die ITP ist der Begriff «Morbus Werlhof». Er geht auf Paul Gottlieb Werlhof (1699-1767) zurück. Werlhof war königlicher Leibarzt in Hannover und berichtete 1735 über ein 16-jähriges Mädchen, das nach einer Infektion Blutungen der Haut und Schleimhäute entwickelte (Morbus maculosus haemorrhagicus) [9]. Im angloamerikanischen Sprachraum wird außerdem auf Robert Willan (1757-1812) verwiesen, ein englischer Arzt und Begründer der Dermatologie, der 1802 das charakteristische und gleichzeitige Auftreten von kutaner Purpura mit Schleimhautblutungen beschrieb. Erst 1883 erkannte dann Eduard Krauss, dass die hämorrhagischen Symptome durch eine Thrombozytopenie hervorgerufen werden (Übersicht bei [10]).

\section{Epidemiologie}

Die ITP-Inzidenz liegt bei Erwachsenen bei 0,2-0,4 Neuerkrankungen pro $10000 / \mathrm{Jahr}$, bei Kindern bei $0,2-0,7$ pro 10 000/Jahr.

Bei Erwachsenen liegt die ITP-Inzidenz zwischen 0,2 und 0,4 Neuerkrankungen pro 10 000/Jahr $[11,12]$ und die Prävalenz bei 0,9-2,6 pro $10000[11,13,14]$.

Bei Kindern und Jugendlichen beträgt die ITP-Inzidenz 0,2-0,7 Neuerkrankungen pro 10 000/Jahr $[12,15,16]$ und die Prävalenz liegt bei 0,4-0,5 pro 10000 [17]. Die Prävalenz ist bei Kindern deutlich geringer als bei Erwachsenen, weil die pädiatrische ITP nur selten chronisch wird (siehe Abschnitt «Prognose und Risiko»).

Das mittlere Alter erwachsener ITP-Patienten liegt bei 50-55 Jahren $[14,18]$.

Geschlechterverhältnis: Bei der pädiatrischen ITP sind Jungen häufiger als Mädchen betroffen [19, 20]. Im mittleren Alter erkran- 
Tab. 2. Aufgaben eines ITP-Zentrums

\begin{tabular}{l} 
Aufgaben von ITP-Zentren \\
\hline 1. Betreuung von ITP-Patienten in enger Zusammenarbeit mit Hausarzt, \\
überweisendem Facharzt oder Klinik \\
2. Erstuntersuchung nach Zuweisung, gegebenenfalls Hinzuziehung weiterer \\
Spezialisten \\
3. Aufstellung eines individuellen Behandlungsplans \\
4. Initiierung der Behandlung incl. Schulung in der Selbsttherapie \\
5. Mindestens halbjährliche Verlaufs- und Kontrolluntersuchungen \\
6. Bei etabliertem Arzt-Patienten-Kontakt regelmäßige Diagnose- und \\
Therapiebesprechungen telefonisch oder per Video-Sprechstunde \\
7. Telefonischer oder webbasierter Video-Konsildienst als Angebot für ex- \\
terne Ärzte und Kliniken auch außerhalb der üblichen Dienstzeiten \\
8. Zweitmeinungssprechstunde für Patienten \\
9. Beratung zur Blutungsprophylaxe vor Operationen \\
10. Beratung zur Antikoagulation, wenn aufgrund von Nebenerkrankungen \\
(KHK, Schlaganfall, Thrombose, etc.) indiziert \\
11. Beratung zur Behandlung bei Infektionen \\
12. Impfberatung \\
13. Beratung bei Auslandsreisen \\
14. Individuelle Beratung und Hilfestellung bei beruflichen, sozialen, versiche- \\
rungstechnischen, familiären, psychologischen Problemen
\end{tabular}

ken häufiger Frauen. Ab dem 60. Lebensjahr überwiegen dann wieder die Männer [8, 14, 21].

Jahreszeitliche Variabilität: Die ITP-Inzidenz ist bei Kindern im Frühjahr bis um das Doppelte höher als im Sommer [16, 19]. Als Grund vermutet man, dass im Winter Infekte, die eine ITP auslösen können, häufiger sind.

Ethnische Variabilität: Ältere Studien finden eine niedrigere ITP-Inzidenz bei Afroamerikanern. Im asiatisch-pazifischen Raum scheint die ITP genauso häufig zu sein wie in Europa.

Schätzungen für die Bundesrepublik Deutschland: Etwa 60\% der erwachsenen und 20-30\% der pädiatrischen ITP-Patienten entwickeln einen chronischen Verlauf (siehe Abschnitt «Prognose und Risiko»). Legt man diese Zahlen zugrunde, dann können für die Bundesrepublik 2400 Neuerkrankungen pro Jahr und 16 000 Patienten mit chronischer ITP angenommen werden. Der Anteil der ITP-Patienten mit niedrigen Thrombozytenzahlen $(<30 \times$ $\left.10^{9} / \mathrm{l}\right)$ schwankt je nach Publikation zwischen $30 \%$ und $70 \%[5,21]$. Das bedeutet für die Bundesrepublik zwischen 5000 und 13000 potenziell behandlungsbedürftige Patienten.

Da ITP-Patienten einerseits selten sind («orphan disease») und weil andererseits Diagnostik und Therapie immer teurer werden, plädieren die Autoren für die Schaffung eines Kompetenznetzwerkes für ITP-Patienten, vergleichbar mit den Hämophilie-Zentren für Bluterkranke. Zur Aufgabe von ITP-Zentren siehe Tabelle 2 .

\section{Pathophysiologie}

Pathomechanismen der ITP

1. Autoantikörper gegen Thrombozyten

1.1. induzieren einen vermehrten Abbau von Thrombozyten in Milz und Leber

1.2. induzieren die Bindung geschädigter Thrombozyten an den Ashwell-Morell Rezeptor der Leber mit anschließendem Abbau

1.3. schädigen Thrombozyten direkt

1.4. stören die Thrombozytenfunktion

2. T-Lymphozyten

2.1. Verminderung der regulatorischen T- Lymphozyten (TREGs) führt zu Immundysregulation

2.2. direktae Schädigung von Thrombozyten durch T-Lymphozyten

3. Hemmung der Thrombozytopoese

3.1. Schädigung der Megakaryozyten durch Antikörper,

3.2. verstärkter Abbau von Thrombopoetin,

3.3. verminderte Thrombopoetinbildung.

Die ITP ist nicht erblich, sie ist eine erworbene Thrombozytopenie. Traditionell wird die ITP als erworbene Thrombozytopenie von den viel selteneren angeborenen Thrombozytopenien (z.B. BernardSoulier-Syndrom, MYH9-assoziierte Syndrome und andere) abgegrenzt. Es gibt aber auch seltene angeborene «ITP-Formen» oder noch besser «Immunthrombozytopenien», zur besseren Unterscheidung von der «normalen» ITP, die wir hier besprechen. (Wiskott-Aldrich-Syndrom, autoimmun-lymphoproliferatives Syndrom = Canale-Smith-Syndrom), diese werden hier nicht behandelt (siehe Lehrbücher der pädiatrischen Hämatologie). Ursächlich ist eine Autoimmunreaktion gegen Thrombozyten und Megakaryozyten $[7,22]$. Die Immunreaktion wird von unterschiedlichen pathogenetischen Mechanismen getragen (Übersicht bei [23-25]).

\section{Thrombozytenantikörper}

Vermehrter Abbau antikörperbeladener Thrombozyten nach Bindung an Fc-Rezeptoren in Milz und Leber: In den 1950er Jahren wurde gezeigt, dass die Übertragung von Plasma eines Patienten mit ITP bei gesunden Probanden eine reversible Thrombozytopenie auslösen kann [26]. Die Publikation von Harrington et al. [26] war entgegen weitläufiger Annahme nicht die erste, die im Blut von ITP-Patienten einen pathogenen Faktor gegen Thrombozyten nachwies. 1938 wurde bereits - allerdings in Tierversuchen - gezeigt, dass die Milz von ITP-Patienten Thrombozytopenie auslösende Substanzen enthält. Ursächlich sind Antikörper gegen Thrombozyten. Heute findet man mit modernen Untersuchungsmethoden bei etwa $60 \%$ aller ITP-Patienten solche Autoantikörper gegen Thrombozytenmembranproteine (z.B. Glykoproteine (GP) Ib/IX, GP IIb/IIIa). Die antikörpermarkierten Thrombozyten werden an Fc-Rezeptoren von Makrophagen und dendritischen Zellen in Milz und Leber gebunden, phagozytiert und abgebaut. 
Vermehrter Abbau antikörperbeladener Thrombozyten nach Bindung an Ashwell-Morell-Rezeptoren in der Leber: Kürzlich wurde ein neuer Abbauweg über die Ashwell-Morell-Rezeptoren in der Leber beschrieben: Wenn Thrombozyten altern oder geschädigt sind, werden Sialinsäure-Reste auf der Thrombozytenmembran hydrolisiert (Desialylation). Desialylierte Thrombozyten binden an den Ashwell-Morell-Rezeptor von Hepatozyten und werden aus dem Blutstrom herausgefiltert, was wiederum die Neubildung von Thrombopoetin in der Leber stimuliert [27, 28].

Apoptose von Thrombozyten nach direkter Schädigung durch Thrombozytenantikörper: Thrombozytenantikörper können Thrombozyten auch durch Komplementbindung direkt schädigen, unabhängig von der Phagozytose in der Milz.

Thrombozytenfunktionsstörung durch Thrombozytenantikörper: Thrombozytenantikörper können durch Bindung an Rezeptoren auf der Thrombozytenmembran deren Adhäsions- oder Aggregationsfunktion stören und die Blutungsneigung zusätzlich verstärken (bei Bindung an GP-IIb/IIIa-Rezeptor $\rightarrow$ erworbene Thrombasthenie Glanzmann).

\section{T-Lymphozyten und Immundysregulation}

Immundysregulation: Eine gegen B-Lymphozyten und die Antikörperbildung gerichtete Therapie erreicht nicht bei allen ITP-Patienten einen Anstieg der Thrombozytenzahl. Es muss also B-Lymphozyten-unabhängige Mechanismen geben. Bei ITP-Patienten findet man ein Ungleichgewicht zwischen aktivierenden und regulatorischen T-Lymphozyten (Tregs).

Direkte Schädigung von Thrombozyten durch T-Lymphozyten: T-Lymphozyten sind nicht nur an einer Immundysregulation beteiligt. Ein direkter toxischer Effekt von T-Lymphozyten auf Thrombozyten und Megakaryozyten ist beschrieben [29].

\section{Hemmung der Thrombozytopoese}

Schädigung der Megakaryozyten durch Autoantikörper gegen GP: Autoantikörper gegen Thrombozytenmembranproteine greifen auch die Megakaryozyten im Knochenmark an und stören die Thrombozytopoese.

Verstärkter Abbau von Thrombopoetin: ITP-Patienten haben häufig einen relativen Thrombopoetinmangel. Darunter versteht man, dass bei ITP-Patienten die Thrombopoetinspiegel zwar höher als bei gesunden Menschen sind, aber nicht so hoch, wie man sie bei anderen Erkrankungen findet, die einen vergleichbaren Thrombozytenmangel aufweisen (z.B. aplastische Anämie oder nach Chemotherapie) [30]. Ein Grund scheint darin zu liegen, dass Thrombopoetin an Thrombozyten bindet und mit diesen zusammen in Leber und Milz abgebaut wird [31]. Außerdem ist bei ITP-Patienten in der Regel die Zahl der Megakaryozyten im Knochenmark erhöht, die auch Thrombopoetin binden und so den Mangel verstärken.

Verminderte Thrombopoetinbildung: Ein weiterer Mechanismus, der die Thrombopoetinspiegel relativ niedrig hält, sind die
Thrombozytenantikörper selber. Im Tierexperiment konnte gezeigt werden, dass der vom Ashwell-Morell-Rezeptor unabhängige Abbau antikörperbeladener Thrombozyten über Fc-Rezeptoren von Makrophagen und dendritischen Zellen die Thrombopoetinbildung nicht stimuliert [27].

\section{Klinisches Bild}

Die verstärkte Blutungsneigung bestimmt das klinische Bild. Typisch sind Petechien und Schleimhautblutungen. Viele ITPPatienten klagen zusätzlich über Erschöpfungssymptome und Müdigkeit («Fatigue»), bis hin zu depressiven Störungen.

\section{Blutungssymptome}

Typische Blutungssymptome sind:

- Petechien an den Beinen, weniger häufig an Rumpf und Armen

- Blutungen der Schleimhäute von Mund und Nase

- urogenitale Blutungen, verstärkte Menstruationsblutungen

- verstärkte Blutungen und Hämatomneigung schon bei kleinen Traumen

- selten innere Blutungen (z.B. intrazerebrale Blutung)

Petechien sind typischerweise nicht palpabel. Eine palpable Purpura spricht eher für eine vaskulitische Purpura. Ebenfalls untypisch für die ITP sind flächenhafte Hämatome (kleinflächig: Ekchymosen, großflächig: Sugillationen) und Gelenkblutungen; diese findet man eher bei plasmatischen Gerinnungsstörungen (z.B. Hämophilie A und B).

Bei der neu diagnostizierten ITP haben $10 \%$ aller pädiatrischen und $20-30 \%$ aller erwachsenen Patienten gar keine Blutungssymptome $[5,32,33]$. Bei der chronischen ITP liegt der Anteil der Patienten ohne jegliche Blutungssymptome bei $30-40 \%$ [32, 34, 35].

Die Blutungsneigung bei ITP-Patienten ist geringer als bei Patienten mit einer vergleichbaren Thrombozytopenie anderer Ursache (z.B. nach Chemotherapie oder bei Myelodysplasien, Leukämien). Man vermutet, dass ITP-Thrombozyten «jünger» und zum Teil stärker reagibel sind als Thrombozyten bei den anderen genannten Erkrankungen. Die verstärkte Reagibilität der ITPThrombozyten erklärt nicht nur die relativ geringere Blutungsneigung, sondern auch das vermehrte Auftreten von Thrombosen bei ITP-Patienten (siehe Abschnitt «ITP als Risikofaktor für venöse und arterielle Thromboembolien»).

\section{Weitere Symptome}

- ITP-Patienten haben durch immunsuppressive Therapien oder Splenektomie ein erhöhtes Infektionsrisiko. In den letzten Jahren vermutet man aber auch, dass die ITP per se ein Infektionsrisiko darstellt [36]. Man hat erkannt, dass Thrombozyten nicht nur eine Rolle bei der Gerinnung, sondern auch bei der Infektabwehr spielen [37]. 
Tab. 3. Blutungsgrade entsprechend WHO und NCI-CTCAE v4.0 [41-43]

\begin{tabular}{|c|c|}
\hline WHO Blutungsgrade & Definition \\
\hline 0 & keine Blutungszeichen \\
\hline I & $\begin{array}{l}\text { Petechien } \\
\text { kleine Hämatome, Ekchymosen }(<10 \mathrm{~cm}) \\
\text { Schleimhautblutungen (Mund, Nase) } \\
\text { Epistaxis ( }<1 \text { h Dauer, keine ärztliche Intervention notwendig) } \\
\text { subkonjunktivale Blutungen } \\
\text { vaginale Blutungen (unabhängig von Menstruation, nicht mehr als } 2 \text { Binden/Tag notwendig) }\end{array}$ \\
\hline $\begin{array}{l}\text { II } \\
\text { (nicht transfusionspflichtig) }\end{array}$ & $\begin{array}{l}\text { Hämatome, Ekchymosen }(>10 \mathrm{~cm}) \\
\text { Epistaxis (>1 h. Dauer oder Tamponade notwendig) } \\
\text { retinale Blutungen ohne Visusverminderung } \\
\text { vaginale Blutungen (unabhängig von Menstruation, mehr als } 2 \text { Binden/Tag notwendig) } \\
\text { Melaena, Hämatemesis, Hämoptysen, Hämaturie, Hämatochezie } \\
\text { Blutungen aus Punktionsstellen } \\
\text { Blutungen in Muskel und Gelenke }\end{array}$ \\
\hline $\begin{array}{l}\text { III } \\
\text { (transfusionspflichtig) }\end{array}$ & $\begin{array}{l}\text { Epistaxis } \\
\text { Schleimhautblutungen (Mund, Nase) } \\
\text { vaginale Blutungen } \\
\text { Melaena, Hämatemesis, Hämoptysen, Hämaturie, Hämatochezie } \\
\text { Blutungen aus Punktionsstellen } \\
\text { Blutungen in Muskel und Gelenke }\end{array}$ \\
\hline $\begin{array}{l}\text { IV } \\
\text { (Gefahr von Dauerschäden, lebens- } \\
\text { bedrohlich) }\end{array}$ & $\begin{array}{l}\text { retinale Blutungen mit Visusverminderung } \\
\text { ZNS Blutungen } \\
\text { andere Organblutungen, die die Funktion der betroffenen Organe (Gelenke, Muskulatur, Niere, Lunge, etc.) gefährden } \\
\text { letale Blutungen (in den NCI CTCAE als Blutungsgrad V bezeichnet) }\end{array}$ \\
\hline
\end{tabular}

- Als Folge verstärkten Blutverlustes kann sich eine Eisenmangelanämie entwickeln. Eine mikrozytäre Eisenmangelanämie wäre also mit einer ITP vereinbar, makrozytäre Anämien dagegen nicht.

- Viele ITP-Patienten klagen zusätzlich zur Blutungsneigung über Erschöpfungssymptome und Müdigkeit («Fatigue»), bis hin zu depressiven Störungen. Auch ein Zusammenhang zwischen ITP und kognitiven Funktionseinschränkungen wird beschrieben $[38,39]$ (siehe dazu Abschnitt «Lebensqualität»).

\section{Schweregrad}

\section{Empfehlungsgrad EK}

Die Graduierung der Blutungsschwere bei Erwachsenen sollte nach WHO/NCI-CTCAE erfolgen.

Die Behandlung der ITP orientiert sich wesentlich an der klinischen Blutungsneigung. Zur Einschätzung der Blutungsschwere wurden in der Vergangenheit zahlreiche Blutungsscores entwickelt (Übersicht bei [40]). Der Nachteil dieser Scores ist der hohe Zeitaufwand, der ihre Anwendung im «eng getakteten» Praxisalltag begrenzt. Deshalb wird weiter eine Orientierung an den Blutungsgraden der Weltgesundheitsorganisation (WHO) oder den National Cancer Institute Common Terminology Criteria for Adverse
Events (NCI-CTCAE) empfohlen [41-43] (Tab. 3). Sie sind in der klinischen Praxis etabliert, den meisten Ärzten nichthämatologischer Fachrichtungen geläufig und haben sich auch bei ITP-Patienten bewährt.

\section{Stadieneinteilung und Verlauf}

\section{Empfehlungsgrad EK}

Man unterscheidet die neu diagnostizierte von der persistierenden und der chronischen ITP.

Je länger die Erkrankung dauert, desto mehr tritt die Normalisierung der Thrombozytenzahl als Therapieziel in den Hintergrund und die Vermeidung von Nebenwirkungen und eine möglichst normale Lebensqualität in den Vordergrund.

Weil sich Therapie und Therapieziele mit der Krankheitsdauer und Schwere ändern, wurde die traditionelle Zweiteilung in «akute» und «chronische» ITP verlassen, eine neue Einteilung in 3 Krankheits- und Therapiephasen entwickelt und von den Leitlinien übernommen (Tab. 4) [4].

Viele erwachsene ITP-Patienten haben jedoch, wenn man älterer Blutbilder habhaft werden kann, schon Monate, zum Teil auch Jahre vorher leicht erniedrigte Thrombozytenwerte, oder die Patienten berichten, dass sie schon längere Zeit vermehrte Hämatome 
Tab. 4. Stadieneinteilung und Therapieziele [4]

\begin{tabular}{|c|c|c|}
\hline Stadium $^{\mathrm{a}}$ & Definition & Therapieziel \\
\hline Neu diagnostiziert & $\begin{array}{l}\text { Bis zu } 3 \text { Monate nach Diagnosestellung } \\
\text { Spontanremission häufig }\end{array}$ & $\begin{array}{l}\text { Blutungsstillung und Kuration } \\
\text { Bei kurzer Therapiedauer unter Inkaufnahme von Nebenwirkungen }\end{array}$ \\
\hline Persistierend & $\begin{array}{l}\text { Zwischen } 3 \text { und } 12 \text { Monaten nach Diagnosestellung } \\
\text { Spontanremission weniger häufig }\end{array}$ & $\begin{array}{l}\text { Blutungsstillung, Kuration } \\
\text { Da Therapie häufiger längerfristig, sind Nutzen und Nebenwirkun- } \\
\text { gen stärker gegeneinander abzuwägen }\end{array}$ \\
\hline Chronisch & $\begin{array}{l}\text { Mehr als } 12 \text { Monate nach Diagnosestellung } \\
\text { Eine spontane Remission ist jetzt nicht mehr wahrscheinlich }\end{array}$ & $\begin{array}{l}\text { Blutungsstillung und Kuration } \\
\text { Lebensqualität, gegebenenfalls unter Inkaufnahme einer chronischen } \\
\text { Thrombozytopenie. } \\
\text { Therapie nur bei schwereren Blutungen zwingend, bei oligo- oder } \\
\text { asymptomatischen Patienten auch «Watch \& Wait» möglich }\end{array}$ \\
\hline
\end{tabular}

${ }^{a}$ Vor 2009 wurde nur zwischen «akuter» und «chronischer» ITP unterschieden und die Grenze bei 6-12 Monaten gezogen.

Tab. 5. Prognose und Risikoindikatoren [53-58]

\begin{tabular}{|c|c|c|}
\hline Eher selbstlimitierender Verlauf & Eher chronischer Verlauf & Erhöhtes Risiko schwerer Blutungen \\
\hline Kinder, Jugendliche & Erwachsene, insbesondere $>60$. Lebensjahr & $\begin{array}{l}\text { Thrombozyten }<20-30 \times 10^{9} / 1 \\
\text { Multiple Hämatome }\end{array}$ \\
\hline Beginn nach Infekt & Keine vorausgehende Erkrankung eruierbar & Schleimhautblutungen («wet purpura») \\
\hline Plötzlicher Beginn & Schleichender Beginn & $\begin{array}{l}\text { Anamnestisch schwere Blutungen } \\
\text { Hämaturie }\end{array}$ \\
\hline Klinisch ausgeprägte Blutungsneigung & $\begin{array}{l}\text { Geringe Blutungsneigung oder Zufallsbefund } \\
\text { bei asymptomatischen Patienten }\end{array}$ & $\begin{array}{l}\text { Fehlende Ansprache auf Steroide } \\
\text { Infektion, Fieber } \\
\text { Alter }>60 \text { Jahre }\end{array}$ \\
\hline
\end{tabular}

beobachtet, dem aber zunächst keine Bedeutung beigemessen haben. Die Definition «neu diagnostiziert», «persistierend» oder «chronisch» sollte jedoch weiterhin nicht an der Symptomdauer, sondern am Zeitpunkt der Diagnosestellung festgemacht werden.

\section{Prognose und Risiko}

Das Risiko tödlicher Blutungen liegt bei Kindern bei fast $0 \%$, bei Erwachsenen bei 0-7\% (besonders ältere Patienten). Ein bis zwei Drittel der chronischen ITP-Patienten erreichen zum Teil noch nach mehreren Jahren eine partielle oder komplette Remission.

Bei der ITP des Erwachsenen hat man bisher einen langfristigen, chronischen Verlauf über mehrere Jahre oder sogar lebenslang postuliert. In der ASH-Leitlinie von 1996 steht noch, dass nur $\sim 5 \%$ eine Remission erreichen [1]. Heute weiß man, dass ein bis zwei Drittel der chronischen ITP-Patienten zum Teil noch nach mehreren Jahren eine partielle oder komplette Remission erreichen $[32,44]$. Dies hat Auswirkungen auf die Therapiewahl, wie z.B. auf die Entscheidung, eine Splenektomie zu empfehlen oder noch abzuwarten (siehe Abschnitt «Splenektomie»). Es gibt keinen Marker, der verlässlich einen chronischen Verlauf vorhersagen könnte.

Noch vor etwas mehr als 10 Jahren wurde das Risiko schwerer Blutungen mit 3\% bei Kindern und über 70\% bei älteren Erwachsenen (> 60 Jahre) angegeben, das Risiko tödlicher Blutungen mit 0\% bzw. 13\% [45-47]. Durch Zurückhaltung bei der Steroidtherapie und durch die neuen Thrombopoetinrezeptor-Agonisten (TRA) ist die Prognose in den letzten Jahren deutlich besser geworden. Die Mortalität liegt in aktuellen pädiatrischen Studien unverändert bei $0 \%$, bei Erwachsenen hat sie sich auf $0-7 \%$ halbiert [34, 48-52] (Tab. 5).

\section{Diagnostik}

\section{Empfehlungsgrad EK}

Für die Erstdiagnose reicht in der Regel der Nachweis der isolierten Thrombozytopenie bei normalen Leukozyten- und Erythrozytenparametern. Der Umfang der weiteren Diagnostik richtet sich nach Krankheitsschwere und Verlauf.

Die Begutachtung des Blutausstriches ist zwingend erforderlich.

Die Diagnose ITP sollte nur durch einen in der Diagnostik von Thrombozytopenien erfahrenen Arzt gestellt werden. 
Tab. 6. Basisdiagnostik bei Erstvorstellung und zunächst nur klinischem Verdacht auf ITP

Diagnostik bei Erstvorstellung

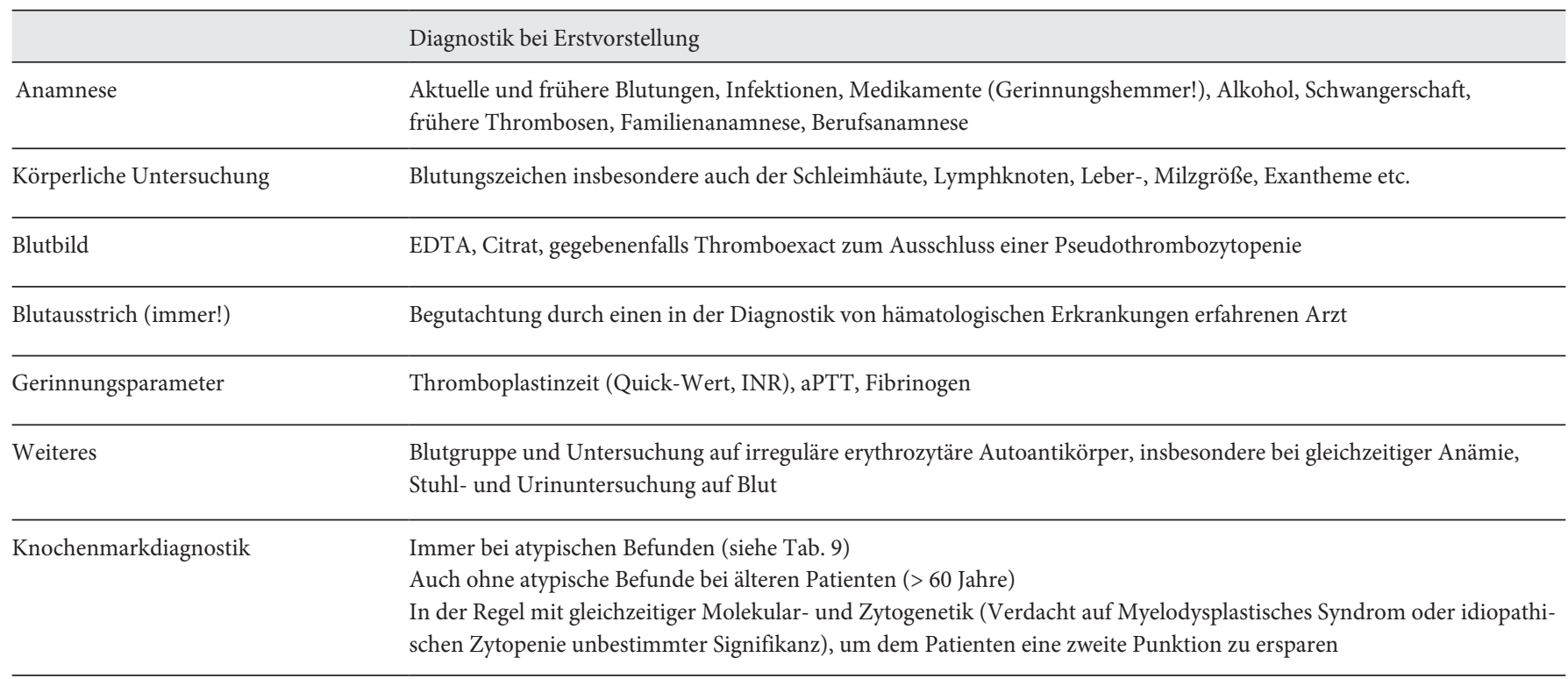

Die ITP ist eine Ausschlussdiagnose. Es gibt keinen Labortest und keine Untersuchung, die eine ITP «beweist». Die Diagnostik und Differenzialdiagnostik erfolgen in der Regel in mehreren Schritten.

\section{Schritt 1: Erste Feststellung einer Thrombozytopenie beim Hausarzt oder durch einen nicht in der Diagnostik von Thrombozytopenien erfahrenen Arzt}

In der Regel werden ITP-Patienten mit Blutungen erst vom Hausarzt gesehen oder sie stellen sich in der Notaufnahme einer Klinik vor. ITP-Patienten ohne Blutungen fallen dagegen bei Routineuntersuchungen («Gesundheitschecks») oder im Rahmen präoperativer Abklärungen auf. Ein in der Diagnostik und Therapie von Thrombozytopenien wenig erfahrener Arzt sollte keine weiteren Untersuchungen veranlassen, sondern den Patienten umgehend an einen Facharzt für Hämatologie oder in eine Klinik überweisen. Auch die Diagnose der EDTA-induzierten Pseudothrombozytopenie (EDTA = Ethylendiamintetraacetat) sollte nicht allein durch den Hausarzt oder Allgemeinmediziner gestellt werden.

\section{Schritt 2: Basisdiagnostik durch den Facharzt}

Nach Weiterleitung zum Facharzt oder in die Klinik sollte eine Basisdiagnostik gemäß Tabelle 6 durchgeführt werden:

Die Diagnose ITP kann gestellt werden, wenn die Basisdiagnostik keine andere Differenzialdiagnose zeigt und wenn die Thrombozytenzahl bei $<100 \times 10^{9} / 1$ liegt [4]. Dieser Wert ist bewusst niedriger gewählt als die untere Normbereichsgrenze (meist $150 \times$ $10^{9} / \mathrm{l}$ ), weil man eine Thrombozytopenie zwischen $100 \times 10^{9} / \mathrm{l}$ und der unteren Normbereichsgrenze in der Regel auch nicht behandeln würde.

\section{Blutausstrich}

Zur Erstdiagnostik nicht nur der ITP, sondern grundsätzlich jeder Thrombozytopenie gehört bei Erwachsenen wie bei Kindern und Jugendlichen zwingend die Begutachtung des Blutausstriches durch einen in der Diagnostik von hämatologischen Erkrankungen erfahrenen Arzt. Eine thrombotisch thrombozytopenische Purpura ist eine wichtige Differenzialdiagnose und ein hämatologischer Notfall, der nicht übersehen werden darf!

\section{Schritt 3: Weiterführende Diagnostik bei persistierender oder chronischer ITP}

Bei persistierender oder chronischer ITP müssen weitere Differenzialdiagnosen erwogen werden (Tab. 7).

Diagnostische Maßnahmen und ihre jeweilige Begründung sind in Tabelle 8 aufgeführt.

Der Nachweis von antinukleären Antikörpern (ANA), AntiPhospholipid-Antikörpern und Lupus-Antikoagulans ist von prognostischer Relevanz, weil bei diesen Patienten Thrombosen häufiger auftreten (siehe Abschnitt «ITP als Risikofaktor für venöse und arterielle Thromboembolien»). Der Nachweis von SchilddrüsenAntikörpern hat keine Auswirkungen auf die Therapie der ITP; eine Autoimmunthyreoiditis sollte jedoch erkannt und behandelt werden.

Bei einigen Patienten zeigt die Sonografie eine vergrößerte Milz. Dann muss neben Erkrankungen der Leber und Lymphomen (Haarzellleukämie, Marginalzonenlymphom und andere) auch an die seltene Differenzialdiagnose eines Morbus Gaucher gedacht werden (hinweisend: Ferritin $\uparrow \uparrow$, Angiotensin Converting Enzyme (ACE) $\uparrow \uparrow$; beweisend: $\beta$-Glukozerebrosidase-Aktivität $\quad \downarrow$ (Trockenbluttests)). 
Tab. 7. Differenzialdiagnosen der ITP und typische Befunde

\begin{tabular}{ll}
\hline Differenzialdiagnose & Anamnese, typische Befunde \\
\hline $\begin{array}{l}\text { Wurde eine EDTA-induzierte Pseudothrombozytopenie bereits aus- } \\
\text { geschlossen? }\end{array}$ & $1-5 \%$ aller Blutproben
\end{tabular}

Hereditäre Thrombozytopenie

Familienanamnese, Untersuchung des Blutausstriches und MPV, ob sehr große (Bernard-Soulier-Syndrom, MYH9-assoziierte Syndrome und andere) oder kleine Thrombozyten (Wiskott-Aldrich-Syndrom) etc.

Medikamenten-induzierte Thrombozytopenie

Zytostatika-induzierte Thrombozytopenie
Virustatika-induzierte Thrombozytopenie

Heparin-induzierte Thrombozytopenie (HIT)

Posttransfusionelle Purpura

Schwangerschaftsassoziierte-Thrombozytopenie

Lymphome

Infektionen (Viren, Bakterien, Parasiten)

Lebererkrankungen

Alkoholabusus
Sarkoidose
$\begin{aligned} & \text { Schwere Vitaminmängel (B12, Folsäure, auch selten bei schwerem } \\ & \text { Eisenmangel) }\end{aligned}$

Andere Autoimmunerkrankungen

Hämatologische Systemerkrankungen (akute Leukämie, myeloproliferative Syndrome, Myelodysplasie, idiopathischen Zytopenie unbestimmter Signifikanz, Plasmozytom, Lymphome, CVID, Autoimmun-lymphoproliferatives Syndrom, aplastische Anämie, paroxysmale nächtliche Hämoglobinurie, Graft-versus-HostErkrankung)

Thrombotisch thrombozytopenische Purpura und hämolytisch urämisches Syndrom

Von-Willebrand-Syndrom Typ 2b

Verbrauchskoagulopathie

Große Hämangiome (z.B. Kasabach-Merritt-Syndrom), große Aneurysmen
Anamnese, Testung auf Medikamenten-abhängige Thrombozyten-Antikörper

Anamnese (nicht nur auf «klassische» Zytostatika, auch moderne molekulare und immunologische Anti-Tumor-Wirkstoffe, z.B. Immun-Checkpoint-Inhibitoren)

Anamnese

Anamnese und HIT-Labordiagnostik

Kurz zurückliegende Bluttransfusionen

Nur schwangere Patientinnen, meist über $80 \times 10^{9}$ Thrombozyten/l

Anamnese, B-Symptome, Sonographie der Lymphknotenstationen, Milzgröße, eventuell Knochenmarkpunktion

Serologie auf HIV, CMV, EBV, Röteln, Parvovirus B19, Hantaviren und andere Bakteriologische Untersuchungen, Blutkultur bei Verdacht auf Sepsis, Blutausstrich, bei Verdacht auf Malaria

Leberwerte, Hepatitis-Serologie, Sonographie auf Splenomegalie,

Gaucher-Diagnostik

Sollte gezielt erfragt werden

Insbesondere bei Milzvergrößerung, Knochenmarkbefall

Labordiagnostik

Labordiagnostik für Lupus erythematodes, rheumatoide Arthritis, AntiphospholipidSyndrom, Autoimmun-Thyreoiditis, und andere Autoimmunsyndrome

Veränderung auch anderer Blutzellreihen und/oder der Serum-Immunglobuline, Knochenmarkpunktion eventuell mit Durchflusszytometrie, Molekular- und Zytogenetik

!Bei Kindern ist die ALL die wichtigste DD der neu diagnostizierten ITP!

Meist weitere Symptome: Fieber, Hämolyse, Niereninsuffizienz, neurologische Symptome etc.

Funktionelle Von-Willebrand-Faktor-Analyse inklusive Multimeranalyse

Veränderung weiterer Gerinnungsparameter

Klinisches Bild

\section{Medikamenteninduzierte Thrombozytopenie}

Diese ist die wichtigste Differenzialdiagnose der ITP und kann manchmal nur durch wiederholte (!) Anamnese ausgeschlossen werden. Dabei sollten auch naturheilkundliche und nicht rezeptpflichtige Medikamente erfragt werden, die von Laien häufig nicht als Medikamente gewertet und bei einer Anamnese nicht genannt werden. Die Inzidenz wird mit 0,1 pro 10000 pro Jahr angegeben (zum Vergleich ITP 0,2-0,4 pro 10000 pro Jahr) [59]. In der Regel hat die medikamenteninduzierte ITP einen akuten Verlauf. Nach Absetzen des Medikamentes erholt sich die Thrombozytenzahl rasch wieder. Eine aktuelle Liste von Arzneistoffen, für die medikamenteninduzierte Thrombozytopenien beschrieben wurden, findet sich unter www.ouhsc.edu/platelets/ditp.html. 
Tab. 8. Weiterführende Diagnostik bei persistierender und chronischer ITP

\begin{tabular}{ll}
\hline Diagnostik & Begründung, Konsequenz \\
\hline Blutgruppentestung & Für Notfall-Pass, vor operativen Eingriffen mit hohem Blutungsrisiko \\
\hline Knochenmarkpunktion & siehe Tabelle 9 \\
\hline Blutzucker/Urinzucker & Ausschluss eines subklinischen Diabetes vor erneuter/fortgesetzter Steroid-Therapie \\
\hline Serum-Elektrophorese und/oder Serum-Immunglobuline & $\begin{array}{l}\text { Ausschluss von Immundefekt-Syndromen (z.B. common variable immunodeficiency), } \\
\text { eines Myeloms }\end{array}$ \\
\hline
\end{tabular}

Autoimmundiagnostik (CCP-Antikörper, ANA, ANCA, Anti-DS-DNA, Ausschluss einer sekundären ITP im Rahmen anderer Immunerkrankungen Antiphospholipid-Antikörper, Lupus Antikoagulans)

Thrombozytenglykoprotein-spezifische Autoantikörper Bei Patienten mit persistierender Thrombozytopenie, wenn Zweifel an der Diagnose ITP bestehen (nur hilfreich, wenn positiv). Gebundene Antikörper haben die höhere Sensitivität

Von-Willebrand-Faktor-Analyse Bei Von-Willebrand-Syndrom Typ 2b können mäßige bis schwere Thrombozytopenien auftreten.

Schilddrüsendiagnostik

Bis zu 10\% der ITP-Patienten haben Hinweise auf eine Autoimmunerkrankung der Schilddrüse und bedürfen gegebenenfalls einer Therapie

Helicobacter-pylori-Testung

siehe Kapitel «Helicobacter pylori»

Hepatitis B, C, HIV-Serologie

Falls positiv, Erkrankungs- bzw. Reaktivierungsrisiko im Falle einer immunsuppressiven Therapie oder vor Splenektomie

Sonographie, Röntgen, CT erwägen

Ausschluss solider Tumor, Lymphom und andere hämatologische Erkrankung. Bei vergrößerter Milz an Morbus Gaucher denken

Tab. 9. Indikationen für eine Untersuchung auf Thrombozytenantikörper und Knochenmarkpunktion

Indikationen für Untersuchung auf Thrombozytenantikörper (hilft nur bei positivem Befund)

Minimale oder völlig fehlende Ansprache auf Kortikosteroide oder i.v. Immunglobuline

Differentialdiagnose ITP vs. medikamentös-toxische Knochenmarkschädigung (z.B. bei chronischem Alkoholabusus).

Differentialdiagnose ITP vs. hereditäre Thrombozytopenie

Sicherung der Diagnose ITP bei gleichzeitiger Lebererkrankungen, Splenomegalie

Indikationen für Knochenmarkpunktion

Neben der Thrombozytenzahl sind auch andere Laborwerte, insbesondere Leukozyten- und Erythrozytenparameter verändert

Anamnese (z.B. B-Symptome, Gewichtsverlust) und körperliche Untersuchungsbefunde (z.B. vergrößerte Lymphknoten, Hepatosplenomegalie) sind nicht typisch für eine ITP

Patienten >60 Jahre wegen der zunehmenden Häufigkeit alternativer Diagnosen: Lymphome, myelodysplastische Syndrome, idiopathische Zytopenie

unbestimmter Signifikanz, Plasmozytom und andere

Vor Splenektomie, um vor diesem irreversiblen Eingriff alternative Diagnosen mit größter Sicherheit auszuschließen

\section{Untersuchung auf Thrombozytenantikörper}

Die Untersuchung auf Thrombozytenantikörper gehört nicht zur Diagnostik der neu diagnostizierten ITP, sondern sollte Patienten mit persistierender bzw. chronischer ITP und atypischem Krankheitsverlauf vorbehalten bleiben.

Relevant sind nur gebundene Antikörper gegen Glykoproteinrezeptoren der Thrombozyten, nicht gegen HLA.

Bei $60-80 \%$ der Patienten findet man mit modernen Untersuchungsmethoden gebundene Autoantikörper gegen Epitope auf den GP Ib und IIb/IIIa (Anmerkung: freie Thrombozytenautoan- tikörper im Serum sind nicht relevant). Die Bestimmung von Thrombozytenantikörpern kann nicht als Routineuntersuchung empfohlen werden. Relevant sind nur gebundene Antikörper, während freie Antikörper wenig sensitiv sind. Bei Patienten mit persistierender bzw. chronischer ITP und atypischen Befunden kann ihr Nachweis in Einzelfällen jedoch dazu beitragen, die Diagnose ITP zu sichern bzw. andere Differenzialdiagnosen auszuschließen (Tab. 9).

Achtung: Nur Autoantikörper gegen Glykoproteinrezeptor-Antigene unterstützen die Diagnose einer primären oder sekundären ITP. Antikörper gegen humane Leukozytenantigene (HLA) auf Thrombozyten sind im klinischen Alltag viel häufiger (z.B. nach Thrombozytentransfusion) und haben nichts mit der ITP zu tun. 


\section{Knochenmarkpunktion}

Heute ist allgemein akzeptiert, dass die ITP-Diagnose durch eine Knochenmarkpunktion nicht belegt werden kann. Die Aufgabe der Knochenmarkpunktion ist es, alternative Diagnosen auszuschließen. Bei typischen klinischen Befunden kann eine Knochenmarkpunktion in der Regel entfallen. Dies ist gerade für pädiatrische Patienten eine große Erleichterung.

Myelodysplastische Syndrome (MDS) und idiopathische Zytopenien unbestimmter Signifikanz (ICUS; insbesondere der Subtyp ICUS-T, siehe Lehrbücher der Hämatologie) können leicht mit einer ITP verwechselt werden. Die Inzidenzen von MDS und ITP sind bei über 60-Jährigen ungefähr gleich hoch [60].

Die Punktion ist nach Aufklärung in der Regel am selben Tag möglich und der Patient braucht nicht ein zweites Mal einbestellt werden. Der Patient sollte vor der Knochenmarkpunktion über das Risiko von Blutungen, lokalen Schmerzen, lokalen Infektionen und das sehr seltene Risiko von Organ- und Nervenschädigungen aufgeklärt werden. Nach Erfahrung der Autoren ist ein Absetzen von Antikoagulanzien (Acetylsalicylsäure (ASS), Vitamin-K-Antagonisten) vor einer Knochenmarkpunktion nicht notwendig. Neue orale Antikoagulanzien (NOAK) erreichen nach 2-4 h ihre höchste Plasmakonzentration und sollten deshalb nicht unmittelbar vor, sondern nach der Punktion genommen werden. Bei schwerer Thrombozytopenie braucht vor der Punktion kein Thrombozytenkonzentrat gegeben werden. Auch bei niedrigsten Thrombozytenwerten sind Blutungen sehr selten und können in der Regel durch verlängerte Kompression kontrolliert werden.

\section{Helicobacter pylori}

\section{Empfehlungsgrad A}

Evidenzlevel 3

Alle erwachsenen Patienten mit ITP, insbesondere bei persistierendem oder chronischem Verlauf, sollen auf Helicobacter pylori untersucht und bei positivem Nachweis eradiziert werden.

Zahlreiche Publikationen beschreiben eine Assoziation zwischen ITP und Helicobacter-pylori-Infektionen der Magenschleimhaut [61]. Diese scheint in Asien klinisch wesentlich relevanter zu sein als in Europa und Nordamerika. Aktuelle Leitlinien empfehlen bei erwachsenen ITP-Patienten (aber nicht bei Kindern) die Prüfung auf eine H.-pylori-Infektion und im positiven Fall die Eradikation [62, 63]. Dies ist schon allein wegen der bei ITP-Patienten häufigen Kortisontherapie und dem damit verbundenen Ulcus-Risiko sinnvoll. Außerdem ist die Therapie einfach und preiswert. Mit einem H.-pylori-Atem- oder Stuhltest kann man den Patienten die potenziell blutungsgefährdete Gastroskopie und Biopsie ersparen.

\section{Therapie}

\section{Empfehlungsgrad EK}

Evidenzlevel 3

Die Therapieindikation soll nicht allein von der Blutungsneigung und der Thrombozytenzahl abhängig gemacht werden. Krankheitsstadium, Krankheitsverlauf und weitere individuelle Faktoren sind zu berücksichtigen.

Ein Algorithmus zur Therapiesequenz bei Patienten mit ITP ist in Abbildung 1 dargestellt.

Arzneimittel und Dosierungen der medikamentösen Therapie sind in Tabelle 10 aufgeführt. Informationen zum Zulassungsstatus finden sich in Tabelle 11 .

\section{Therapieindikation}

Bei der Entscheidung zur Behandlung sollten zahlreiche Faktoren berücksichtigt werden:

- klinische Blutungsneigung

- Thrombozytenzahl

- Krankheitsstadium (neu diagnostizierte vs. persistierende vs. chronische ITP)

- bisheriger Krankheitsverlauf und Blutungsanamnese

- Therapienebenwirkungen

- Konsequenzen für Ausbildung und Beruf (Berufsunfähigkeit vermeiden)

- Patientenalter, Nebenerkrankungen, Begleitmedikation (insbesondere Antikoagulanzien)

- Zugang zu ambulanter und stationärer fachärztlicher Versorgung

- Erfahrung des betreuenden Arztes/der Klinik in der Therapie der ITP

- Patientenpräferenz, Gesundheitskompetenz, psychosoziale Situation

- bei Kindern und Jugendlichen stärkerer Bewegungsdrang, deshalb besondere Berücksichtigung des Verletzungsrisikos in Kindergarten, Schule, Freizeitaktivitäten

Die Auflistung bedeutet keine Rangfolge, grundsätzlich sind alle Faktoren bei der Entscheidung für oder gegen eine Therapie zu berücksichtigen.

\section{Der Thrombozytenschwellenwert}

Sicher steigt das Blutungs- und Mortalitätsrisiko, wenn eine Thrombozytenzahl von $30 \times 10^{9} / 1$ unterschritten wird, jedoch bestehen große individuelle Schwankungen. Die traditionelle Annahme eines Thrombozytenschwellenwertes, bei dessen Unterschreiten jeder Patient behandelt werden muss und bei dessen Überschreiten keine Therapieindikation mehr besteht, ist nicht evidenzbasiert. 


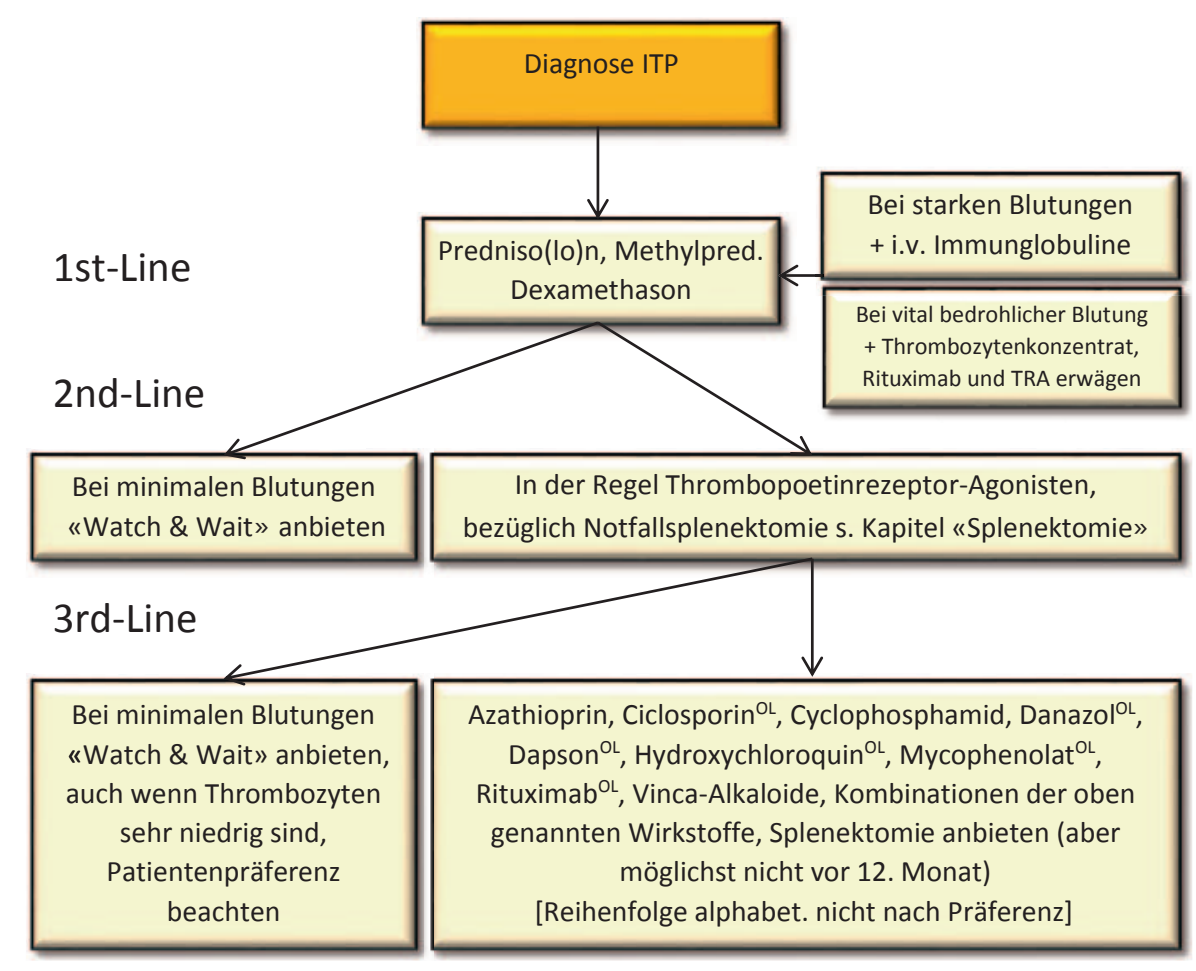

Abb. 1. Therapiesequenz (für Details und Spezialsituationen siehe Text). OL = Off-label.

Die ITP-Leitlinie der ASH von 1996 sah eine zwingende Therapieindikation bei niedrigen Thrombozytenwerten vor, auch wenn ein Patient völlig beschwerdefrei war [1]. Dies führte dazu, dass viele Patienten über Monate bis Jahre mit Kortikosteroiden behandelt und zum Teil schwerste Nebenwirkungen (Cushing, Infektionen, Diabetes) in Kauf genommen wurden, nur um die Werte «hoch zu halten». Der Internationale Consensus-Report von 2009 [64] gab dann lediglich vor, dass bei Werten über $50 \times 10^{9} / 1$ eine Therapie nicht notwendig sei. Es wurde aber offen gelassen, ob man bei niedrigeren Werten behandeln muss oder nicht. Die Experten der ASH-Leitlinie von 2010 empfehlen dann wieder einen Schwellenwert von $30 \times 10^{9} / 1$ und begründen dies damit, dass dieser Wert allgemein etabliert sei [63]. Es gibt keine höhergradige wissenschaftliche Evidenz, die diesen Schwellenwert unterstützt. Seine wesentliche Begründung liegt in der haftungsrechtlichen Absicherung im angloamerikanischen Gesundheitssystem. Die Indikationsstellung allein nach der Thrombozytenzahl ohne Berücksichtigung individueller Patientenfaktoren ist heute obsolet.

Folgende Strategie hat sich als praktikabel erwiesen:

Bei neu diagnostizierter ITP, bei fehlender bis milder Blutungsneigung (WHO 0-II, siehe Tab. 4) und bei Thrombozytenwerten unter $20 \times 10^{9}-30 \times 10^{9} / 1$ wird man in der Regel eine Behandlung anbieten, schon allein weil der Patient verunsichert und ein Therapieverzicht in der Regel nicht vermittelbar ist.

Bei neu diagnostizierter ITP, bei fehlender bis milder Blutungsneigung (WHO 0-II) und bei Thrombozytenwerten über $20 \times 10^{9}-30 \times 10^{9} / 1$ wäre eine «Watch \& Wait»-Strategie kein Behandlungsfehler; wenn der Patient aber die Behandlung wünscht, dann sollte sie ihm nicht verwehrt werden. Die im Abschnitt
«Therapieindikation» genannten Faktoren sollen bei der Entscheidung für oder gegen eine Therapie mit berücksichtigt werden.

Bei neu diagnostizierter ITP und schweren Blutungen (WHO III/IV) besteht eine Therapieindikation unabhängig von der Thrombozytenzahl. Eine stationäre Aufnahme wird empfohlen.

Je länger die Krankheit andauert, desto weniger relevant werden die Thrombozytenzahlen bei der Indikationsstellung. Die Nebenwirkungen der Therapie müssen gegen den Nutzen abgewogen werden. In späteren Therapielinien wird zwar in der Regel eine Therapie angeboten, es wäre aber auch kein Fehler, selbst bei niedrigsten Werten eine «Watch \& Wait»-Strategie zu verfolgen, solange der Patient nicht oder nur gering blutet und wenn er nach umfassender Aufklärung mit diesem Vorgehen einverstanden ist. Im umgekehrten Fall, wenn der Patient eine Therapie wünscht, dann sollte ein Konflikt unbedingt vermieden werden.

\section{Erstlinientherapie}

\section{Kortikosteroide}

\section{Empfehlungsgrad A}

Evidenzlevel 3

Zur Erstlinientherapie sollen Kortikosteroide eingesetzt werden.

Der Patient braucht einen Therapiefahrplan, wie lange und in welcher Dosis die Steroide gegeben und bis wann sie vollständig ausgeschlichen seien sollen. 
Tab. 10. Häufig eingesetzte Medikamente und Dosierungen bei ITP

\begin{tabular}{|c|c|}
\hline \multicolumn{2}{|c|}{ Kortikosteroide bei Erwachsenen } \\
\hline Predniso(lo)n & $\begin{array}{l}\text { 1-2 mg/kg/Tag p.o. oder i.v. für 1-2 Wochen } \\
\text { Bei Therapieansprache wöchentliche Dosis-Reduktion in 10-mg-Schritten, bis eine Dosis von 0,5 mg/kg Körpergewicht/Tag } \\
\text { erreicht wird, danach Dosisreduktion um } 5 \mathrm{mg} \text { pro Woche [67] }\end{array}$ \\
\hline Methylprednisolon & 125-1000 mg i.v. während 1-5 Tagen (gefolgt von Prednison 1 mg/kg/Tag p.o. und anschließend Dosisreduktion wie oben) \\
\hline Dexamethason & 40 mg p.o. täglich $\times 4$ Tage, 4-6 Zyklen alle 14-28 Tage \\
\hline \multicolumn{2}{|c|}{ Kortikosteroide bei Kindern } \\
\hline Predniso(lo)n & 0,25-4 mg/kg Körpergewicht/Tag in zwei Einzeldosen, empfohlene Dosis $2 \mathrm{mg} / \mathrm{kg} \times 4$ Tage, nicht länger als 2 Wochen \\
\hline Methylprednisolon & $30 \mathrm{mg} / \mathrm{kg}$ (maximal $1000 \mathrm{mg}$ ) i.v. \\
\hline Dexamethason & $0,7 \mathrm{mg} / \mathrm{kg} / \mathrm{Tag}$ per os (maximale Dosis $40 \mathrm{mg} / \mathrm{Tag}$ ) für 4 Tage \\
\hline \multicolumn{2}{|l|}{ Weitere Wirkstoffe } \\
\hline i.v. Immunglobuline & 0,4-1 g/kg Körpergewicht/Tag, bei fehlender Ansprache kann diese Dosis einmal innerhalb von 3 Tagen wiederholt werden \\
\hline Romiplostim & $1-10 \mu \mathrm{g} / \mathrm{kg}$ s.c. $1 \times$ pro Woche, Dauertherapie \\
\hline Eltrombopag & 25-75 mg p.o. täglich, Dauertherapie \\
\hline Azathioprin & 2 mg/kg p.o. täglich, kein frühes Ansprechen, zum Teil erst nach Monaten \\
\hline Rituximab $^{1}$ & $375 \mathrm{mg} / \mathrm{m}^{2} 1 \times$ pro Woche i.v. für 4 Wochen \\
\hline Cyclophosphamid & 1-2 mg/kg p.o. täglich, bezüglich Zulassung siehe Tabelle 11 \\
\hline Ciclosporin $^{1}$ & Dosierung nach Blutspiegel, Ziel 100-400 ng/ml \\
\hline Danazol $^{1}$ & 400-800 mg p.o. täglich \\
\hline Dapson $^{1}$ & 75-100 mg p.o. täglich \\
\hline Anti-D & $\begin{array}{l}\text { Das einzige bisher für die ITP zugelassene Präparat (WinRho }{ }^{\circledR} \text { SDF) wurde } 2009 \text { vom europäischen Markt genommen, ist in } \\
\text { den USA und anderen außereuropäischen Ländern aber noch erhältlich }{ }^{2}\end{array}$ \\
\hline
\end{tabular}

${ }^{1}$ Keine arzneimittelrechtliche Zulassung zur Behandlung der ITP. Bei nichtzugelassenen Therapien sollte vorher eine ausführliche Patienten-Aufklärung erfolgen und in der Krankenakte dokumentiert werden.

${ }^{2}$ Andere anti-D Immunglobuline (z.B. Rhophylac ${ }^{\circledR}$, Rhesonativ ${ }^{\circledR}$ ) sind nicht für die ITP, sondern nur zur Prophylaxe des Morbus haemolyticus neonatorum zugelassen.

Kortikosteroide wirken immunsuppressiv und die gängige Vorstellung ist, dass sie die Bildung von Thrombozytenantikörpern hemmen. Zahlreiche ältere Studien zeigten, dass bei den allermeisten Erwachsenen mit Kortikosteroiden ein Anstieg der Thrombozytenzahl erreicht werden kann. Nach Absetzen der Kortikosteroide fallen die Thrombozyten bei Erwachsenen jedoch in der Regel wieder ab; dauerhafte Remissionen sind selten (in älteren Publikationen mit 5-6\% angegeben) $[1,65]$. Die hohe Rezidivrate spricht dafür, dass Kortikosteroide nur die Krankheitsschwere abmildern, den Krankheitsverlauf aber nicht abkürzen.

Die Therapiedauer mit Kortikosteroiden sollte einerseits nicht zu kurz sein (nicht unter 3 Wochen) [66]. Deutlich längere Steroidtherapien erreichen aber auch keine Verbesserung der Ansprechrate. Für Dosierungen siehe Tabelle 10. Eine Prednison-Erstlinientherapie erstreckt sich häufig über mehrere Monate, wenn man den empfohlenen Dosierungen folgt (z.B. «McMillan-Schema») [67]. Es gibt praktisch keinen Patienten, der in dieser Zeit nicht belastende Nebenwirkungen entwickelt (zum Umgang mit Nebenwirkungen siehe Tab. 12).

\section{Prednison versus Dexamethason}

Dexamethason wurde erstmals in den 1990er Jahren in der Zweitlinientherapie der therapierefraktären, chronischen ITP eingesetzt [68]. Mehrere nicht randomisierte Studien zeigten in den Folgejahren, dass Dexamethason auch bei neu diagnostizierter ITP gut wirksam ist. Spezifische Effekte auf Tregs und myeloide Suppressorzellen wurden beschrieben. Mehrere Vergleichsuntersuchungen beschreiben höhere Langzeitremissionsraten bei der Erstlinientherapie mit Dexamethason im Vergleich zu Prednison [6971], während andere keinen Vorteil finden [72, 73]. Zur Dosierung siehe Tabelle 10. Cushingoide Veränderungen sind unter Dexamethason nicht so häufig wie unter Prednison [70]. Die Entscheidung zwischen Predniso(lo)n und Dexamethason sollte der Expertise des Arztes vorbehalten bleiben. 
Tab. 11. Zulassungsstatus von Medikamenten in Deutschland und Österreich

\begin{tabular}{|c|c|c|}
\hline Substanz & Zulassung & Anmerkungen \\
\hline Anti-D Immunglobulin & nein & $\begin{array}{l}\text { Das einzige bisher für die ITP zugelassene Präparat (WinRho }{ }^{\circledR} \text { SDF) wurde } 2009 \text { in der EU vom Markt } \\
\text { genommen, ist in den USA und anderen außereuropäischen Ländern erhältlich. Andere Anti-D- } \\
\text { Immunglobuline sind nicht für die Therapie der ITP zugelassen }\end{array}$ \\
\hline Azathioprin & ja & Chronische, refraktäre ITP \\
\hline Ciclosporin & nein & Fallberichte \\
\hline Cyclophosphamid & ja & Bedrohlich verlaufende Autoimmunerkrankungen \\
\hline Danazol & nein & $\begin{array}{l}\text { Fallberichte; in Deutschland ist kein Danazol mehr zugelassen; zugelassene Präparate gibt es unter } \\
\text { anderem in Österreich und der Schweiz }\end{array}$ \\
\hline Dapson & nein & Fallberichte \\
\hline Dexamethason & ja & Nur Anfangsbehandlung von Autoimmunerkrankungen \\
\hline Eltrombopag & ja & $\begin{array}{l}\text { Behandlung von Patienten mit chronischer ITP, die gegenüber anderen Therapien (z.B. } \\
\text { Kortikosteroide, Immunglobuline) refraktär sind }\end{array}$ \\
\hline Hydroxychloroquin & nein & Fallberichte \\
\hline Immunglobuline & ja & $\begin{array}{l}\text { Die meisten der zugelassenen intravenösen Immunglobuline haben die ITP explizit in der } \\
\text { Zulassungsindikation aufgeführt }\end{array}$ \\
\hline Methylprednisolon & ja & Erkrankungen, die einer systemischen Therapie mit Glukokortikoiden bedürfen \\
\hline Mycophenolat & nein & Fallberichte \\
\hline Predniso(lo)n & ja & $\begin{array}{l}\text { Erkrankungen aus der Hämatologie, die einer systemischen Behandlung mit Glukokortikoiden } \\
\text { bedürfen }\end{array}$ \\
\hline Rituximab & nein & in Phase-I-, Phase-II- und Phase-III-Studien eingesetzt \\
\hline Vinblastin & nein & Fallberichte \\
\hline Vincristin & ja & ITP, nicht als Primärtherapie (nach Expertenmeinung kein Stellenwert in der ITP-Therapie mehr) \\
\hline
\end{tabular}

Tab. 12. Nebenwirkungen von Kortikosteroiden und vorbeugende Maßnahmen

\section{Nebenwirkungen}

Akne

Blutdruckerhöhung

Cushingoider Habitus (Mondgesicht)

Dünne, atrophische Haut, Striae

Erhöhungen der Blutzuckerwerte

Gewichtszunahme

Infektionen

Magenbeschwerden

Muskelschwund

Osteoporose

Schlaflosigkeit

Stimmungsschwankungen

Vorbeugende Maßnahmen

Patient über oben genannten Nebenwirkungen aufklären und Therapiefahrplan, wie lange diese Therapie durchgeführt werden soll, mit an die Hand geben

Osteoporoseprophylaxe: 600-1000 Einheiten Vitamin D3/Tag und 1000 mg

Kalzium/Tag

Magenprotektion mit Protonenpumpenhemmern

Antibiotikagabe zur Infektionsprophylaxe in der Regel nicht indiziert

\section{Erstlinientherapie bei Kindern und Jugendlichen [76]}

\section{Empfehlungsgrad B}

Evidenzlevel 3

Bei der neu diagnostizierten ITP im Kindes- und Jugendalter ohne oder mit nur milden Blutungen ist eine Therapie in der Regel verzichtbar. Hämatome und Sugillationen sind keine Therapieindikation. Schleimhautblutungen («wet purpura») können jedoch eine Indikation darstellen.

Die Thrombozytenzahlen sind grundsätzlich kein Entscheidungskriterium für die Behandlung der neu diagnostizierten ITP.

Eine Aktualisierung der Leitlinie «Immunthrombozytopenie im Kindes- und Jugendalter» ist aktuell in Vorbereitung und wird für Mitte 2018 erwartet. Die pädiatrische ITP unterscheidet sich in Verlauf und Prognose von der ITP des Erwachsenenalters. Je jünger das Kind ist, desto eher findet sich ein akutes Auftreten der Blutungsneigung, häufig nach einem Infekt. Meist ist die Throm- 
bozytopenie aber nur vorübergehend und chronische Verläufe sind selten. Je älter das Kind, desto eher ähnelt der Verlauf dem des Erwachsenenalters («schleichendes» Auftreten, keine Infektanamnese, häufig chronischer Verlauf mit leichteren Blutungen) $[5,74,75]$.

Bei der neu diagnostizierten ITP im Kindes- und Jugendalter ist eine Therapie in den allermeisten Fällen verzichtbar. Hämatome und Sugillationen stellen keine Therapieindikation dar. Schleimhautblutungen, die mit lokalen Mitteln nicht kontrollierbar sind, können jedoch zur Therapie führen. Die Thrombozytenzahlen sind grundsätzlich kein Entscheidungskriterium für die Behandlung der neu diagnostizierten pädiatrischen ITP [76, 77]. Individuelle Gesichtspunkte wie Alter, Verletzungsanfälligkeit oder psychosoziale Aspekte sollen mit berücksichtigt werden.

Retrospektive Studien und Registerdaten (die sowohl behandelte als auch unbehandelte Kinder umfassen) beschreiben eine Inzidenz von $~ 3 \%$ für schwere bis lebensbedrohliche Blutungen [47]. Besonders gefürchtet sind intrakranielle Blutungen. Deren Inzidenz beträgt $<1 \%[54,78,79]$. In der Regel liegen die Thrombozytenzahlen zum Zeitpunkt der Blutung bei $<20 \times 10^{9} / 1$. Die betroffenen Kinder haben im Vorfeld häufig Blutungen aus Mund und Nase («wet purpura»).

Bei schweren Blutungen sollten bevorzugt intravenöse Immunglobuline (IVIG), bei sehr schweren Blutungen auch Thrombozytenkonzentrate gegeben werden, weil dies schneller als Kortikosteroide die Thrombozytenzahl anhebt [79].

Bei geringer oder fehlender Therapieansprache sollte die Diagnose hinterfragt und der Patient - wenn noch nicht erfolgt - in einem Zentrum mit ausgewiesener hämatologischer Expertise vorgestellt werden (siehe auch Abschnitt «Therapie der chronischen ITP bei Kindern und Jugendlichen»). Die wichtigste Differenzialdiagnose der neu diagnostizierten ITP im Kindesalter ist die akute lymphatische Leukämie (ALL).

\section{Therapie von Notfällen}

\section{Empfehlungsgrad A}

Evidenzlevel 3

Bei schweren und lebensbedrohlichen (WHO III/IV) Blutungen oder vor nicht aufschiebbaren Operationen sollen neben Steroiden zusätzlich intravenöse Immunglobuline (IVIG) zur schnellen Anhebung der Thrombozytenzahl gegeben werden.

Bei lebensbedrohlichen Blutungen sollen zusätzlich Thrombozytenkonzentrate gegeben werden.

Bei lebensbedrohlichen Blutungen sollte, wenn die oben genannten Maßnahmen keine Blutstillung erreichen, die zeitnahe Gabe von Rituximab und Thrombopoetinrezeptor-Agonisten (TRA) erwogen werden.

Zur Splenektomie siehe Abschnitt «Splenektomie».

\section{Notfalltherapie mit IVIG}

Intravenös applizierte Immunglobuline blockieren die Phagozytose von antikörperbeladenen Thrombozyten und führen $\mathrm{zu}$ einem raschen, aber meist nur kurzfristigen Thrombozytenanstieg. Sie erreichen keine anhaltenden Remissionen. Nach 2-4 Wochen fallen die Werte in der Regel wieder auf das Ausgangsniveau. Dadurch beschränkt sich die Indikation von IVIG auf Situationen, in denen ein schneller Thrombozytenanstieg erreicht werden muss (Blutungen, nicht aufschiebbare Operationen) oder wenn höher dosierte Steroide vermieden werden sollen (z.B. Schwangerschaft, siehe Abschnitt «ITP und Schwangerschaft»). Zur Dosierung siehe Tabelle 10.

\section{Notfalltherapie mit Anti-D-Immunglobulinen}

Seit den 1980er Jahren wird Anti-D-Immunglobulin zur Behandlung der chronischen ITP eingesetzt [80]. Anti-D bindet an Rhesus (Rh)-positive Erythrozyten. Die antikörperbeladenen Erythrozyten werden in der Milz phagozytiert. Bei ITP-Patienten wird dadurch der Abbau von antikörperbeladenen Thrombozyten kompetitiv gehemmt und die Thrombozytenzahl steigt. Deshalb ist Anti-D nur bei Rh-positiven Patienten wirksam und auch nur, wenn die Milz noch nicht entfernt wurde. Eine klinisch relevante Nebenwirkung sind intravasale Hämolysen.

Die in Deutschland, Österreich und der Schweiz erhältlichen Anti-D-Präparate (Rhophylac ${ }^{\circledR}$, Rhesonativ ${ }^{\circledR}$ und andere) wurden zwar in der Vergangenheit auch schon bei ITP eingesetzt, die arzneimittelrechtliche Zulassung ist jedoch auf die Prophylaxe des Morbus haemolyticus neonatorum beschränkt.

\section{Monoklonales Anti-D}

Aufgrund der Infektionsrisiken von Plasmaprodukten hat man versucht, rekombinantes Anti-D-Immunglobulin herzustellen. Rozrolimupab ist eine Mischung aus 25 verschiedenen, rekombinant hergestellten Anti-D-Antikörpern. Erste Ergebnisse zeigen eine gute Wirksamkeit bei ITP [81]. Die arzneimittelrechtliche Zulassung wird erwartet.

\section{Notfalltherapie mit Thrombozytenkonzentraten}

Bei schweren Blutungen (WHO III, IV) kann mit Thrombozytenkonzentraten ein kurzfristiger Anstieg der Thrombozytenzahl und ein Sistieren der Blutung erreicht werden. Meist reichen dazu die üblichen 1-2 Konzentrate nicht. Bei diesen zum Glück seltenen Notfällen beginnt man gleichzeitig auch mit Steroiden und Immunglobulinen. Bei schwersten Blutungen kann auch der zusätzliche Einsatz von Rituximab und die frühzeitige Gabe von TRA erwogen werden.

Eine Stimulation der Bildung von Thrombozytenantikörpern durch die Thrombozytengabe wurde bisher nicht beobachtet. 


\section{Zweitlinien- und weitere Therapien}

\section{Empfehlungsgrad EK}

Evidenzlevel 3

Es gibt keinen Thrombozytenschwellenwert, bei dessen Unterschreitung eine Zweitlinientherapie angeboten werden muss bzw. bei dessen Überschreitung auf eine Therapie grundsätzlich verzichtet werden kann. Die Indikation zur Behandlung ist immer eine individuelle Entscheidung.

Eine Zweitlinientherapie ist indiziert, wenn der Patient auf die Erstlinientherapie mit Steroiden nur partiell oder gar nicht anspricht oder wenn er nach initialer Therapieansprache einen erneuten Thrombozytenabfall entwickelt. Wie bei der Erstlinientherapie gilt, dass es keinen Thrombozytenschwellenwert gibt, bei dessen Unterschreitung behandelt werden muss bzw. bei dessen Überschreitung auf eine Therapie grundsätzlich verzichtet werden kann. Die Indikation zur Behandlung ist immer eine individuelle Entscheidung. Dabei sind die gleichen Faktoren zu berücksichtigen wie bei der Indikation zur Erstlinientherapie (siehe Abschnitt «Therapieindikation»).

Im Unterschied zur Erstlinientherapie treten bei der Zweitlinientherapie und auch bei den weiteren Therapielinien die Lebensqualität und die Vermeidung von Nebenwirkungen immer mehr in den Vordergrund. Während bei neu diagnostizierter ITP alle Therapieversuche darauf ausgerichtet sein sollten, eine Kuration $\mathrm{zu}$ erreichen, ist mit zunehmender Krankheitsdauer eine dauerhafte Remission immer unwahrscheinlicher und der potenzielle Nutzen einer Therapie muss gegen die Nebenwirkungen abgewogen werden. Grundsätzlich sollten alle Behandlungsoptionen inklusive einer «Watch \& Wait»-Strategie angeboten werden. Die Patientenpräferenz ist zu berücksichtigen.

Folgende Strategie hat sich als praktikabel erwiesen:

Bei Patienten mit fehlender oder minimaler Blutungsneigung (WHO 0-I) (siehe Tab. 4) kann man nach Versagen der Erstlinientherapie eine Zweitlinientherapie anbieten. Ein Therapieverzicht oder eine «Watch \& Wait»-Strategie wäre aber auch möglich.

Die Erfahrung zeigt jedoch, dass sich viele dieser Patienten mit geringer oder gänzlich fehlender Blutungsneigung angesichts des als bedrohlich empfundenen Blutungsrisikos für eine Zweitlinientherapie entscheiden. Wenn der Patient jedoch mit einer «Watch \& Wait»-Strategie einverstanden ist, dann wäre diese selbst bei niedrigsten Werten kein Behandlungsfehler.

Bei Patienten mit mittelschweren Blutungen (WHO II) kann eine Therapie angeboten werden. Die individuelle Belastung durch die Blutungssymptome sollte berücksichtigt werden. Auch hier werden sich viele Patienten für eine Therapie entscheiden. Ein Therapieverzicht oder eine «Watch \& Wait»-Strategie wäre aber ebenfalls kein Behandlungsfehler.

Bei Patienten mit WHO-III- oder -IV-Blutungen besteht eine Therapieindikation unabhängig von der Thrombozytenzahl. Eine stationäre Aufnahme wird empfohlen.
Tab. 13. Dosierung von Eltrombopag und Romiplostim

Romiplostim

Die in der Fachinformation empfohlene Anfangsdosis von Romiplostim beträgt $1 \mu \mathrm{g} / \mathrm{kg}$ bezogen auf das tatsächliche Körpergewicht. Die einmal pro Woche anzuwendende Dosis sollte so lange in Schritten von $1 \mu \mathrm{g} / \mathrm{kg}$ erhöht werden, bis eine stabile Thrombozytenzahl $\left(\geq 50 \times 10^{9} / \mathrm{l}\right)$ erreicht ist

Die Maximaldosis soll $10 \mu \mathrm{g} / \mathrm{kg}$ nicht überschreiten

Der Zielbereich der Thrombozytenzahl ist 50-150 $\times 10^{9} / 1$, d.h. eine Normalisierung der Thrombozytenzahl wird nicht angestrebt

Die Thrombozytenzahl sollte unter Romiplostim nicht über $250 \times 10^{9} / 1$ ansteigen

Die Thrombozytenzahl sollte anfangs wöchentlich, dann alle 4 Wochen kontrolliert werden.

Anmerkung: bei Blutungen wird häufig mit einer mittleren (z.B. $3-5 \mu \mathrm{g} / \mathrm{kg}$ ), bei starken Blutungen auch mit der maximalen Therapiedosis begonnen, um langes Auftitrieren zu vermeiden

\section{Eltrombopag}

Die empfohlene Anfangsdosis für Eltrombopag beträgt $50 \mathrm{mg}$ einmal täglich (bei Patienten ostasiatischer Abstammung $25 \mathrm{mg}$ ). Die Dosis sollte solange angepasst werden, bis eine stabile Thrombozytenzahl $\left(\geq 50 \times 10^{9} / 1\right)$ erreicht ist

Die Maximaldosis soll $75 \mathrm{mg}$ einmal täglich nicht überschreiten

Der Zielbereich der Thrombozytenzahl ist $50-150 \times 10^{9} / 1$

Die Thrombozytenzahl soll nicht über $250 \times 10^{9} / 1$ ansteigen

Die Thrombozytenzahl sollte anfangs wöchentlich, dann alle 4 Wochen kontrolliert werden

\section{Zweitlinientherapie mit TRA}

\section{TRA - Wirksamkeit}

\section{Empfehlungsgrad A}

Evidenzlevel 2

TRA sollen als Zweitlinientherapie angeboten werden.

Rationale für TRA: Bis Anfang der 1990er Jahre war man der Meinung, dass es keinen Sinn mache, bei einer Erkrankung mit erhöhtem Thrombozytenumsatz wie der ITP die Thrombozytopoese noch weiter zu stimulieren. Dann fand man jedoch, dass bei ITP-Patienten die Thrombopoetinspiegel im Vergleich zu gesunden Menschen zwar erhöht, aber nicht so hoch sind wie bei anderen Erkrankungen mit vergleichbarem Thrombozytenmangel. Man spricht deshalb von einem relativen Thrombopoetinmangel $[30,82]$. Ausgehend von dieser Beobachtung wurden die TRA Romiplostim und Eltrombopag entwickelt. Romiplostim (Nplate ${ }^{\circledR}$ ) ist seit 2009 in der Europäischen Union (EU) zugelassen, Eltrombopag seit 2010 (in der EU unter dem Handelsnamen Revolade ${ }^{\circledR}$, in den USA und anderen Ländern heißt das Präparat Promacta ${ }^{\mathrm{TM}}$ ) (Tab. 13). Beide Wirkstoffe haben in umfangreichen Studien gezeigt, dass sie bei vielen Patienten mit chronischer ITP die Thrombozytenzahl in einen sicheren Bereich steigern können. 
- Bei über 90\% der Patienten wird ein kurzfristiges Ansprechen erreicht.

- Die Zahl der Patienten mit langfristigem Ansprechen ist nicht ganz so hoch. Die Angaben zum langfristigen Ansprechen schwanken zwischen 30 und 90\%, wobei man berücksichtigen muss, dass sich die Patienten und die Definitionen für «langfristiges Ansprechen» von Studie zu Studie zum Teil stark unterscheiden [50, 83-87].

- TRA sind bei Patienten mit und ohne Splenektomie wirksam [88].

- TRA sind bei alten und jungen Patienten gleich gut wirksam [89].

- Die beiden TRA Eltrombopag und Romiplostim sind nicht kreuzresistent, d.h. wenn der eine TRA nicht ausreichend wirksam ist, kann durchaus der andere noch ansprechen [90, 91].

- Bei erhöhten Serum-Thrombopoetinspiegeln scheint Romiplostim weniger gut wirksam zu sein [92].

- Etwa die Hälfte der Patienten können unter TRA alle andere ITP-Medikamente (z.B. Steroide) absetzen.

Der Hersteller empfiehlt, Eltrombopag erst $4 \mathrm{~h}$ nach einer kalzium-, magnesium-, aluminium- oder eisenhaltigen Mahlzeit (Antazida, Milchprodukte, Vitamintabletten, Eisensubstitution bei Anämie) einzunehmen. Die Einnahme auf nüchternen Magen oder zur Nacht, vor dem Zubettgehen, ist für viele Patienten am besten praktikabel. Patienten asiatischer Herkunft sprechen stärker auf Eltrombopag an; hier soll eine niedrigere Anfangsdosierung, in der Regel 25 mg, gewählt werden.

\section{TRA - Nebenwirkungen}

In der Erfahrung der Autoren sind TRA deutlich besser verträglich als Kortikosteroide oder andere ITP-Therapien. In der Literatur wird auf folgende Nebenwirkungen hingewiesen.

Häufig genannt werden Kopf-, Gelenk-, Muskelschmerzen und Magenbeschwerden. Ähnliche Nebenwirkungen werden auch für andere Wachstumsfaktoren beschrieben.

Beschwerden der oberen Luftwege: Viele Patienten (10-26\%) klagen über Erkältungssymptome und ähnliche Beschwerden der oberen Luftwege. Bei ITP-Patienten, die nicht mit TRA behandelten werden, sind diese Beschwerden allerdings auch häufig.

Arterielle und venöse Thrombosen: Sowohl unter der Behandlung mit Romiplostim als auch mit Eltrombopag wurden venöse und arterielle Thrombosen beobachtet (siehe Abschnitt «ITP als Risikofaktor für venöse und arterielle Thromboembolien»). Eine klare Korrelation zur Thrombozytenzahl fehlt [93]. Bei Patienten mit Thrombosen in der Vorgeschichte sollte der Patient über das Risiko und eventuelle Symptome aufgeklärt werden. Bei diesen Patienten sollte auch ein Anti-Phospholipid-Syndrom ausgeschlossen sein.

Gastrointestinale Nebenwirkungen und Leberwerterhöhungen: Bei Eltrombopag werden Leberwerterhöhungen berichtet. Auch andere abdominelle Beschwerden (Obstipation, Nausea, Vomitus, Diarrhoe, Pankreatitis) scheinen mit Eltrombopag häufiger zu sein als mit Romiplostim [94].
Thrombosen der Vena porta: Bei Patienten mit chronischer Lebererkrankung (z.B. Zirrhose) wurden Portalvenenthrombosen beschrieben.

Hautveränderungen: Bei Eltrombopag wurden Hautveränderungen (Juckreiz, Rötung, makulopapulöses Exanthem) beschrieben. Dann kann alternativ Romiplostim gegeben werden.

Katarakte: Bei ITP-Patienten wurden sowohl unter Eltrombopag als auch mit Placebo Katarakte gefunden. Es könnte durchaus sein, dass dies auf andere Ursachen, z.B. Alter oder vorhergehende Steroidtherapien zurückzuführen ist. Es wird empfohlen, dass sich Patienten augenärztlich untersuchen lassen.

Überschießender Abfall der Thrombozyten nach dem Absetzen von TRA: Beim abrupten Absetzen von Romiplostim oder Eltrombopag kann es zu einem überschießenden Abfall der Thrombozytenzahl unter die Ausgangswerte kommen. Deshalb soll nach dem Absetzen die Thrombozytenzahl noch für mindestens 4 Wochen nachkontrolliert werden.

Pro-leukämische Wirkung: Bei Patienten mit MDS, die TRA erhalten haben, wurde eine Blastenvermehrung beschrieben [95]. Andererseits gibt es auch Befunde, die gegen einen pro-leukämischen Effekt sprechen [96]. In MDS-Studien zeigten TRA keine erhöhte Zahl an leukämischen Transformationen [97]. Einige Autoren empfehlen deshalb vor der Gabe von TRA eine Knochenmarkpunktion, um ein MDS (und eine Fibrose, siehe unten) auszuschließen. In jedem Fall sollten regelmäßig Differenzialblutbilder bestimmt werden.

Knochenmarksfibrose: Bei etwa 2-11\% der Patienten kommt es unter TRA zu einer leichtgradigen Retikulinfaservermehrung im Knochenmark [98-100]. Allerdings wurde im Knochenmark einiger ITP-Patienten auch unabhängig von der Behandlung mit TRA eine Retikulinfaservermehrung gefunden [99]. Echte Myelofibrosen sind bisher nur in Einzelfällen beschrieben.

Antikörper gegen TRA: Bei einzelnen mit Romiplostim behandelten Patienten wurden neutralisierende Anti-Romiplostim-Antikörper beobachtet, die nach dem Absetzen von Romiplostim wieder verschwanden. Die Antikörper waren nur gegen Romiplostim gerichtet und neutralisierten kein humanes Thrombopoetin. Für Eltrombopag ist dergleichen bisher nicht beschrieben.

Sonderfall: Therapie der neu diagnostizierten und persistierenden ITP mit TRA

TRA sind formal nur für die chronische ITP, d.h. für Patienten mit einer Erkrankungsdauer über 12 Monate zugelassen. Dennoch ergibt sich immer wieder die Situation, dass neu diagnostizierte Patienten oder Patienten mit persistierender ITP auf die Therapie nicht adäquat ansprechen und klinisch relevant bluten. Für diese Patienten mit neu diagnostizierter ITP und nicht beherrschbarer Thrombozytopenie werden in Fallberichten zunehmend auch TRA eingesetzt, meist in Kombination mit anderen ITP-Medikamenten.

Man muss jedoch berücksichtigen, dass die Eingrenzung des Begriffes «chronische ITP» auf Verläufe von länger als 12 Monaten [4] erst nach der arzneimittelrechtlichen Zulassung der TRA 
Tab. 14. Absetzen von Romiplostim und Eltrombopag

Absetzprotokoll Romiplostim

Bei Patienten mit $>50 \times 10^{9}$ Thrombozyten/l für wenigstens 12 Monate wird Romiplostim um $1 \mu \mathrm{g} / \mathrm{kg}$ alle 2 Wochen reduziert. Solange die Thrombozytenzahl nach der Dosisreduktion nicht wieder unter $50 \times 10^{9} / 1$ abfällt reduziert man weiter [103]

\section{Absetzprotokoll Eltrombopag}

Bei Patienten mit $>50 \times 10^{9}$ Thrombozyten/l für wenigstens 4 Monate wird Eltrombopag um 10-20\% alle 4 Wochen reduziert (man reduziert die Wochen-, nicht die Tagesdosis). Solange die Thrombozytenzahl nach der Dosisreduktion nicht wieder unter $50 \times 10^{9} / 1$ abfällt, reduziert man weiter [104]

erfolgte. In den TRA-Zulassungsstudien waren auch viele Patienten mit deutlich kürzeren Krankheitsverläufen. Die Autoren halten deshalb die Anwendung von TRA bei Patienten, die auf eine Erstlinientherapie nicht ansprechen, auch dann für indiziert, wenn die Gesamterkrankungsdauer noch kein ganzes Jahr beträgt und das formale Kriterium der chronischen ITP nach heutiger Definition nicht erfüllt ist. Der Einwurf der Kostenträger, die 12-Monats-Grenze vor der Verordnung von TRA abzuwarten, ist weder medizinisch sinnvoll noch aus den Zulassungsstudien nachvollziehbar.

\section{Remissionen unter TRA}

In den letzten Jahren wurden zahlreiche Einzelfälle berichtet, bei denen nach dem Absetzen von TRA die Thrombozytenzahl nicht wieder abgefallen ist. Übersichtsarbeiten nennen Remissionszahlen von 13-30\% [101, 102]. Wenn die Thrombozyten längere Zeit im Zielbereich sind, kann ein Absetzversuch unternommen werden. Wichtig ist, dass TRA nicht abrupt, sondern langsam über viele Monate ausgeschlichen werden (Tab. 14).

\section{TRA-Medikamenteninteraktionen}

Eltrombopag zeigt Interaktionen mit 3-Hydroxy-3-methylglutaryl-Coenzym-A (HMG-CoA)-Reduktase-Hemmern; das sind im klinischen Alltag insbesondere Statine (für Details und Dosisanpassung siehe Fachinformation). Bei Romiplostim werden in der Fachinformation keine Wechselwirkungen genannt. Weitere relevante Medikamenten- und Krankheitsinteraktionen können z.B. in der Online-Datenbank www.drugs.com nachgeschlagen werden (Stand 7/2017).

\section{TPIAO}

TPIAO ist ein rekombinantes Thrombopoetinmolekül, das seit 2005 in China zur Behandlung der Chemotherapie-induzierten Thrombozytopenie und seit 2010 zur Zweitlinientherapie der ITP zugelassen ist (www.3sbio.com/en/products/oncology/tpiao). Während Romiplostim und Eltrombopag bei Schwangeren nicht empfohlen bzw. sogar kontraindiziert sind, scheint TPIAO bei diesen Patientinnen wirksam und sicher zu sein [105].

\section{Splenektomie}

\section{Empfehlungsgrad EK}

Evidenzlevel 3

Die Splenektomie ist indiziert bei Patienten mit persistierender oder chronischer Thrombozytopenie und schweren Blutungen (WHO III, IV), die kein oder nur ein ungenügendes Ansprechen auf alle anderen, bisherigen Therapiemodalitäten aufweisen.

Es besteht keine zwingende Indikation zur Splenektomie für Patienten mit chronischer, therapieresistenter ITP, die keine, leichte oder mittelschwere Blutungen (WHO 0, I, II) haben.

Die Splenektomie sollte nicht vor dem 12. Monat erfolgen.

Der Patient sollte nicht zur Splenektomie gedrängt werden.

Die Splenektomie hat bei der Behandlung der ITP die höchste Rate an dauerhaften Remissionen in dem Sinne, dass keine weitere Behandlung notwendig ist (zwei Drittel partielle oder komplette Remissionen). TRA erreichen zwar noch höhere Remissionsraten, wenn man nur das Ansprechen der Thrombozytenzahl betrachtet. Wenn sie abgesetzt werden, fallen die Thrombozyten aber wieder ab, sodass in der Regel eine Dauertherapie notwendig ist.

Es besteht eine klare Indikation zur Splenektomie für alle Patienten mit persistierender oder chronischer Thrombozytopenie und schweren Blutungen (WHO III, IV), die ein ungenügendes Ansprechen auf alle anderen, bisherigen Therapiemodalitäten aufweisen. Bei dringlicher Therapie (z.B. lebensbedrohliche Blutung, die nicht auf Steroide und IVIG anspricht!) ist die Splenektomie die Therapie der Wahl, weil die alternative Gabe von TRA oder Rituximab nicht ad hoc die Thrombozytenzahl anhebt, sondern Zeit braucht (häufig $>1$ Woche).

Es besteht keine zwingende Indikation zur Splenektomie für Patienten mit chronischer, therapieresistenter ITP, die keine, leichte oder mittelschwere Blutungen (WHO 0, I, II) haben, auch wenn deren Thrombozytenzahlen bei $<30 \times 10^{9} / 1$ liegen. Hier soll individuell entschieden werden.

Vor der Splenektomie wird zur zusätzlichen Diagnosesicherung eine Knochenmarkpunktion empfohlen (siehe Abschnitt «Knochenmarkpunktion»). Dies gilt insbesondere bei atypischem Verlauf (z.B. fehlendes Ansprechen auf Kortikosteroide und Immunglobuline) und/oder bei Patienten $>60$ Jahre. Alle Patienten sollten präoperativ gegen Pneumokokken, Haemophilus influenzae B und Meningokokken geimpft werden [106]. Meningokokken-Konjugatimpfstoff sollte nur intramuskulär (i.m.) gegeben werden, was bei schwerer Thrombozytopenie ein Problem sein kann. Dann wären die älteren Meningokokken-Polysaccharidimpfstoffe, die man auch subkutan (s.c.) geben kann, vorzuziehen (siehe jeweilige Fachinformation); siehe auch die Onkopedia-Leitlinie «Prävention 
Tab. 15. Risiken und Komplikationen nach Splenektomie

\begin{tabular}{l}
\hline Splenektomie: Risiken und Kontraindikationen (Übersicht in [109]) \\
\hline Postoperative Morbidität ca. 10\% (Wundinfektionen, Pneumonien) \\
\hline Postoperative Mortalität <1\% (bei älteren Patienten durchaus höher) \\
\hline Erhöhte Rate an Infektionen \\
\hline Overwhelming post splenectomy infection (OPSI, Sepsisrisiko 3× erhöht) \\
Postoperative Thrombozytose (bei >1000 × $10^{9}$ Thrombozyten/l \\
$\quad$ Acytylsalicylsäure oder niedermolekulares Heparin erwägen) \\
Venöse Thromboembolien
\end{tabular}

Pulmonale Hypertonie

Aktive Infektionen (insbesondere Tuberkulose)

Erhöhtes Infektionsrisiko bei Aufenthalt in Gebieten mit Malaria und Babesiose

von Infektionen und Thrombosen nach Splenektomie oder bei funktioneller Asplenie» (www.dgho-onkopedia.de) und die Empfehlungen von «Asplenie-Net» (https://asplenie-net.org/). AsplenieNet ist eine Initiative der Deutschen Gesellschaft für Infektiologie (DGI) in Kooperation mit mehreren weiteren medizinischen Fachgesellschaften. Asplenie-Net wird vom Universitätsklinikum Freiburg, Zentrum für Chronische Immundefizienz (CCI) und Zentrum Infektiologie \& Reisemedizin betreut. Auf der Internetseite von Asplenie-Net können aktuelle Empfehlungen zu Impfungen, Antibiotikaprophylaxe und Notfalltherapie bei Asplenie/Splenektomie und Bestellformulare für einen neu aufgelegten Notfallpass heruntergeladen werden.

Heute wird nur noch bei wenigen ITP-Patienten eine Splenektomie durchgeführt. Dafür ist nur zum Teil die Sorge vor den mit einer Splenektomie verbundenen Risiken und Nebenwirkungen verantwortlich (Tab. 15). Weitere wichtige Gründe sind:

Nur $\sim 60 \%$ der Patienten erreichen eine dauerhafte Remission [107-109], d.h. der Rest erleidet kurz oder im längeren Verlauf nach Splenektomie einen Rückfall der Erkrankung [110, 111]. Diese Zahlen stammen überwiegend aus der Zeit vor Einführung der TRA. Es ist deshalb nicht klar, ob die heutigen ITP-Patienten, die einer Splenektomie bedürfen, weil sie auf TRA nicht ansprechen, nicht als therapieresistenter zu werten sind und möglicherweise eine geringere Ansprechrate als 60\% haben.

Es ist bisher nicht möglich vorherzusagen, welcher Patient auf eine Splenektomie ansprechen wird und welcher nicht. Eine Versagensrate von $40 \%$ oder mehr ist für viele Patienten nicht akzeptabel. Der Internationale Consensus-Report empfiehlt die Splenektomie auch nur, wenn der Abbau radioaktiv markierter Thrombozyten vorwiegend in der Milz erfolgt [64]. Diese Empfehlung kann jedoch aufgrund widersprüchlicher Daten bisher nicht als verbindlich betrachtet werden. Auch wenn die Szintigrafie zeigt, dass die Thrombozyten primär nicht in der Milz abgebaut werden, hat die Splenektomie immer noch eine Erfolgsrate von 35-40\% [112, 113]. Nach Kenntnis der Autoren gibt es in der Bundesrepublik nur noch wenige nuklearmedizinische Abteilungen, die eine Thrombozytenszintigrafie anbieten.
Es scheint keinen Unterschied zu machen, ob die Splenektomie laparoskopisch oder mit Laparotomie durchgeführt wird. Hier kommt es primär auf die Expertise des Operateurs an. Zur Anhebung der Thrombozytenzahl im Vorfeld der Splenektomie gibt man IVIG, Steroide und gegebenenfalls auch Thrombozytenkonzentrate.

\section{Splenektomie aufschiebende Therapien}

Viele Patienten lehnen die Splenektomie ab und fragen nach sogenannten Splenektomie aufschiebenden oder ersetzenden medikamentösen Therapien. Dies ist zum Teil damit begründet, dass in anderen Ländern medikamentöse Therapiealternativen (Rituximab) vor der Splenektomie eingesetzt werden können. Aufgrund der bis zum Ablauf des ersten Erkrankungsjahres häufigen spontanen Remissionen ist das Hinausschieben der Operation aber auch medizinisch sinnvoll und wird von vielen Leitlinien empfohlen [3, $58,64]$.

Die Möglichkeit der medikamentösen Therapie mit Rituximab vor Splenektomie sollte mit dem Patienten besprochen werden. Die fehlende arzneimittelrechtliche Zulassung entbindet den Arzt nicht von der Verpflichtung, diese Therapiealternativen gegenüber dem Patienten zu erwähnen. Die Patienten sind auf den fehlenden Zulassungsstatus («off-label») von Rituximab vor einer Splenektomie hinzuweisen und über Nebenwirkungsrisiken entsprechend ausführlicher aufzuklären. Der Patient hat in der Regel keinen Kostenerstattungsanspruch bei Off-label-Therapien.

\section{Drittlinientherapie mit Rituximab}

\section{Empfehlungsgrad EK}

Evidenzlevel 2

Rituximab kann bei ITP als Drittlinientherapie nach Versagen von Kortikosteroiden und TRA eingesetzt werden.

Rituximab induziert eine selektive Depletion CD20-positiver BLymphozyten. Dadurch werden weniger Antikörper gebildet und bei der ITP weniger Anti-Thrombozyten-Antikörper. 1998 wurde Rituximab erstmals bei einem Patienten mit chronischer, therapierefraktärer ITP erfolgreich eingesetzt [114]. Seither sind zahlreiche Fallberichte und Studien publiziert [115-119] (Übersicht bei [120]). Im Mittel erreicht Rituximab bei 60\% der Patienten eine kurzfristige Steigerung der Thrombozytenzahl. Es kommt jedoch zu Rezidiven. Die längerfristigen Remissionsraten liegen bei 10-40\%.

Es scheint 2 Formen des Ansprechens zu geben. Manche Patienten zeigen eine Besserung bereits nach den ersten Infusionen («Early Responder»), bei anderen tritt der Thrombozytenanstieg erst Wochen nach Therapieende ein («Late Responder») [121]. Bei fehlender Ansprache in den ersten 4 Wochen sollte man nicht gleich von einer Unwirksamkeit ausgehen. Als Erklärung für dieses unterschiedliche Ansprechen wird vermutet, dass bei den Early Re- 
spondern antikörperbeladene B-Lymphozyten das retikulohistiozytäre System sättigen und blockieren, während bei den Late Respondern die verminderte Neubildung von Thrombozytenantikörpern zum Tragen kommt.

Rituximab ist vor und nach Splenektomie wirksam.

Kinder scheinen etwas besser anzusprechen als Erwachsene. Rückfälle treten bei Kindern nur in den ersten Jahren auf, bei Erwachsenen auch später.

Frauen und Mädchen scheinen auf Rituximab besser anzusprechen als Männer und Jungen. Dies mag am unterschiedlichen Metabolismus von Rituximab liegen.

ITP-Patienten, bei denen die Erkrankung noch nicht so lange besteht, scheinen auch besser anzusprechen.

Dosierung von Rituximab: Die Standarddosierung von Rituximab liegt bei $375 \mathrm{mg} / \mathrm{m}^{2}$ 1-mal pro Woche für 4 aufeinanderfolgende Wochen [120]. Es gibt auch Publikationen mit niedrigeren Dosierungen [118]. Ein Vergleich hat bisher nicht stattgefunden. Es gibt auch keine Daten zu s.c. Rituximab oder Rituximab-Biosimilars bei ITP.

Rituximab Nebenwirkungen: Die Behandlung mit Rituximab ist in der Regel gut verträglich. Wichtige Nebenwirkungen, auf die man achten sollte sind:

- Infusionsreaktion mit Schwäche, Übelkeit, Fieber, Schüttelfrost, Kopfschmerzen sind häufig (etwa 60\%), in der Regel mild und treten meist nur während der ersten Infusion auf (deshalb Prämedikation mit Kortikosteroid).

- Anaphylaktische Reaktionen sind selten (nicht zu verwechseln mit dem Zytokin-Freisetzungssyndrom bei Lymphomen).

- Das Infektionsrisiko ist erhöht (bei Fieber umgehende Vorstellung beim Arzt, auch am Wochenende).

- Impfungen sind bis zu 6 Monate nach Rituximab wenig oder gar nicht wirksam [122].

Es wurden aber auch seltene ernste Nebenwirkungen berichtet, insbesondere schwere Infektionen und Einzelfälle von progressiver multifokaler Leukoenzephalopathie. Es muss offen bleiben, inwieweit diese auf Rituximab oder die immunsuppressive Vor- und Begleittherapie zurückzuführen waren. Vor der Gabe von Rituximab sollte eine Virushepatitis ausgeschlossen werden.

Rituximab «off-label»: Rituximab hat in keinem Land der Welt eine arzneimittelrechtliche Zulassung zur Therapie der ITP und angesichts des ausgelaufenen Patentschutzes ist dies auch für die $\mathrm{Zu}$ kunft nicht zu erwarten. Die fehlende Zulassung spricht jedoch nicht gegen die Wirksamkeit von Rituximab. Es gibt keine medizinische Evidenz, Rituximab erst nach einer Splenektomie anzubieten.

Rituximab bei sekundärer ITP im Rahmen einer chronischen lymphatischen Leukämie (CLL) oder bei Autoimmunerkrankungen: Rituximab ist sowohl gegen die CLL als auch gegen die Autoimmundysregulation gut wirksam und sollte in dieser speziellen Situation als primäre Therapie (in der Regel zusammen mit Zytostatika) angeboten werden. Bei Autoimmunerkrankungen (variables Immundefektsyndrom (CVID), systemischer Lupus erythematodes (SLE)) mit sekundärer ITP wird Rituximab erfolgreich eingesetzt.

Rituximab bei rezidivierter/therapieresistenter ITP mit klinisch relevanten Blutungen: Bei diesen Patienten wird Rituximab häufig als «Rescue»-Therapie eingesetzt, wenn Kortikosteroide und IVIG nicht ausreichend wirksam sind. Für diese Indikation gibt es keine randomisierten Daten, zahlreiche Fallberichte sprechen jedoch für die Wirksamkeit und Rituximab sollte in dieser Situation den Patienten angeboten werden (siehe Abschnitt «Kombinationstherapien bei multirefraktärer ITP»).

Rituximab als Splenektomie ersparende Therapie bei rezidivierter/ therapieresistenter ITP ohne klinisch relevante Blutungen: Etwas anderes ist die Gabe von Rituximab als Drittlinientherapie (nach Kortikosteroiden und TRA) vor Splenektomie bei Patienten ohne bedrohliche Blutungen. Es gibt keine medizinischen Gründe, die gegen eine Anwendung vor einer Splenektomie sprechen, wenn der Patient dies wünscht, um die Chance einer Remission und Vermeidung der Operation zu nutzen. Die Off-label-Situation und die mögliche Ablehnung der Kostenübernahme sind jedoch anzusprechen (siehe auch Abschnitt «Splenektomie aufschiebende Therapien»).

\section{Weitere Drittlinientherapien (Übersicht [123, 124])}

Empfehlungsgrad EK

Evidenzlevel 3

Medikamente mit sogenannten Altzulassungen für die ITP (Azathioprin, Cyclophosphamid, Vinca) oder nicht zugelassene Wirkstoffe sollten erst nach Versagen von Steroiden, TRA und Rituximab eingesetzt werden.

\section{Azathioprin}

Die Dosis beträgt 1-3 mg/kg/Tag oral (p.o.).

Üblicherweise kombiniert man initial Azathioprin und Steroide, um nach einigen Wochen die Steroiddosis langsam zu reduzieren («steroid-sparing agent»).

Neutropenien sind häufig (etwa 30\%), die Leukozytenzahl soll regelmäßig (zu Beginn z.B. alle 2-4 Wochen) kontrolliert werden.

Die Therapie spricht langsam an und sollte mindestens 3-4 Monate gegeben werden, bevor man die Wirksamkeit beurteilt.

Azathioprin hat eine «Altzulassung» für die Therapie der ITP.

Azathioprin darf in der Schwangerschaft nur nach sorgfältiger Nutzen-Risiko-Abwägung angewendet werden.

\section{Ciclosporin}

Ciclosporin A (CSA; 2,5-8 mg/kg/Tag) wird als Monotherapie oder in Kombination mit Prednison eingesetzt. Die niedrigeren Dosen $(2,5-3 \mathrm{mg} / \mathrm{kg} / \mathrm{Tag})$ scheinen besser verträglich und nicht weniger wirksam zu sein. Ein CSA-Zielspiegel von 150-400 ng/ml wird angestrebt.

Häufige Nebenwirkungen: Erschöpfung, Schwäche, Niereninsuffizienz, Hypertonie, Neuropathie.

Die Therapie spricht langsam an und sollte mindestens 2-3 Monate gegeben werden, bevor man die Wirksamkeit beurteilt. 
CSA hat in der Bundesrepublik keine arzneimittelrechtliche Zulassung für die Therapie der ITP.

\section{Cyclophosphamid}

Die Dosis beträgt $1-2 \mathrm{mg} / \mathrm{kg} / \mathrm{Tag}$ p.o., sie soll an die Leukozytenzahl angepasst werden.

Neben den üblichen Zytostatika-Nebenwirkungen (Knochenmarksuppression usw.) werden seltene Fälle von Blasenkrebs und sekundärer Leukämie beschrieben. Die Fertilität kann eingeschränkt sein.

Cyclophosphamid hat in der Bundesrepublik eine arzneimittelrechtliche "Altzulassung» nur für «bedrohlich verlaufende Immunkrankheiten», also nicht für leichte Formen der ITP.

\section{Danazol}

Die Dosis beträgt 400-800 mg/Tag.

Danazol ist ein modifiziertes Androgen und bei längerfristiger Therapie sollte auf die Leberfunktion geachtet werden. Bei Frauen sollte es nicht gegeben werden (Virilisierung).

Weitere Nebenwirkungen sind Gewichtszunahme, Myalgien, Haarverlust.

Die Therapie spricht langsam an und sollte mindestens 2-3 Monate gegeben werden, bevor man die Wirksamkeit beurteilt.

Danazol hat in der Bundesrepublik keine arzneimittelrechtliche Zulassung und wird auch nicht vertrieben. Es muss über die Auslandsapotheke importiert werden (Danol Kapseln à 200 mg).

\section{Dapson}

Die Dosis beträgt 75-100 mg/Tag p.o.

Bei Patienten aus mediterranen Ländern und besonders bei Afrikanern und Afroamerikanern sollte ein Mangel oder Defekt der Glukose-6-Phosphat-Dehydrogenase vorher ausgeschlossen werden.

Die Therapie spricht langsam an und ein Effekt ist in der Regel erst nach 4-6 Wochen zu erwarten. Danach sollte versucht werden, die Dosis zu reduzieren.

Dapson (DAPSON-Fatol ${ }^{\circledR}$ Tabletten à $50 \mathrm{mg}$ ) hat in der Bundesrepublik keine arzneimittelrechtliche Zulassung für die Therapie der ITP.

\section{Hydroxychloroquin}

Hydroxychloroquin hat multiple Wirkungen auf das Immunsystem. Es wurde in Studien bei ITP-Patienten gegeben, die einen positiven Nachweis von ANA oder einen gesicherten SLE hatten.

Die Dosis beträgt $200 \mathrm{mg}$ p.o. 2-mal täglich.

Die Therapie spricht langsam an und sollte mindestens 2-3 Monate gegeben werden, bevor man die Wirksamkeit beurteilt. Meist kombiniert man Hydroxychloroquin zunächst mit Steroiden, um nach einigen Wochen die Steroiddosis langsam zu reduzieren («steroid-sparing agent»).

Hydroxychloroquin (Quensyl ${ }^{\circledR}$ Tabletten à $200 \mathrm{mg}$ ) hat in der Bundesrepublik keine arzneimittelrechtliche Zulassung für die Therapie der ITP.

\section{Mycophenolat-Mofetil}

Zur besseren Verträglichkeit beginnt man in der Regel mit einer niedrigen Dosis und steigert dann langsam: die ersten 2 Wochen $250 \mathrm{mg}$ 2-mal täglich, 3. bis 4 . Woche 2-mal $500 \mathrm{mg} / \mathrm{Tag}$, nach 4 Wochen 2-mal $1000 \mathrm{mg} / \mathrm{Tag}$.

Häufig sind gastrointestinale Nebenwirkungen (Übelkeit, Appetitlosigkeit, Durchfall, Erbrechen).

Mycophenolat-Mofetil hat in der Bundesrepublik keine arzneimittelrechtliche Zulassung zur Therapie der ITP.

\section{Vinca-Alkaloide}

Dosierung: Vincristin 1-2 mg oder Vinblastin 5-10 mg werden 1-mal pro Woche für maximal 4-6 Wochen verabreicht.

Typische Nebenwirkungen sind die Zytostatika-induzierte Thrombozytopenie, Neuropathie, Obstipation.

Die Wirkung hält meist nicht lange an, weshalb diese Therapieform seit der Einführung der Immunglobulintherapie kaum noch angewendet wird.

Vincristin hat eine «Altzulassung» für die ITP, Vinblastin hat keine Zulassung. Sie sind hier erwähnt, weil sie in vielen älteren Quellen noch genannt werden. Nach Meinung der Autoren haben Vinca-Alkaloide keinen Stellenwert mehr in der aktuellen Therapielandschaft.

Die Reihenfolge der oben genannten Therapien impliziert keine Präferenz. Die Entscheidung muss individuell getroffen werden (zu Dosierung und Zulassungsstatus siehe Tab. 10 und 11). Man soll berücksichtigen, dass Azathioprin, Cyclophosphamid und VincaAlkaloide nur «Altzulassungen» zur Behandlung der ITP haben. Das bedeutet, dass diese Präparate nicht nach heutigen «Good Clinical Practice»- und «Evidence-Based Medicine»-Standards untersucht wurden und dass ihre Zulassung eher auf Tradition als auf Studiendaten beruht. Sie sollten deshalb nur gegeben werden, wenn modernere und besser untersuchte Wirkstoffe wie TRA und Rituximab nicht wirksam sind. Auch ist der Anteil dauerhafter Remissionen nicht sehr hoch, dafür sind die Nebenwirkungen zum Teil erheblich.

\section{Kombinationstherapien bei multirefraktärer ITP}

Eine ITP, die auf multiple Vortherapien nicht anspricht und bei der die Patienten immer wieder klinisch relevant bluten, ist eine ernsthafte Erkrankung mit hoher Morbidität und Mortalität [125, 
126]. In dieser Situation werden meist Kombinationen mehrerer ITP-Wirkstoffe eingesetzt, z.B. Rituximab mit Steroiden und TRA. Beispielhaft seien hier 3 aktuelle Protokolle aufgeführt (weitere Protokolle beim Verfasser).

Choi et al., 2014 [127], sogenanntes TT4-Protokoll: Rituximab (100 mg (abs.) i.v., Tage 7, 14, 21, 28), Dexamethason (40 mg/Tag p.o., Tage 1-4), Ciclosporin (2,5-3 mg/kg/Tag p.o., Tage 1-28).

Veneri et al., 2015 [128]: Rituximab (375 mg/m² i.v., Tage 1, 8, 15, 22), Romiplostim (Startdosis $1 \mu \mathrm{g} / \mathrm{kg}$ s.c., 1 -mal pro Woche).

Rashidi und Blinder, 2016 [129]: Eltrombopag (50-75 mg/Tag p.o.), Azathioprin (1 mg/kg/Tag p.o.), Mycophenolat (1000 mg/ Tag p.o.), Ciclosporin (1 mg/kg/Tag p.o.).

\section{Antifibrinolytika}

Durch die Gabe des Fibrinolyseinhibitors Tranexamsäure kann bei leichten oralen Schleimhautblutungen, bei Menorrhagien und im Rahmen von Zahneingriffen häufig eine ausreichende Blutstillung erreicht werden [130].

\section{Dosierung}

Oral: Cyklokapron ${ }^{\circledR}$ Filmtabletten à $500 \mathrm{mg}, 20-25 \mathrm{mg} / \mathrm{kg}$ alle $8 \mathrm{~h}$.

Herstellung einer 5\%igen Tranexam-Mundspüllösung: Cyklokapron ${ }^{\circledR}$ Injektionslösung ist $\sim 10 \%$ ig, $\rightarrow$ Verdünnung mit gleichem Volumen ergibt eine 5\%ige Lösung, Mundspülung 4-mal täglich.

Parenteral: Injektionslösung 0,5-1 g (Cyklokapron ${ }^{\circledR}$ Ampullen à 5 oder $10 \mathrm{ml}$ ) alle $8-12 \mathrm{~h}$ langsam i.v. (CAVE: bei parenteraler Anwendung selten Thrombosen).

Bei Blutungen in das Auge, Zentralnervensystem (ZNS) oder bei Organblutungen sind Antifibrinolytika nicht ausreichend wirksam.

\section{Therapie der chronischen ITP bei Kindern und Jugendlichen}

\section{Empfehlungsgrad EK}

Evidenzgrad 5

Bisher kann kein Standard zur Therapie der chronischen ITP bei Kindern und Jugendlichen definiert werden. Deshalb sollten die Patienten in Zentren mit pädiatrisch-hämatologischer Expertise betreut werden.

Bei der chronischen ITP des Kindesalters ist meist keine Therapie notwendig, sondern nur bei häufigen und belastenden Blutungssymptomen. Es gibt keinen Therapiestandard. TRA sind bei chronischer ITP im Kindes- und Jugendalter wirksam [49, 52, 84, 131-133]. Seit 2016 ist Eltrombopag für diese Indikation zugelas- sen. Die Zulassung für Romiplostim wird für 2018 erwartet. Häufige Nebenwirkungen sind Kopfschmerzen und Beschwerden im Hals und Rachenbereich (wie bei Erwachsenen). Bisher wurden keine schweren Nebenwirkungen wie neutralisierende Antikörper oder Myelodysplasien berichtet (sicherlich auch wegen der bei Kindern naturgemäß begrenzten Zahl von Knochenmarkbefunden). Bei einigen Kindern fand sich eine leichte Retikulinfaservermehrung (Grad 1-2).

Die Splenektomie sollte bei Kindern vermieden werden. Sie kann jedoch bei therapieresistenter ITP und ständigen Blutungen als Ultima Ratio diskutiert werden.

In der Pädiatrie hat sich die antifibrinolytische Therapie mit Tranexamsäure, insbesondere bei Schleimhautblutungen bewährt.

\section{Vorgehen bei Operationen und Zahneingriffen}

Wenn bei Patienten mit ITP eine Operation oder ein invasiver diagnostischer Eingriff geplant wird, dann stellt sich die Frage nach den präoperativ anzustrebenden Thrombozytenwerten (Tab. 16) [134, 135]. Bei Notfalloperationen wird man in der Regel Steroide mit i.v. applizierten Immunglobulinen und gegebenenfalls auch Thrombozytenkonzentraten kombinieren. In allen anderen Fällen, insbesondere bei elektiven Operationen, sollte präoperativ eine Anhebung der Thrombozytenzahl mit Kortikosteroiden, TRA oder anderen bei dem Patienten als wirksam erkannten Maßnahmen erreicht werden.

\section{Impfungen}

\section{Impfen bei ITP}

\section{Empfehlungsgrad EK \\ Evidenzlevel 3}

ITP-Patienten sollten alle empfohlenen Impfungen erhalten. Unter Immunsuppression sind Lebendimpfstoffe jedoch kontraindiziert.

Patienten, bei denen aufgrund häufiger oder schwerer Blutungen bzw. bei Therapieresistenz eine baldige Splenektomie zu den näherliegenden Therapieoptionen zählt, sollten frühzeitig gegen Pneumo-, Meningokokken und Haemophilus influenzae $B$ geimpft werden.

ITP-Patienten können alle Standardimpfungen erhalten, die von den nationalen Gesundheitsbehörden empfohlen werden. Nur bei ITP-Patienten mit immunsuppressiver Therapie (z.B. Kortison, Rituximab usw., aber z.B. nicht bei Therapie mit TRA) sind Lebendimpfungen kontraindiziert. IVIG können ebenfalls die Wirkung von Lebendimpfstoffen beeinträchtigen. Die Hersteller empfehlen einen Abstand von mindestens 3 Monaten nach IVIG (für Details siehe Fachinformationen der Präparate). 
Tab. 16. Anzustrebende Thrombozytenwerte bei Operationen und anderen invasiven Verfahren $[134,135]^{*}$

\begin{tabular}{|c|c|}
\hline Operationen und anderen invasiven Verfahren & Anzustrebende Thrombozytenwerte \\
\hline Zahnärztliche Zahnreinigung, Zahnsteinentfernung & $>20-30 \times 10^{9} / 1$ \\
\hline Zahnextraktion (einfach) & $>30 \times 10^{9} / 1$ \\
\hline Zahnextraktion (komplex, z.B. molar) & $>50 \times 10^{9} / 1$ \\
\hline Leitungsanästhesie bei Zahneingriff & $>30 \times 10^{9} / 1$ \\
\hline Lumbalpunktion (elektiv) & $>50 \times 10^{9} / 1$ \\
\hline Lumbalpunktion (vitale Indikation) & $>20 \times 10^{9} / 1$ \\
\hline Spinalanästhesie & $>50 \times 10^{9} / 1$ \\
\hline Epiduralanästhesie & $>80 \times 10^{9} / 1$ \\
\hline Anlage eines zentralen Venenkatheters & $>20 \times 10^{9} / 1$ \\
\hline \multicolumn{2}{|l|}{ Gastrointestinale Endoskopie ohne Biopsie auch bei sehr niedrigen Werten möglich } \\
\hline Gastrointestinale Endoskopie mit Biopsie & $>20 \times 10^{9} / 1$ \\
\hline Bronchoskopie/Bronchiallavage & $>20 \times 10^{9} / 1$ \\
\hline Bronchoskopie mit transbronchialer Biopsie & $>50 \times 10^{9} / 1$ \\
\hline Leberpunktion bei transjugulärem Zugang (bei Thrombozytopenie bevorzugt) & $>10 \times 10^{9} / 1$ \\
\hline Leberpunktion bei transkutanem Zugang & $>50 \times 10^{9} / 1$ \\
\hline \multicolumn{2}{|l|}{ Eine Beckenkammbiopsie ist auch bei niedrigsten Werten möglich } \\
\hline Andere Organpunktionen/Biopsien & $>50 \times 10^{9} / 1$ \\
\hline Kleine Operation ${ }^{1}$ & $>50 \times 10^{9} / 1$ \\
\hline Kleine Operationen, bei denen durch Kompression eine Blutstillung erreicht werden kann & $>20 \times 10^{9} / 1$ \\
\hline Größere Operation $^{2}$ & $>80 \times 10^{9} / 1$ \\
\hline Neurochirurgischer Eingriff & $>70-100 \times 10^{9} / 1$ \\
\hline Eingriffe am hinteren Augenabschnitt & $>70-100 \times 10^{9} / 1$ \\
\hline
\end{tabular}

${ }^{1}$ Kleine Operationen sind operative Eingriffe mit einem geringen Blutungsrisiko, zu denen die Mehrzahl der peripheren Eingriffe zählt.

${ }^{2}$ Größere Operationen sind z.B. abdominelle oder thoraxchirurgische Eingriffe und Operationen in Regionen, die im Falle einer postoperativen Blutung nicht komprimiert werden können.

${ }^{*}$ Diese Zahlen wurden für Patienten mit Thrombozytenbildungsstörungen erhoben. Für ITP-Patienten gibt es keine entsprechenden Daten. Hier soll auch die individuelle Blutungsanamnese berücksichtigt werden, ob ein Patient in seiner Vorgeschichte bereits bei den angegebenen Thrombozytenzahlen geblutet hat.

Viele Impfungen können bei ITP-Patienten mit niedrigen Thrombozytenzahlen s.c. statt i.m. verabreicht werden, um eine Muskelblutung zu vermeiden (analog dem Vorgehen bei Patienten mit therapeutischer Antikoagulation, gegebenenfalls Rücksprache mit dem Hersteller).

Bei Patienten, die eine ITP in der Anamnese haben und die jetzt in Remission sind, oder bei Patienten, die aktuell unter einer chronischen ITP leiden, scheinen Impfungen keinen Rückfall oder eine Verschlimmerung der Thrombozytopenie zu induzieren. Wenn die Impfung unterlassen wird und der Patient dann an der Infektion erkrankt, hat er möglicherweise ein höheres Risiko, dass diese Infektion die Thrombozytopenie verschlimmert [136]. Deshalb sollte auch die «Thrombozytopenie-behaftete» MMR-Impfung (Masern, Mumps, Röteln) allen bisher nicht geimpften Kindern mit ITP angeboten werden.

ITP-Patienten gehören außerdem zu dem Personenkreis, bei denen im Falle einer Hepatitis-B-Infektion und bei einer aktuellen oder zukünftigen therapieinduzierten Immundefizienz ein schwerer Verlauf zu erwarten wäre. Bei Reisen in Länder, deren medizinische Versorgung nicht den europäischen Standards entspricht, wäre im Fall einer Gabe von Blutprodukten außerdem eine Infektion nicht ausgeschlossen. Deshalb wird auch eine Hepatitis-BImpfung empfohlen.

\section{Thrombozytopenie nach Impfungen}

Kurzfristige Thrombozytopenien in Assoziation mit Impfungen wurden beschrieben. In Studien werden ITP-Inzidenzen von 0,15 pro 1 Million Impfungen (verschiedene Impfstoffe), 20 pro 1 Million MMR-Impfungen, 0,16 pro 1 Million Masernimpfungen genannt. Wenn man eine natürliche, d.h. nicht impfassoziierte «Hintergrundsinzidenz» von 0,2-0,4/10 000/Jahr annimmt (siehe Abschnitt «Epidemiologie»), dann würden schon allein aufgrund dieser Zahl 1,6-3,0 Kinder bzw. Erwachsene pro 1 Million im Sinne einer zufälligen Koinzidenz innerhalb 4 Wochen nach einer Impfung an einer ITP erkranken. Nach einer MMR-Impfung ist die Inzidenz 1: 40 000. Studien finden aber keine Häufung chronischer ITP-Erkrankungen nach Impfungen [136]. Bei den seltenen Patienten, bei denen ein Zusammenhang zwischen dem Auftreten einer ITP und einer vorhergehenden Impfung vermutet wird, sollte der Nutzen weiterer Impfungen mit diesem oder anderen Impfstoffen, die ähnliche Bestandteile enthalten, gegen die Risiken abgewogen werden.

\section{Impfungen vor Splenektomie oder Rituximab}

ITP-Patienten, bei denen aufgrund häufiger oder schwerer Blutungen bzw. bei Therapieresistenz eine baldige Splenektomie zu 
den näherliegenden Therapieoptionen zählt, sollten frühzeitig gegen Pneumo-, Meningokokken und Haemophilus influenzae B geimpft werden (siehe Abschnitt «Splenektomie»). Das Gleiche gilt für Patienten, die Rituximab erhalten sollen.

\section{Sekundäre ITP}

Man unterscheidet bei der ITP eine primäre Form, bei der keine auslösende Ursache für die ITP erkennbar ist, von sekundären Formen, bei denen die ITP durch Medikamente oder andere Erkrankungen ausgelöst wird (Tab. 1). Etwa 20\% der ITPErkrankungen sind sekundär [7, 137]. Folgende Auslöser werden häufiger genannt:

- Autoimmunerkrankungen (Sjögren-Syndrom, SLE, rheumatoide Arthritis, Autoimmunthyreoiditis und andere)

- autoimmune entzündliche Darmerkrankungen (Colitis ulcerosa, Morbus Crohn)

- Immundefektsyndrome (z.B. CVID)

- hämatologische Neoplasien: MDS und Lymphome (2-5\% der CLL-Patienten haben eine sekundäre ITP)

- nach allogener Stammzelltransplantation

- solide Tumoren

- Virusinfektionen (Epstein-Barr-Virus (EBV), Cytomegalovirus (CMV), Hepatitis-B- und -C-Virus (HBV, HCV), humanes Immundefizienzvirus (HIV) und andere)

- Medikamente (siehe Abschnitt «Medikamenteninduzierte Thrombozytopenie»)

Besonders bei älteren Patienten sollte man an eine sekundäre ITP denken. Die Splenektomie hat bei sekundärer ITP niedrigere Langzeitremissionsraten als bei primärer ITP. Die Milzentfernung verstärkt außerdem eine bereits vorbestehende Immunsuppression und erhöht das Risiko für Infekte. Sie sollte deshalb vermieden werden. In der Regel steht die Therapie der Grunderkrankung im Vordergrund.

\section{ITP und Schwangerschaft}

Empfehlungsgrad EK

Evidenzlevel 3

Schwangere ITP-Patientinnen, die einer Therapie bedürfen, sollten Kortikosteroide oder IVIG erhalten.

Die Art der Entbindung (Sectio vs. vaginal) wird nicht durch die ITP, sondern allein durch die geburtshilfliche Situation der Mutter bestimmt.

\section{Epidemiologie}

Bei 6-12\% aller Schwangerschaften zeigt sich eine Thrombozytopenie $[63,64,138]$. Die häufigsten Ursachen sind Gestationsthrombozytopenie, Präeklampsie, Eklampsie und das HELLP-Syndrom. Die nächsthäufigste Thrombozytopenie in der Schwangerschaft ist dann schon die ITP mit 1-4\%. Die absolute Häufigkeit in der Schwangerschaft beträgt 1 ITP auf etwa 1000-10 000 [138]. Nur ein Drittel der ITP-Erkrankungen sind vorbekannt, zwei Drittel werden erst in der Schwangerschaft diagnostiziert.

\section{Blutungs- und andere Risiken}

Das Blutungsrisiko für Schwangere mit ITP wird mit 16-22\% angegeben und ist damit geringer als bei Nicht-Schwangeren mit ITP. Möglicherweise spielt die prokoagulatorische Gerinnungsaktivierung in der Schwangerschaft für die geringere Blutungsneigung eine Rolle.

Auch das ungeborene Kind ist durch die ITP der Mutter betroffen, weil durch den plazentaren Übertritt von Thrombozytenantikörpern eine Thrombozytopenie beim Neugeborenen ausgelöst werden kann. Das Risiko liegt bei etwa 5-10\%. Intrazerebrale Blutungen treten bei $<1,5 \%$ auf und die neonatale Mortalität beträgt $<$ $1 \%$. Die Blutungen manifestieren sich nicht wie bei der neonatalen Allo-ITP bereits intrauterin, sondern in der Regel peri- und bis etwa 1 Woche postnatal $[139,140]$.

Die mütterlichen Thrombozytenwerte korrelieren nicht mit denen des Kindes. Dies ist insbesondere bei splenektomierten Frauen zu beachten. Dann können die Thrombozytenwerte der Mutter gering erniedrigt oder sogar normal sein, während der Antikörper, der durch die Splenektomie nicht verschwunden ist, beim Kind eine viel stärkere Thrombozytopenie verursacht. Der einzige prädiktive Marker ist, ob bereits bei einer vorhergehenden Geburt eine Thrombozytopenie des Neugeborenen aufgetreten war [139]. Dann ist die Wahrscheinlichkeit hoch, dass sich dies bei der nächsten Geburt wiederholt.

\section{Diagnostik}

Bei einer in der Schwangerschaft neu diagnostizierten Thrombozytopenie $>100 \times 10^{9} / 1$ ist in der Regel keine weitere Diagnostik notwendig. Die Wahrscheinlichkeit ist hoch, dass es sich um eine harmlose Schwangerschaftsthrombozytopenie handelt. Bei Werten von $<100 \times 10^{9} / 1$ wird eine Basisdiagnostik analog dem Vorgehen bei nicht schwangeren ITP-Patienten empfohlen (siehe Abschnitt «Diagnostik») (Abb. 2).

\section{Therapieindikation in der Schwangerschaft}

Die Therapie einer ITP in der Schwangerschaft bereitet besondere Probleme, da die notwendigen Medikamente Nebenwirkungen auf die Schwangerschaft und den Fötus haben können. Glücklicherweise sind die Thrombozytenwerte meist nicht sehr niedrig, sodass nur etwa die Hälfte aller Schwangeren eine Therapie benötigt.

Eine Therapieindikation besteht:

- bei klinisch relevanten Blutungen,

- zur Vorbereitung invasiver Eingriffe (z.B. Sectio, Periduralanästhesie), 


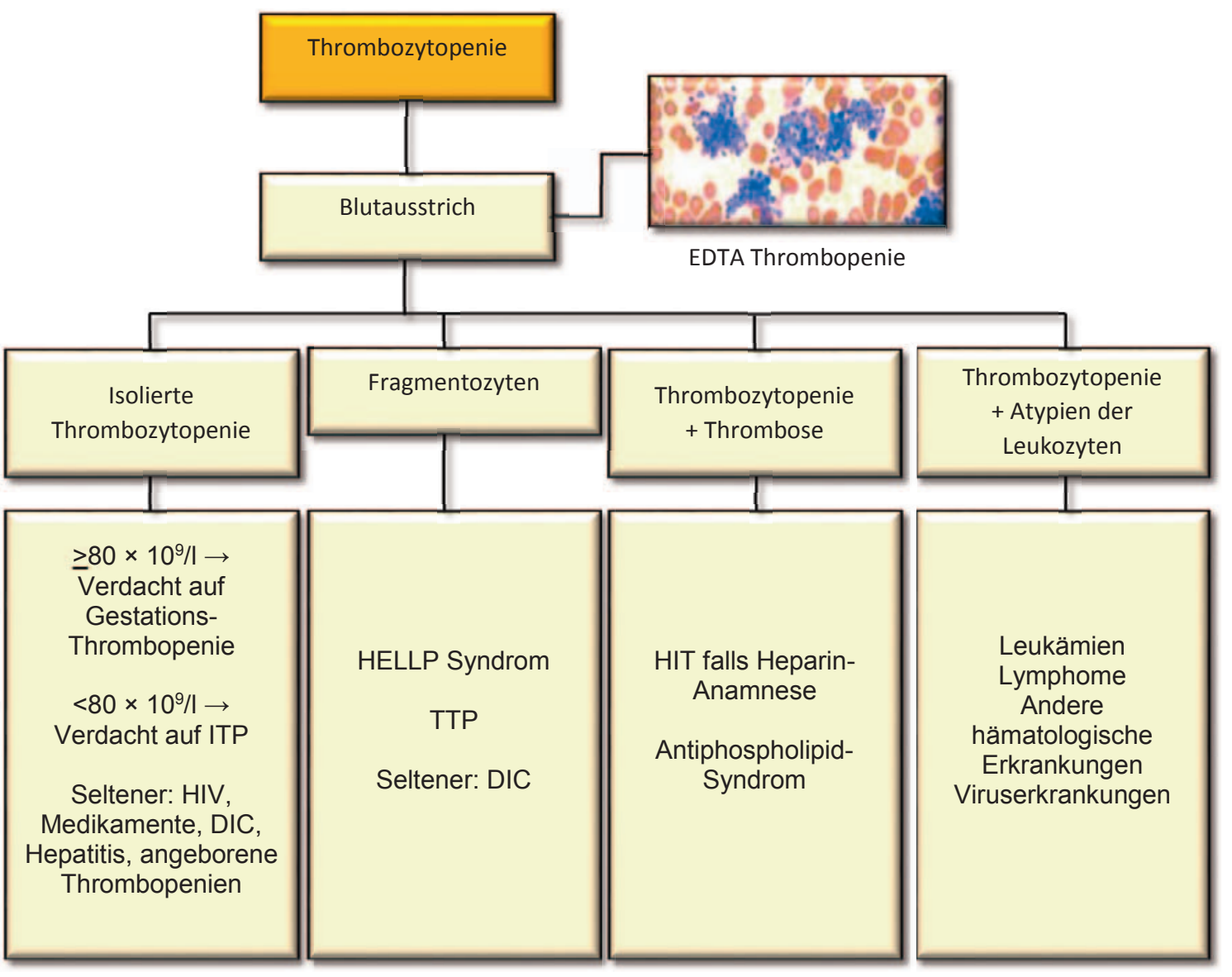

- bei Thrombozyten unter $20 \times 10^{9}-30 \times 10^{9} / 1$ im ersten und zweiten Trimenon,

- bei Werten unter $50 \times 10^{9} / 1$ im letzten Trimenon. Für eine Sectio wird eine Thrombozytenzahl über $50 \times 10^{9} / 1$ als ausreichend angesehen, für eine Periduralanästhesie Werte über $80 \times 10^{9} / 1$.

\section{Therapieoptionen (Übersicht bei [138])}

Steroide (Predniso(lo)n): Man wird - wenn kein Notfall die Verwendung höherer Dosen erforderlich macht - mit einer Dosis von 20-30 mg/Tag beginnen und versuchen, diese rasch soweit $\mathrm{zu}$ reduzieren, dass eine Thrombozytenzahl von $20 \times 10^{9}-30 \times 10^{9} / 1$ gehalten werden kann (meist reichen 10-20 mg/Tag). Für Dexamethason in der Schwangerschaft gibt es keine Daten, Störungen der Fötalentwicklung sind möglich.

Neben den bekannten Nebenwirkungen von Kortison auf die Mutter (Hochdruck, Diabetes, Osteoporose, Cushing usw.) wurde in den letzten Jahren auch ein vermehrtes Auftreten von Fehlbildungen beim Neugeborenen diskutiert (Lippen-Kiefer-Gaumenspalten). Diese sind jedoch insgesamt so selten, dass ein Therapieverzicht allein aus Furcht vor diesem Risiko nicht gerechtfertigt erscheint.

IVIG: Wenn höhere Steroiddosen notwendig sind oder wenn Nebenwirkungen auftreten (Hypertonie, diabetische Stoffwechsel- lage, Osteoporose, starker Gewichtsanstieg, Psychose usw.) kann man alternativ IVIG anwenden. Immunglobuline können wiederholt und besonders zum Ende der Schwangerschaft zur Vorbereitung der Entbindung gegeben werden.

Splenektomie: Bei schwerer, nicht anders kontrollierbarer Thrombozytopenie und Blutungen ist die Splenektomie indiziert. Wenn möglich sollte die Splenektomie laparoskopisch im 2. Trimester durchgeführt werden.

\section{Weitere Therapien}

Thrombozytenkonzentrate können bei nicht beherrschbarer Thrombozytopenie und klinisch relevanten Blutungen gegeben werden (siehe Abschnitt «Therapie von Notfällen»).

TRA sind in der Schwangerschaft kontraindiziert.

Vor kurzem wurde über die erfolgreiche Gabe von TPIAO bei Schwangeren berichtet (siehe Abschnitt «TPIAO»). TPIAO ist aktuell in Deutschland nicht erhältlich.

\section{Peri- und postpartales Management}

Früher wurde ITP-Patientinnen die Sectio empfohlen unter der Annahme, dass dadurch das Geburtstrauma und das Blutungsrisiko für das Kind unter der Geburt geringer seien als bei einer vagi- 
nalen Entbindung. Die Entscheidung zur Sectio sollte nicht durch die ITP, sondern allein durch die geburtshilfliche Situation der Mutter bestimmt werden [141].

Unmittelbar nach der Entbindung kann die kindliche Thrombozytenzahl z.B. aus Nabelschnurblut bestimmt und ein transkranieller Ultraschall durchgeführt werden. Hat das Neugeborene < $20 \times 10^{9}$ Thrombozyten/l oder bei Blutungszeichen, dann soll mit IVIG und Steroiden behandelt werden. Da der Thrombozytennadir zum Teil auch erst nach einigen Tagen auftritt (bis zu 1 Woche nach der Geburt), sollte entsprechend lange kontrolliert werden.

Postpartal hat die Mutter durch die präpartale ITP-Therapie meist Thrombozytenzahlen von $>50 \times 10^{9} / 1$ oder sogar Werte im Normbereich. Da die ITP eine «thrombophile» Erkrankung ist (siehe Abschnitt «ITP als Risikofaktor für venöse und arterielle Thromboembolien»), sollte bei diesen Werten und Immobilität der Wöchnerin eine Thromboseprophylaxe erwogen werden (Kompressionsstrümpfe, niedermolekulares Heparin).

\section{ITP bei älteren Patienten, Komorbiditäten, Komedikation}

\section{Ältere Patienten (Übersicht bei [142, 143])}

Zwischen 20 und 40\% aller ITP-Patienten sind > 60 Jahre alt. Bei älteren Patienten ist die ITP-Inzidenz fast doppelt so hoch wie bei jüngeren. Die ITP des älteren Patienten unterscheidet sich von der des jüngeren:

- Blutungen sind bei älteren Patienten häufiger.

- Ältere Patienten nehmen mehr Medikamente und haben eine erhöhte Inzidenz medikamenteninduzierter Thrombozytopenien.

- Ältere Patienten sprechen nicht so gut auf die Therapie an wie jüngere. Auch Nebenwirkungen der Therapie sind häufiger.

- Bei älteren Patienten werden andere Erkrankungen, die mit einer isolierten Thrombozytopenie einhergehen können, z.B. ein MDS, eher als ITP fehldiagnostiziert.

- Viele ältere Patienten haben Komorbiditäten.

\section{Komorbiditäten}

Fast zwei Drittel aller ITP-Patienten über 60 Jahre hat Komorbiditäten, die den Verlauf und die Therapie der ITP beeinflussen. Häufig sind: Hypertonie, Diabetes, koronare Herzkrankheit, neuropsychiatrische Erkrankungen, Pneumonien, Anämie und Katarakte.

ITP-Patienten haben ein etwa 3-mal höheres Risiko als NichtITP-Patienten, an einem Malignom und insbesondere an einem Lymphom zu erkranken [144, 145].

\section{ITP und Antikoagulation}

Schon allein aufgrund ihres Alters haben viele ITP-Patienten kardiale oder vaskuläre Nebenerkrankungen, die eine Antikoagulation erfordern. Andererseits sind Antikoagulanzien bei Thrombozytopenie in der Regel formal kontraindiziert. Für diese Situationen gibt es nur Fallberichte, die keine evidenzbasierte Empfehlung erlauben. Die Autoren empfehlen bei Thrombozytopenie und gleichzeitig dringender Indikation zur therapeutischen Antikoagulation ein wie in Abbildung 3 dargestelltes Vorgehen.

\section{ITP als Risikofaktor für venöse und arterielle Thromboembolien}

Die ITP schützt nicht vor Herzinfarkten, Schlaganfällen oder Thrombosen [146, 147]. Im Gegenteil scheint das Risiko venöser und arterieller Thromboembolien bei ITP-Patienten etwa 2-mal höher zu sein als bei einer vergleichbaren Gruppe von Nicht-ITPPatienten. Bei entsprechenden Symptomen sollten diese Differenzialdiagnosen nicht hintan gestellt werden.

- Das Risiko ist nicht nur nach Diagnosestellung und unter Therapie erhöht, sondern auch schon vorher, wenn noch gar keine ITP-spezifische Therapie gegeben wurde.

- Patienten mit niedriger Thrombozytenzahl $\left(<50 \times 10^{9} / \mathrm{l}\right)$ sind von dem Risiko nicht ausgenommen.

- Das Risiko ist besonders hoch:

- nach Splenektomie,

- bei schnellem Thrombozytenanstieg unter Therapie,

- bei älteren Patienten,

- bei ITP mit Anti-Phospholipid-Antikörpern oder Lupus-Antikoagulans [148].

Der Grund für die erhöhte venöse und arterielle Thromboembolieneigung bei ITP ist unklar. Veränderungen von Gerinnungsund Fibrinolysefaktoren und die vermehrte Freisetzung von Mikropartikeln werden diskutiert.

Als Konsequenz sollten alle ITP-Patienten darüber aufgeklärt werden, dass ihre Erkrankung nicht nur das Blutungsrisiko, sondern auch das Risiko venöser und arterieller Thromboembolien erhöht. Sie sollten über die Symptome informiert sein und wissen, wo sie sich außerhalb der Dienstzeit und an Wochenenden vorstellen können. Risikofaktoren (z.B. Rauchen, Bluthochdruck, Blutfettwerte usw.) sind anzugehen und gegebenenfalls in fachärztliche Mitbetreuung zu geben.

\section{Lebensqualität}

ITP-Patienten haben eine Lebensqualität, die der von Krebspatienten nahekommt, zum Teil sogar schlechter ist [149]. Dies gilt besonders zu Anfang der Erkrankung, wenn Blutungssymptome noch häufig sind und wenn der Patient bzw. seine Angehörigen erst lernen müssen, mit der Thrombozytopenie umzugehen [150]. Neben den Blutungssymptomen und der niedrigen Thrombozytenzahl erleben ITP-Patienten zahlreiche weitere Einschränkungen:

Oncol Res Treat 2018;41(suppl 2):5-36 


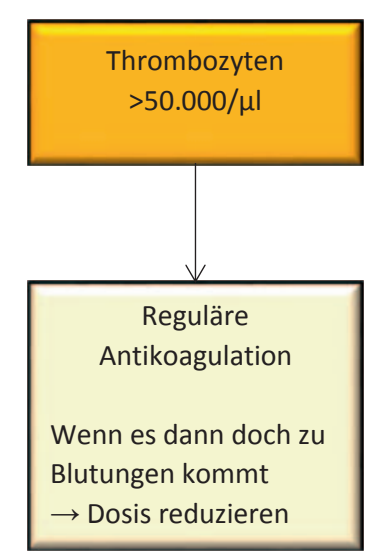

Abb. 3. Antikoagulation bei Thrombozytopenie.

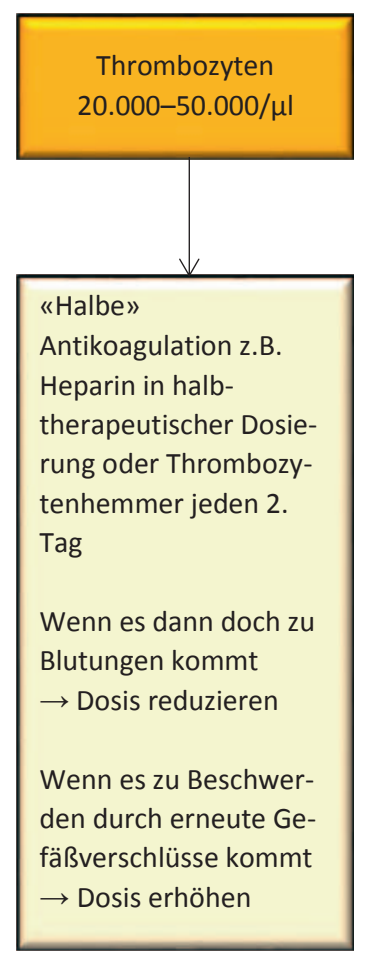

Wenn Blutungen

durch die

Thrombozytopenie

klinisch im

Vordergrund stehen

$\rightarrow$ Möglichst keine

Antikoagulation

Wenn die Beschwer-

den durch

Gefäßverschlüsse im

Vordergrund stehen

$\rightarrow$ Entweder

Antikoagulation mit

halber Dosis und je

nachdem ob dann

Blutungen auftreten

oder nicht, Dosis

anpassen

Oder

$\rightarrow$ Gabe von Thrombo-

zyten bis diese

$>50.000 / \mu$ l und dann

volldosierte Antikoa-

gulation
- ITP-assoziierte Nicht-Blutungssymptome: kognitive Einschränkungen, Fatigue, Schwäche, Depression

- erhöhtes Infektionsrisiko (neben Blutungen eine der häufigsten Todesursachen bei ITP)

- lange, zum Teil lebenslange Therapie

- Nebenwirkungen der ITP-Therapie (insbesondere durch Steroide) [151]

- geschlechtsspezifische Einschränkungen (Blutungsrisiko während Schwangerschaft und Geburt, Risiko der Thrombozytopenie beim Neugeborenen)

- soziale Stigmatisierung durch sichtbare Hämatome (Sport, Strand, Schwimmbad)

- erhöhte Risiken bei der Behandlung anderer Erkrankungen (erhöhtes Blutungsrisiko bei Antikoagulation für Arrhythmien oder bei koronarer Herzkrankheit)

- Zeitaufwand für Arzt- und Krankenhausbesuche

- verminderte Produktivität

- Zuzahlungen und andere Kosten der Therapie («finanzielle Toxizität»)
- begrenzte Erfahrung anderer Fachdisziplinen im Umgang mit dieser seltenen Erkrankung und häufige Überweisung - selbst für einfache Routineeingriffe - an entfernte Zentren

- Umstellung der Lebensgewohnheiten

- Einschränkungen in Beruf und Freizeit, bei Reisen

- Einschränkungen oder höhere Kosten bei Kranken-, Lebensversicherung usw.

Es wird der Situation von ITP-Patienten deshalb nicht gerecht, wenn man den Therapieerfolg allein an der Blutungsneigung und Thrombozytenzahl festmacht. Alle oben genannten Aspekte sollten in die Therapieentscheidung mit einfließen.

\section{ITP und Sport}

ITP-Patienten können Sport treiben. Das gilt ganz besonders für Kinder und Jugendliche. Bei niedrigen Thrombozytenzahlen $\left(<50 \times 10^{9} / 1\right)$ sollten Kampf- und Kontaktsportarten vermieden werden (z.B. Rugby, Fußball, Eishockey), problemlos sind Schwimmen, Fahrradfahren, Leichtathletik [152]. 


\section{Grad der Behinderung, Sozialrecht (gilt nur für die Bundesrepublik Deutschland)}

Die Einschätzung des Grades der Behinderung (GdB) gemäß Sozialgesetzbuch Neun (SGB IX - Rehabilitation und Teilhabe behinderter Menschen) richtet sich nach den Versorgungsmedizinischen Grundsätzen (VMG) Teil B [153]. Darin gibt es keine spezifischen Vorgaben für Patienten mit Thrombozytopenien. Die ITP wird unter die Gruppe der sonstigen Blutungsleiden subsumiert; nach Nr. 16.10 der VMG sind folgende Grade der Behinderungen vorgesehen:

Blutungsneigung: $G d B$

- ohne wesentliche Auswirkungen: GdB 10\%

- mäßige Auswirkungen: GdB 20-40\%

- starke Auswirkungen (starke Blutungen bereits bei leichten Traumen): GdB 50-70\%

- ständige klinisch manifeste Blutungsneigung (Spontanblutungen, Gefahr lebensbedrohlicher Blutungen): GdB 80-100\%

Nach Auffassung der Rechtsprechung ist für die Einschätzung allein die tatsächliche Blutungsneigung ausschlaggebend und nicht die abstrakte Möglichkeit, dass es aufgrund niedriger Thrombozytenwerte in der Zukunft zu starken Blutungen kommen könnte.

Im Alltag erleben die Patienten jedoch die genau umgekehrte Situation, dass sie aufgrund ihres potenziellen Blutungsrisikos und der Sorge vor möglichen Haftungsrisiken Einschränkungen im Beruf und bei der sozialen Teilhabe hinnehmen müssen (z.B. Ablehnung der Aufnahme in Kindertagesstätte und Kindergarten, keine Teilnahme am Schul- oder Vereinssport, Ablehnung der Verbeamtung). Die tatsächliche Blutungsneigung spielt dann keine Rolle mehr. Diese Diskrepanz zwischen einer niedrigen Krankheitsbewertung, wenn es um Ansprüche auf Versorgungsleistungen geht, und die Einschätzung als Risikopatient in fast allen anderen Lebensbereichen, führt bei den Betroffenen häufig zum Gefühl des Ausgeliefertseins an ein nicht dem Patientenwohl verpflichtetes System, zur Unzufriedenheit mit den schulmedizinischen Therapieangeboten und zur Hinwendung zu alternativen Behandlungsformen.

\section{Alternative Behandlungsmethoden}

Mehr als die Hälfte aller Patienten mit chronischer ITP probiert sogenannte alternative Behandlungsformen. Dazu gehören Vitaminkuren, Mikronährstoffe, Ginkgo, Mistel, Akupressur, Akupunktur, traditionelle chinesische Medizin, Kolostrum, Reiki, Magnettherapie, Ernährungsumstellung, verschiedenste Diäten, aber auch Meditation, Psychotherapie, Gebete und vieles mehr. Man kann über den Wert solcher unwissenschaftlichen Verfahren diskutieren. Viele Patienten fühlen sich hierunter jedoch besser und sicherer, und manchmal sind diese Methoden mehr Ausdruck der Unzufriedenheit mit den schulmedizinischen Therapieangeboten und des Wunsches, selber aktiv zur Genesung beizutragen.

Es ist nicht möglich, eine dieser alternativen Therapieformen zu empfehlen oder rundweg abzulehnen. Der Arzt sollte aber aktiv danach fragen. Es ist nicht auszuschließen, dass manches natur- heilkundliche Präparat Wechselwirkungen mit anderen Medikamenten hat. Deshalb sollte die Thrombozytenzahl, wenn man solche Therapien beginnt, häufiger kontrolliert werden.

\section{Adhärenz/Compliance und Umsetzung von Leitlinienempfehlungen}

Zahlreiche Studien zeigen, dass Leitlinien im Praxisalltag zum Teil nur sehr begrenzt umgesetzt werden. Die häufigsten Abweichungen bei ITP-Patienten sind [154]:

- Es wurde kein Blutausstrich begutachtet.

- Es wurde ohne klare Indikation eine Knochenmarkpunktion durchgeführt.

- Es wurden Immunglobuline gegeben, auch wenn die Patienten gar nicht bluten.

- Die Milzentfernung wurde zu früh (vor dem 6. Monat) durchgeführt.

- Es wurde zu häufig und zu lange mit Steroiden behandelt. Aber auch aufseiten der Patienten gibt es zahlreiche Gründe, warum Leitlinienempfehlungen und Therapieempfehlungen nicht umgesetzt werden. Diese sind gezielt vom Arzt zu erfragen, wenn eine Therapie nicht wie erwartet anspricht:

- Die empfohlene Therapie wird als zu komplex empfunden.

- Sie erfordert eine Umstellungen der Lebensgewohnheiten.

- Belastung durch häufige Arzttermine, Wartezeiten und Aufwand für Transport, Zuzahlungen.

- Selbst milde Nebenwirkungen werden bei langer Therapiedauer als nicht tragbar empfunden.

- Sozioökonomischer Status, kultureller Hintergrund.

- Distanz zur Schulmedizin, Bevorzugung alternativ-medizinischer Behandlungsformen (siehe Abschnitt «Alternative Behandlungsmethoden»).

Zur Stärkung der Patienten-Adhärenz werden folgende Maßnahmen empfohlen:

- ITP-Pass (analog zum Mutterpass) oder ITP-Patientenordner (analog zum Brustzentrumsordner), in dem alle relevanten Befunde und Therapien mit Zeitpunkt und Therapieansprache festgehalten werden

- Schaffung von ITP-Zentren mit einem barrierefreien Zugang für Ärzte und (!) Patienten (Tab. 2)

- Kontakt mit Selbsthilfegruppen

- Informationsmaterial für Patienten

\section{Abschließende Stellungnahme}

Die Autoren beschreiben in dieser Leitlinie den aktuellen Kenntnisstand in der Behandlung der ITP. Sämtliche Aussagen sind ausschließlich als Hilfen zur ärztlichen Entscheidungsfindung intendiert und nicht geeignet, einen medizinischen Standard im sozial- oder strafrechtlichen Sinne zu definieren.

Die Autoren übernehmen keine Gewähr und Haftung für die Richtigkeit, Vollständigkeit, Aktualität, Qualität und jederzeitige 
Verfügbarkeit der Textinhalte und Quellenangaben. Haftungsansprüche gegen die Autoren, die sich auf Schäden materieller oder ideeller Art beziehen, die durch die Nutzung oder Nichtnutzung der dargebotenen Informationen bzw. durch die Nutzung fehlerhafter und unvollständiger Informationen verursacht wurden, sind ausgeschlossen. Soweit Gesetze, Normen, Verordnungen oder Ähnliches zitiert werden, übernehmen die Autoren keine Gewähr für die Richtigkeit bzw. Aktualität. In Zweifelsfällen sind die Originalquellen heranzuziehen. Für Angaben über Verfahrensweisen oder Anwendungen, Applikationsformen und Dosierungen wird von den Autoren keine Gewähr übernommen. Jeder Benutzer ist angehalten, z.B. durch Lesen der Gebrauchsanweisung von medizinisch-technischen Geräten, durch das Studium des Beipackzettels von verwendeten Präparaten und gegebenenfalls durch zusätzliche Konsultation eines Spezialisten oder weiterer Literatur festzustellen, ob die dort angegebene Empfehlung zur Anwendung bzw. zur Dosierung oder die Beachtung von Kontraindikationen gegenüber den Angaben in dieser Leitlinie abweicht. Jede Anwendung, Applikation oder Dosierung erfolgt auf eigene Gefahr des Benutzers.

Die Angaben in dieser Leitlinie sind kein Ersatz für eine individuelle professionelle Beratung oder Behandlung durch ausgebildete und anerkannte Fachleute.

\section{Links zu Selbsthilfegruppen und weiteren Informationen}

Selbsthilfegruppen (SHG)

ITP-SHG Gießen:

www.itp-information.de

Kontakt: Fr. Arnold (über Homepage)

ITP-SHG Sömmerda:

Kontakt: Fr. Riese (s-riese@t-online.de)

USA: Platelet Disorder Support Organisation www.pdsa.org

Großbritannien: ITP Support Association www.itpsupport.org.uk

Weitere Informationsseiten

International ITP Alliance

www.globalitp.org/

ITP-Foundation, USA

www.itpfoundation.org/itpdefined.htm

European Society for Blood and Marrow Transplantation

www.ebmt.org/Contents/Resources/Library/Resourcesfornurses/Documents/Forms/Allitems.aspx

Über diese Webseite können zahlreiche Informationen heruntergeladen werden, z.B. ein ITP-Handbuch auf Deutsch und Englisch für Pflegekräfte und andere Gesundheitsberufe.

\section{Evidenzgraduierung und Empfehlungsgrade}

Die Evidenzgraduierung folgt der Empfehlung des Oxford Centre of Evidence-Based Medicine, Stand März 2009 (www.cebm.net).

Die Festlegung der Empfehlungsgrade A, B oder 0 folgt den Empfehlungen des Nationalen Programms für die Versorgungsleitlinien (Methoden-Report des NVL-Programms 2010, www.leitlinien.de).

\section{Empfehlungsgrade}

- A: Starke Empfehlung «soll»

- B: Empfehlung «sollte»

- 0: Empfehlung offen «kann»

- Expertenkonsens (EK): Es gibt keine ausreichenden wissenschaftlichen Daten. Dennoch soll eine Empfehlung ausgesprochen werden, die nach Meinung der Mehrheit der beteiligten Experten einer guten klinischen Praxis am nächsten kommt.

\section{Disclosure Statement}

\section{Autor: Matzdorff}

Anstellungsverhältnis oder Führungsposition: Asklepios. Beratungstätigkeit: AMGEN, GlaxoSmithKline, Leo Pharma, Boehringer Ingelheim, BristolMyers Squibb. Besitz von Geschäftsanteilen, Aktien oder Fonds: Familienbesitz Aktien von Bayer, Roche, Johnson \& Johnson. Referentenhonorare: AMGEN, Aspen, Boehringer Ingelheim, Bristol-Myers Squibb, Gilead, GlaxoSmithKline, Leo Pharma, Novartis, Pfizer, Roche, Sanofi. Finanzierung wissenschaftlicher Untersuchungen: Leo Pharma. Gutachtertätigkeit: keine. Andere finanzielle Beziehungen: Aspen, Bristol-Myers Squibb, Celgene, Chugai, Gilead, GSK, Janssen, Leo Pharma, Lilly, MSD, Mundipharma, Novartis, Pfizer, Roche, Sanofi. Immaterielle Interessenkonflikte: keine.

Autor: Meyer

Anstellungsverhältnis oder Führungsposition: nein. Beratungs- bzw. Gutachtertätigkeit: Teilnahme an Advisory Boards der Firmen Amgen GmbH und der Firma Novartis Pharma GmbH. Besitz von Geschäftsanteilen, Aktien oder Fonds: nein. Patent, Urheberrecht, Verkaufslizenz: nein. Honorare: Vortraghonorare der Firma Novartis Pharma GmbH, Wissenschaftliche Leitung einer Beobachtungsstudie der Firma Novartis Pharma GmbH. Finanzierung wissenschaftlicher Untersuchungen: nein. Andere finanzielle Beziehungen: nein. Immaterielle Interessenkonflikte: nein.

Autor: Ostermann

Anstellungsverhältnis oder Führungsposition: keine. Beratungs- bzw. Gutachtertätigkeit: Novartis Amgen. Besitz von Geschäftsanteilen, Aktien oder Fonds: keine. Patent, Urheberrecht, Verkaufslizenz: keine. Honorare: Novartis, Amgen. Finanzierung wissenschaftlicher Untersuchungen: keine. Andere finanzielle Beziehungen: keine. Immaterielle Interessenkonflikte: keine.

Autor: Kiefel

Anstellungsverhältnis oder Führungsposition: kein Interessenskonflikt. Beratungs- bzw. Gutachtertätigkeit: kein Interessenskonflikt. Besitz von Geschäftsanteilen, Aktien oder Fonds: kein Interessenskonflikt. Patent, Urheberrecht, Verkaufslizenz: kein Interessenskonflikt. Honorare: Novartis, Amgen. Finanzierung wissenschaftlicher Untersuchungen: kein Interessenskonflikt. Andere finanzielle Beziehungen: kein Interessenskonflikt. Immaterielle Interessenkonflikte: kein Interessenskonflikt.

Autor: Eberl

Anstellungsverhältnis oder Führungsposition: keine. Beratungs- bzw. Gutachtertätigkeit: Teilnahme an Advisory-Boards (Fa. Bayer) zur Thematik Patientenkommunikation Hämophilie. Besitz von Geschäftsanteilen, Aktien oder Fonds: keine. Patent, Urheberrecht, Verkaufslizenz: keine. Honorare: Vortragshonorare Shire, Bayer, CSL-Behring, Octapharma, Novo-Nordisk, alle zur Thematik Hämophilie. Finanzierung wissenschaftlicher Untersuchungen: keine. Andere finanzielle Beziehungen: Einwerbung von Sponsoring und Spenden zur Finanzierung einer Website zur Patienten- und Elterninformation zu Blu- 
terkrankungen bei Kindern als Funktionsträger einer Fachgesellschaft (GTH). Immaterielle Interessenkonflikte: keine.

Autor: Kühne

Anstellungsverhältnis oder Führungsposition: nein. Beratungs- bzw. Gutachtertätigkeit: Amgen, Beratertätigkeit, UCB, Beratertätigkeit. Besitz von Geschäftsanteilen, Aktien oder Fonds: nein. Patent, Urheberrecht, Verkaufslizenz: nein. Honorare: Amgen, Novartis (Referate). Finanzierung wissenschaftlicher Untersuchungen: Amgen. Andere finanzielle Beziehungen: nein.

Autor: Pabinger

Anstellungsverhältnis oder Führungsposition: keine. Beratungs- bzw. Gutachtertätigkeit: Amgen, Novartis, CSL Behring. Besitz von Geschäftsanteilen,
Aktien oder Fonds: keine. Patent, Urheberrecht, Verkaufslizenz: keine. Honorare für Vorträge: Amgen, Novartis, CSL Behring. Finanzierung wissenschaftlicher Untersuchungen: CSL Behring, Novartis. Andere finanzielle Beziehungen: keine.

\section{Autor: Rummel}

Anstellungsverhältnis oder Führungsposition: keine; Beratungs- bzw. Gutachtertätigkeit: Teilnahme an Advisory Boards der Firmen Amgen GmbH, Besitz von Geschäftsanteilen, Aktien oder Fonds. Keine, Patent, Urheberrecht, Verkaufslizenz. keine; Honorare: Vortraghonorare der Firma Amgen GmbH; Finanzierung wissenschaftlicher Untersuchungen: Keine; Andere finanzielle Beziehungen: keine; Immaterielle Interessenkonflikte: keine.

\section{Literatur}

1 George JN, Woolf SH, Raskob GE, Wasser JS, Aledort LM, Ballem PJ, Blanchette VS, Bussel JB, Cines DB, Kelton JG, Lichtin AE, McMillan R, Okerbloom JA, Regan DH, Warrier I: Idiopathic thrombocytopenic purpura: a practice guideline developed by explicit methods for the American Society of Hematology. Blood 1996;88:3-40.

2 Eden OB, Lilleyman JS: Guidelines for management of idiopathic thrombocytopenic purpura: the British Paediatric Haematology Group. Arch Dis Child 1992;67: 1056-1058.

3 Matzdorff A, Eberl W, Giagounidis A, Imbach P, Pabinger I, Wörmann B: Immunthrombozytopenie Onkopedia-Leitlinien Update: Empfehlungen einer gemeinsamen Arbeitsgruppe der DGHO, ÖGHO, SGH + SSH und GPOH. Oncol Res Treat 2014; 37(suppl 2):6-25.

4 Rodeghiero F, Stasi R, Gernsheimer T, Michel M, Provan $\mathrm{D}$, Arnold $\mathrm{DM}$, Bussel JB, Cines $\mathrm{DB}$, Chong $\mathrm{BH}$, Cooper N, Godeau B, Lechner K, Mazzucconi MG, McMillan R, Sanz MA, Imbach P, Blanchette V, Kühne T, Ruggeri M, George JN: Standardization of terminology, definitions and outcome criteria in immune thrombocytopenic purpura (ITP) of adults and children: report from an international working group. Blood 2009;113:2386-2393.

5 Kühne T, Berchtold W, Michaels LA, Wu R, Donato H, Espina B, Tamary H, Rodeghiero F, Chitlur M, Rischewski J, Imbach P; Intercontinental Cooperative ITP Study Group: Newly diagnosed immune thrombocytopenia in children and adults: a comparative prospective observational registry of the Intercontinental Cooperative Immune Thrombocytopenia Study Group. Haematologica 2011;96:1831-1837.

6 Frederiksen H, Lund Maegbaek M, Nørgaard M: Twenty-year mortality of adult patients with primary immune thrombocytopenia: a Danish populationbased cohort study. Br J Haematol 2014;166:260-267.

7 Cines DB, Bussel JB, Liebman HA, Prak ETL: The ITP syndrome: pathogenic and clinical diversity. Blood 2009:113:6511-6521.

8 Moulis G, Germain J, Comont T, Brun N, Dingremont C, Castel B, Arista S, Sailler L, Lapeyre-Mestre M, Beyne-Rauzy O, Godeau B, Adoue D; CARMEN Investigators Group: Newly diagnosed immune thrombocytopenia adults: clinical epidemiology, exposure to treatments, and evolution. Results of the CARMEN multicenter prospective cohort. Am J Hematol 2017; 92:493-500

9 Werlhof PG: Disquisitio medica et philologica de variolis et anthracibu. Hannoverae: Sumptibus haeredum Nicolai Foersteri et filii, 1735. https://catalog.hathitrust. org/Record/009272744.

10 Imbach P, Kühne T, Signer E: Historical aspects and present knowledge of idiopathic thrombocytopenic purpura. Br J Haematol 2002;119:894-900.
11 Abrahamson PE, Hall SA, Feudjo-Tepie M, Mitrani-Gold FS, Logie J: The incidence of idiopathic thrombocytopenic purpura among adults: a population-based study and literature review. Eur J Haematol 2009;83:83-89.

12 Terrell DR, Beebe LA, Vesely SK, Neas BR, Segal JB, George JN: The incidence of immune thrombocytopenic purpura in children and adults: a critical review of published reports. Am J Hematol 2010;85:174-180.

13 Feudjo-Tepie MA, Robinson NJ, Bennett D: Prevalence estimates of adult chronic idiopathic thrombocytopenic purpura (ITP) in the United States. J Thromb Haemost 2008;6:711-712.

14 Segal JB, Powe NR: Prevalence of immune thrombocytopenia: analyses of administrative data. J Thromb Haemost 2006;4:2377-2383.

15 Rosthøj S, Hedlund-Treutiger I, Rajantie J, Zeller B, Jonsson OG, Elinder G, Wesenberg F, Henter JI; NOPHO ITP Working Group: Duration and morbidity of newly diagnosed idiopathic thrombocytopenic purpura in children: a prospective Nordic study of an unselected cohort. J Pediatr 2003;143:302-307.

16 Zeller B, Helgestad J, Hellebostad M, Kolmannskog S, Nystad T, Stensvold K, Wesenberg F: Immune thrombocytopenic purpura in childhood in Norway: a prospective, population-based registration. Pediatr Hematol Oncol 2000;17:551-518.

17 Hedman A, Henter JI, Hedlund I, Elinder G: Prevalence and treatment of chronic idiopathic thrombocytopenic purpura of childhood in Sweden. Acta Paediatr 1997;86:226-227.

18 Weide R, Feiten S, Friesenhahn V, Heymanns J, Kleboth K, Thomalla J, van Roye C, Köppler H: Outpatient management of patients with immune thrombocytopenia (ITP) by hematologists 1995-2014. Oncol Res Treat 2016;39:41-44.

19 Kühne T, Imbach P, Bolton-Maggs PH, Berchtold W, Blanchette V, Buchanan GR; Intercontinental Childhood ITP Study Group: Newly diagnosed idiopathic thrombocytopenic purpura in childhood: an observational study. Lancet 2001;358:2122-2125.

20 Zeller B, Rajantie J, Hedlund-Treutiger I, Tedgard U, Wesenberg F, Jonsson OG, Henter JI: Childhood idiopathic thrombocytopenic purpura in the Nordic countries: epidemiology and predictors of chronic disease. Acta Paediatr 2005;94:178-184.

21 Schoonen WM, Kucera G, Coalson J, Li L, Rutstein M, Mowat F, Fryzek J, Kaye JA: Epidemiology of immune thrombocytopenic purpura in the General Practice Research Database. Br J Haematol 2009; 145:235-244.

22 Cines DB, Blanchette VS: Immune thrombocytopenic purpura. N Engl J Med 2002;346:995-1008.

23 Audia S, Mahévas M, Samson M, Godeau B, Bonnotte B: Pathogenesis of immune thrombocytopenia. Autoimmun Rev 2017;16:620-632.
24 Cines DB, Cuker A, Semple JW: Pathogenesis of immune thrombocytopenia. Presse Med 2014;43(4 Pt 2): e49-e59.

25 Zufferey A, Kapur R, Semple JW: Pathogenesis and therapeutic mechanisms in immune thrombocytopenia (ITP). J Clin Med 2017;6:16.

26 Harrington WJ, Minnich V, Holingsworth JW, Moore $\mathrm{CV}$ : Demonstration of a thrombocytopenic factor in the blood of patients with thrombocytopenic purpura. J Lab Clin Med 1951;38:1-10.

27 Grozovsky R, Begonja AJ, Liu K, Visner G, Hartwig $\mathrm{JH}$, Falet H, Hoffmeister KM: The Ashwell-Morell receptor regulates hepatic thrombopoietin production via JAK2-STAT3 signaling. Nat Med 2015;21:47-54.

28 Grozovsky R, Giannini S, Falet H, Hoffmeister KM: Regulating billions of blood platelets: glycans and beyond. Blood 2015;126:1877-1884

29 Olsson B, Andersson PO, Jernås M, Jacobsson S, Carlsson B, Carlsson LM, Wadenvik H: T-cell-mediated cytotoxicity toward platelets in chronic idiopathic thrombocytopenic purpur. Nat Med 2003;9:1123-1124.

30 Emmons RV, Reid DM, Cohen RL, Meng G, Young NS, Dunbar CE, Shulman NR: Human thrombopoietin levels are high when thrombocytopenia is due to megakaryocyte deficiency and low when due to increased platelet destruction. Blood 1996;87:4068-4071.

31 Fielder PJ, Gurney AL, Stefanich E, Marian M, Moore MW, Carver-Moore K, de Sauvage FJ: Regulation of thrombopoietin levels by c-mpl-mediated binding to platelets. Blood 1996;87:2154-2161.

32 Grimaldi-Bensouda L, Nordon C, Michel M, Viallard JF, Adoue D, Magy-Bertrand N, Durand JM, Quittet P, Fain O, Bonnotte B, Morin AS, Morel N, Costedoat-Chalumeau N, Pan-Petesch B, Khellaf M, Perlat A, Sacre K, Lefrere F, Abenhaim L, Godeau B; Group for the PGRxITP Study: Immune thrombocytopenia in adults: a prospective cohort study of clinical features and predictors of outcome. Haematologica 2016;101:1039-1045.

33 Portielje JE, Westendorp RG, Kluin-Nelemans HC, Brand A: Morbidity and mortality in adults with idiopathic thrombocytopenic purpura. Blood 2001;97: 2549-2554.

34 Bussel JB, Provan D, Shamsi T, Cheng G, Psaila B, Kovaleva $L$, Salama A, Jenkins JM, Roychowdhury D, Mayer B, Stone N, Arning M: Effect of eltrombopag on platelet counts and bleeding during treatment of chronic idiopathic thrombocytopenic purpura: a randomised, double-blind, placebo-controlled trial. Lancet 2009;373:641-648.

35 Gernsheimer TB, George JN, Aledort LM, Tarantino MD, Sunkara U, Matthew Guo D, Nichol JL: Evaluation of bleeding and thrombotic events during longterm use of romiplostim in patients with chronic immune thrombocytopenia (ITP). J Thromb Haemost 2010;8:1372-1382. 
36 Ekstrand C, Linder M, Cherif H, Kieler H, Bahmanyar $\mathrm{S}$ : Increased susceptibility to infections before the diagnosis of immune thrombocytopenia. J Thromb Haemost 2016;14:807-814.

37 Semple JW, Italiano JE Jr, Freedman J: Platelets and the immune continuum. Nat Rev Immunol 2011;11: 264-274.

38 Ahn YS, Horstman LL, Jy W, Jimenez JJ, Bowen B Vascular dementia in patients with immune thrombocytopenic purpura. Thromb Res 2002;107:337-344.

39 Frith J, Watson S, Bolton Maggs PH, Newton JL: Cognitive symptoms are common in immune thrombocytopenia and associate with autonomic symptom burden. Eur J Haematol 2012;88:224-228.

40 Rodeghiero F, Michel M, Gernsheimer T, Ruggeri M, Blanchette V, Bussel JB, Cines DB, Cooper N, Godeau B, Greinacher A, Imbach P, Khellaf M, Klaassen RJ Kühne T, Liebman H, Mazzucconi MG, Newland A, Pabinger I, Tosetto A, Stasi R: Standardization of bleeding assessment in immune thrombocytopenia: report from the International Working Group. Blood 2013;121:2596-2606

41 Miller AB, Hoogstraten B, Staquet M, Winkler A: Reporting results of cancer treatment. Cancer 1981;47: 207-214.

42 Heddle NM, Cook RJ, Tinmouth A, Kouroukis CT, Hervig T, Klapper E, Brandwein JM, Szczepiorkowski ZM, AuBuchon JP, Barty RL, Lee KA; SToP Study Investigators of the BEST Collaborative: A randomized controlled trial comparing standard- and low-dose strategies for transfusion of platelets (SToP) to patients with thrombocytopenia. Blood 2009;113:1564-1573.

43 National Cancer Institute: NCI Common Terminology Criteria for Adverse Events CTCAE v4.03:2010. https://ctep.cancer.gov/protocoldevelopment/electronic_ applications/ctc.htm

44 Sailer T, Lechner K, Panzer S, Kyrle PA, Pabinger I: The course of severe autoimmune thrombocytopenia in patients not undergoing splenectomy. Haematologica 2006;91:1041-1045

45 Cohen YC, Djulbegovic B, Shamai-Lubovitz O, Mozes $\mathrm{B}$ : The bleeding risk and natural history of idiopathic thrombocytopenic purpura in patients with persistent low platelet counts. Arch Intern Med 2000;160:16301638.

46 Djulbegovic B, Cohen Y: The natural history of refractory idiopathic thrombocytopenic purpura. Blood 2001;98:2282-2283.

47 Neunert CE, Buchanan GR, Imbach P, Bolton-Maggs PH, Bennett CM, Neufeld EJ, Vesely SK, Adix L, Blanchette VS, Kühne T; Intercontinental Childhood ITP Study Group Registry II participants: Severe hemorrhage in children with newly diagnosed immune thrombocytopenic purpura. Blood 2008;112:4003-4008.

48 Bussel JB, de Miguel PG, Despotovic JM, Grainger JD, Sevilla J, Blanchette VS, Krishnamurti L, Connor P, David M, Boayue KB, Matthews DC, Lambert MP, Marcello LM, Iyengar M, Chan GW, Chagin KD, Theodore D, Bailey CK, Bakshi KK: Eltrombopag for the treatment of children with persistent and chronic immune thrombocytopenia (PETIT): a randomised, multicentre, placebo-controlled study. Lancet Haematol 2015;2:e315-e325.

49 Grainger JD, Locatelli F, Chotsampancharoen T, Donyush E, Pongtanakul B, Komvilaisak P, Sosothikul D, Drelichman G, Sirachainan N, Holzhauer S, Lebedev V, Lemons R, Pospisilova D, Ramenghi U, Bussel JB, Bakshi KK, Iyengar M, Chan GW, Chagin KD, Theodore D, Marcello LM, Bailey CK: Eltrombopag for children with chronic immune thrombocytopenia (PETIT2): a randomised, multicentre, placebo-controlled trial. Lancet 2015;386:1649-1658.
50 Kuter DJ, Bussel JB, Lyons RM, Pullarkat V, Gernsheimer TB, Senecal FM, Aledort LM, George JN, Kessler CM, Sanz MA, Liebman HA, Slovick FT, de Wolf JT, Bourgeois E, Guthrie TH Jr, Newland A, Wasser JS, Hamburg SI, Grande C, Lefrère F, Lichtin AE, Tarantino MD, Terebelo HR, Viallard JF, Cuevas FJ, Go RS, Henry DH, Redner RL, Rice L, Schipperus MR, Guo DM, Nichol JL: Efficacy of romiplostim in patients with chronic immune thrombocytopenic purpura: a double-blind randomised controlled trial. Lancet 2008; 371:395-403.

51 Neunert CE, Buchanan GR, Imbach P, Bolton-Maggs $\mathrm{PH}$, Bennett CM, Neufeld E, Vesely SK, Adix L, Blanchette VS, Kühne T; Intercontinental Cooperative ITP Study Group Registry II participants: Bleeding manifestations and management of children with persistent and chronic immune thrombocytopenia: data from the Intercontinental Cooperative ITP Study Group (ICIS). Blood 2013;121:4457-4462.

52 Tarantino MD, Bussel JB, Blanchette VS, Despotovic J, Bennett C, Raj A, Williams B, Beam D, Morales J, Rose MJ, Carpenter N, Nie K, Eisen M: Romiplostim in children with immune thrombocytopenia: a phase 3 , randomised, double-blind, placebo-controlled study. Lancet 2016;388:45-54.

53 Cortelazzo S, Finazzi G, Buelli M, Molteni A, Viero P, Barbui T: High risk of severe bleeding in aged patients with chronic idiopathic thrombocytopenic purpura. Blood 1991;77:31-33.

54 Grainger JD, Harrison L, Bolton-Maggs PHB: United Kingdom experience of intracranial bleeds in childhood immune thrombocytopenia. Blood 2016;128:1380.

55 Iyori H, Bessho F, Ookawa H, Konishi S, Shirahata A, Miyazaki S, Fujisawa K, Akatsuka J; Japanese Study Group on childhood ITP: Intracranial hemorrhage in children with immune thrombocytopenic purpura. Japanese Study Group on childhood ITP. Ann Hematol 2000;79:691-695.

56 Melboucy-Belkhir S, Khellaf M, Augier A, Boubaya M, Levy V, Le Guenno G, Terriou L, Lioger B, Ebbo M, Morin AS, Chauveheid MP, Michel M, Belkhir F, About F, Rose C, Moulis G, Mekinian A, Stirnemann J, Papo T, Cheze S, Rosenthal E, Viallard JF, Schleinitz N, Galicier L, Adoue D, Lambotte O, Hamidou M, Godeau B, Fain O: Risk factors associated with intracranial hemorrhage in adults with immune thrombocytopenia: a study of 27 cases. Am J Hematol 2016;91:E499-E501.

57 Moulis G, Sailler L, Lapeyre-Mestre M: Severe bleeding events in adults and children with primary immune thrombocytopenia: a systematic review: comment. J Thromb Haemost 2015;13:1521-1522.

58 Neunert C, Noroozi N, Norman G, Buchanan GR, Goy J, Nazi I, Kelton JG, Arnold DM: Severe bleeding events in adults and children with primary immune thrombocytopenia: a systematic review. J Thromb Haemost 2015; 13:457-464

59 George JN, Aster RH: Drug-induced thrombocytopenia: pathogenesis, evaluation, and management. Hematology Am Soc Hematol Educ Program 2009:153-158.

60 Ma X: Epidemiology of myelodysplastic syndromes. Am J Med 2012;125(7 suppl):S2-S5.

61 Stasi R, Sarpatwari A, Segal JB, Osborn J, Evangelista ML, Cooper N, Provan D, Newland A, Amadori S, Bussel JB: Effects of eradication of Helicobacter pylori infection in patients with immune thrombocytopenic purpura: a systematic review. Blood 2009;113:1231-1240.

62 Chey WD, Leontiadis GI, Howden CW, Moss SF: ACG clinical guideline: Treatment of Helicobacter pylori infection. Am J Gastroenterol 2017;112:212-239.

63 Neunert C, Lim W, Crowther M, Cohen A, Solberg L Jr, Crowther MA; American Society of Hematology: The American Society of Hematology 2011 evidencebased practice guideline for immune thrombocytopenia. Blood 2011;117:4190-4207.
64 Provan D, Stasi R, Newland AC, Blanchette VS, Bol ton-Maggs $\mathrm{P}$, Bussel JB, Chong BH, Cines DB, Gernsheimer TB, Godeau B, Grainger J, Greer I, Hunt BJ, Imbach PA, Lyons G, McMillan R, Rodeghiero F, Sanz MA, Tarantino M, Watson S, Young J, Kuter DJ: International consensus report on the investigation and management of primary immune thrombocytopenia Blood 2010;115:168-186.

65 Pizzuto J, Ambriz R: Therapeutic experience on 934 adults with idiopathic thrombocytopenic purpura: multicentric trial of the Cooperative Latin American Group on Hemostasis and Thrombosis. Blood 1984;64 1179-1183.

66 Godeau B, Chevret S, Varet B, Lefrère F, Zini JM, Bassompierre F, Chèze S, Legouffe E, Hulin C, Grange MJ, Fain O, Bierling P; French ATIP Study Group: Intravenous immunoglobulin or high-dose methylprednisolone, with or without oral prednisone, for adults with untreated severe autoimmune thrombocytopenic purpura: a randomised, multicentre trial. Lancet 2002;359 23-29.

67 McMillan R: Therapy for adults with refractory chronic immune thrombocytopenic purpura. Ann Intern Med 1997;126:307-314

68 Andersen JC: Response of resistant idiopathic thrombocytopenic purpura to pulsed high-dose dexamethasone therapy. N Engl J Med 1994;330:1560-1564.

69 Din B, Wang X, Shi Y, Li Y: Long-term effect of highdose dexamethasone with or without low-dose dexamethasone maintenance in untreated immune thrombocytopenia. Acta Haematol 2015;133:124-128.

70 Matschke J, Müller-Beissenhirtz H, Novotny J, Vester I, Hertenstein B, Eisele L, Lax H, Ose C, Dührsen U: A randomized trial of daily prednisone versus pulsed dexamethasone in treatment-naïve adult patients with immune thrombocytopenia: EIS 2002 study. Acta Haematol 2016;136:101-107.

71 Wei Y, Ji XB, Wang YW, Wang JX, Yang EQ, Wang ZC, Sang YQ, Bi ZM, Ren CA, Zhou F, Liu GQ, Peng J, Hou M: High-dose dexamethasone vs prednisone for treatment of adult immune thrombocytopenia: a prospective multicenter randomized trial (NCT01356511). Blood 2016;127:296-302.

72 Bae SH, Ryoo HM, Lee WS, Joo YD, Lee KH, Lee JH Lee JH, Kim H, Park JH, Kim MK, Hyun MS, Kim HJ, Zang DY: High dose dexamethasone vs. conventional dose prednisolone for adults with immune thrombocytopenia: a prospective multicenter phase III trial Blood 2010;116:3687

73 Mithoowani S, Gregory-Miller K, Goy J, Miller MC Wang G, Noroozi N, Kelton JG, Arnold DM: Highdose dexamethasone compared with prednisone for previously untreated primary immune thrombocytopenia: a systematic review and meta-analysis. Lancet Haematol 2016;3:e489-e496.

74 Kuehne T, Schifferli A: A Comparative prospective observational study of children and adults with immune thrombocytopenia: 2-year follow-up. Blood 2016;128:3741.

75 Kühne T: Diagnosis and management of immune thrombocytopenia in childhood. Hamostaseologie 2017;37:36-44.

76 Dickerhoff R, Eberl W: Leitlinie «Immunthrombozytopenie (ITP) im Kindes- und Jugendalter», Stand 8/2011, AWMF-Register Nr. 086/001 Klasse: S2k. www.awmf.org/leitlinien/detail/ll/086-001.html.

77 Schoettler ML, Graham D, Tao W, Stack M, Shu E, Kerr L, Neufeld EJ, Grace RF: Increasing observation rates in low-risk pediatric immune thrombocytopenia using a standardized clinical assessment and management plan $\left(\mathrm{SCAMP}^{\circledR}\right)$. Pediatr Blood Cancer 2017; 64:e26303. 
78 Cooper N: A review of the management of childhood immune thrombocytopenia: how can we provide an evidence-based approach? Br J Haematol 2014;165: 756-767.

79 Grainger JD, Bolton-Maggs PHB, Pearce E: Response to first line treatment in childhood ITP. Blood 2016; 128:1372

80 Salama A, Kiefel V, Amberg R, Mueller-Eckhardt C: Treatment of autoimmune thrombocytopenic purpura with rhesus antibodies (anti-Rho [D]). Blut 1984;49: 29-35.

81 Robak T, Windyga J, Trelinski J, von Depka Prondzinski M, Giagounidis A, Doyen C, Janssens A, AlvarezRomán MT, Jarque I, Loscertales J, Rus GP, Hellmann A, Jêdrzejczak WW, Kuliczkowski K, Golubovic LM, Celeketic D, Cucuianu A, Gheorghita E, Lazaroiu M, Shpilberg O, Attias D, Karyagina E, Svetlana K Vilchevska K, Cooper N, Talks K, Prabhu M, Sripada P, Bharadwaj TP, Næsted H, Skartved NJ, Frandsen TP, Flensburg MF, Andersen PS, Petersen J: Rozrolimupab, a mixture of 25 recombinant human monoclonal RhD antibodies, in the treatment of primary immune thrombocytopenia. Blood 2012;120:3670-3676.

82 Porcelijn L, Folman CC, Bossers B, Huiskes E, Overbeeke MA, v d Schoot CE, de Haas M, von dem Borne AE: The diagnostic value of thrombopoietin level measurements in thrombocytopenia. Thromb Haemost 1998;79:1101-1105.

83 Bussel JB, Kuter DJ, Pullarkat V, Lyons RM, Guo M, Nichol JL: Safety and efficacy of long-term treatment with romiplostim in thrombocytopenic patients with chronic ITP. Blood 2009;113:2161-2171.

84 Bussel JB, Tarantino MD, Blanchette VS, Raj A, Despotovic J, Beam D, Roy J, Wang X, Mehta B, Eisen M: Safety and efficacy of long-term open-label dosing of subcutaneous (SC) romiplostim in children with immune thrombocytopenia (ITP). Blood 2016;128:3738.

85 Cheng G, Saleh MN, Marcher C, Vasey S, Mayer B, Aivado M, Arning M, Stone NL, Bussel JB: Eltrombopag for management of chronic immune thrombocytopenia (RAISE): a 6-month, randomised, phase 3 study. Lancet 2011;377:393-402.

86 Kuter DJ, Bussel JB, Newland A, Baker RI, Lyons RM, Wasser J, Viallard JF, Macik G, Rummel M, Nie K, Jun S: Long-term treatment with romiplostim in patients with chronic immune thrombocytopenia: safety and efficacy. Br J Haematol 2013;161:411-423.

87 Saleh MN, Bussel JB, Cheng G, Meyer O, Bailey CK, Arning M, Brainsky A; EXTEND Study Group: Safety and efficacy of eltrombopag for treatment of chronic immune thrombocytopenia: results of the long-term, open-label EXTEND study. Blood 2013;121:537-545.

88 Cines DB, Wasser J, Rodeghiero F, Chong BH, Steurer M, Provan D, Lyons R, Garcia-Chavez J, Carpenter N, Wang X, Eisen M: Safety and efficacy of romiplostim in splenectomized and nonsplenectomized patients with primary immune thrombocytopenia. Haematologica 2017;102:1342-1351.

89 Michel M, Wasser J, Godeau B, Aledort L, Cooper N Tomiyama Y, Khellaf M, Wang X: Efficacy and safety of the thrombopoietin receptor agonist romiplostim in patients aged $\geq 65$ years with immune thrombocytopenia. Ann Hematol 2015;94:1973-1980.

90 D’Arena G, Guariglia R, Mansueto G, Martorelli MC, Pietrantuono G, Villani O, Lerose R, Musto P: No cross-resistance after sequential use of romiplostim and eltrombopag in chronic immune thrombocytopenic purpura. Blood 2013;121:1240-1242.

91 Khellaf M, Viallard JF, Hamidou M, Cheze S, RoudotThoraval F, Lefrere F, Fain O, Audia S, Abgrall JF, Michot JM, Dauriac C, Lefort S, Gyan E, Niault M, Durand JM, Languille L, Boutboul D, Bierling P, Michel $\mathrm{M}$, Godeau B: A retrospective pilot evaluation of switching thrombopoietic receptor-agonists in immune thrombocytopenia. Haematologica 2013;98:881-887.
92 Makar RS, Zhukov OS, Sahud MA, Kuter DJ: Thrombopoietin levels in patients with disorders of platelet production: diagnostic potential and utility in predicting response to TPO receptor agonists. Am J Hematol 2013;88:1041-1044.

93 Saleh MN, Bussel JB, Wong RSM, Meddeb B, Salama A, El-Ali A, Quebe-Fehling E, Khelif A: Hepatobiliary and thromboembolic events during long-term E.X.T.E.N.Ded treatment with eltrombopag in adult patients with chronic immune thrombocytopenia (ITP). Blood 2016;128:1368.

94 Moulis G, Bagheri H, Sailler L, Jonville-Bera AP, Weber E, Guy C, Petitpain N, Laroche ML, Favrelière S, Béné J, Baldin B, Villeval-Federici L, Tebacher-Alt M, Bres V, Veyrac G, Grandvuillemin A, Mauprivez C, Lapeyre-Mestre M, Montastruc JL; French Association of PharmacoVigilance Centers: Are adverse drug reaction patterns different between romiplostim and eltrombopag? 2009-2013 French PharmacoVigilance assessment. Eur J Intern Med 2014;25:777-780.

95 Prica A, Sholzberg M, Buckstein R: Safety and efficacy of thrombopoietin-receptor agonists in myelodysplastic syndromes: a systematic review and meta-analysis of randomized controlled trials. Br J Haematol 2014; 167:626-638.

96 Roth M, Will B, Simkin G, Narayanagari S, Barreyro L, Bartholdy B, Tamari R, Mitsiades CS, Verma A, Steidl U: Eltrombopag inhibits the proliferation of leukemia cells via reduction of intracellular iron and induction of differentiation. Blood 2012;120:386-394.

97 Kantarjian H, Fenaux P, Sekeres MA, Szer J, Platzbecker U, Kuendgen A, Gaidano G, Wiktor-Jedrzejczak W, Carpenter N, Mehta B, Franklin J, Giagounidis A: Romiplostim in thrombocytopenic patients with low- or int-1- risk MDS results in reduced bleeding without impacting leukemic progression: final followup results from a randomized, double-blind, placebocontrolled study. Blood 2016;128:2000.

98 Brynes RK, Orazi A, Theodore D, Burgess P, Bailey CK, Thein MM: Evaluation of bone marrow reticulin in patients with chronic immune thrombocytopenia treated with eltrombopag: data from the EXTEND study. Am J Hematol 2015;90:598-601.

99 Brynes RK, Wong RS, Thein MM, Bakshi KK, Burgess P, Theodore D, Orazi A: A 2-year, longitudinal, prospective study of the effects of eltrombopag on bone marrow in patients with chronic immune thrombocytopenia. Acta Haematol 2017;137:66-72.

100 Janssens A, Rodeghiero F, Anderson D, Chong BH, Boda Z, Pabinger I, Červinek L, Terrell DR, Wang X, Franklin J: Changes in bone marrow morphology in adults receiving romiplostim for the treatment of thrombocytopenia associated with primary immune thrombocytopenia. Ann Hematol 2016;95:1077-1087.

101 Ghadaki B, Nazi I, Kelton JG, Arnold DM: Sustained remissions of immune thrombocytopenia associated with the use of thrombopoietin receptor agonists. Transfusion 2013;53:2807-2812.

102 Mahévas M, Fain O, Ebbo M, Roudot-Thoraval F, Limal N, Khellaf M, Schleinitz N, Bierling P, Languille L, Godeau B, Michel M: The temporary use of thrombopoietin-receptor agonists may induce a prolonged remission in adult chronic immune thrombocytopenia. Results of a French observational study. Br J Haematol 2014;165:865-869.

103 Stasi R, Newland A, Godeau B, Priego V, Viallard JF, Lopez-Fernandez MF, Jia C, Lopez A: An interim analysis of a phase 2, single-arm study of platelet responses and remission rates in patients with immune thrombocytopenia (ITP) receiving romiplostim. Blood 2013; 122:1074.

104 Bussel JB, Mahmud SN, Brigstocke S, Torneten SM: Tapering eltrombopag in patients with chronic ITP: how successful is this and in whom does it work? Blood 2015;126:1054.
105 Kong Z, Qin P, Xiao S, Zhou H, Li H, Yang R, Liu X, Luo J, Li Z, Ji G, Cui Z, Bai Y, Wu Y, Shao L, Peng J, Ma J, Hou M: A novel recombinant human thrombopoietin therapy for the management of immune thrombocytopenia in pregnancy. Blood 2017;130: 1097-1103.

106 Davies JM, Lewis MPN, Wimperis J, Rafi I, Ladhani S, Bolton-Maggs PH; British Committee for Standards in Haematology: Review of guidelines for the prevention and treatment of infection in patients with an absent or dysfunctional spleen: prepared on behalf of the British Committee for Standards in Haematology by a Working Party of the Haemato-Oncology Task Force. Br J Haematol 2011;155:308-317.

107 Ahmed R, Devasia AJ, Viswabandya A, Lakshmi KM, Abraham A, Karl S, Mathai J, Jacob PM, Abraham D, Srivastava A, Mathews V, George B: Long-term outcome following splenectomy for chronic and persistent immune thrombocytopenia (ITP) in adults and children : splenectomy in ITP. Ann Hematol 2016;95: 1429-1434.

108 Kumar S, Diehn FE, Gertz MA, Tefferi A: Splenectomy for immune thrombocytopenic purpura: long-term results and treatment of postsplenectomy relapses. Ann Hematol 2002;81:312-319.

109 Rodeghiero F, Ruggeri M: Short- and long-term risks of splenectomy for benign haematological disorders: should we revisit the indications? Br J Haematol 2012; 158:16-29.

110 Kojouri K, Vesely SK, Terrell DR, George JN: Splenectomy for adult patients with idiopathic thrombocytopenic purpura: a systematic review to assess long-term platelet count responses, prediction of response, and surgical complications. Blood 2004; 104:2623-2634.

111 Vianelli N, Valdrè L, Fiacchini M, de Vivo A, Gugliotta L, Catani L, Lemoli RM, Poli M, Tura S: Long-term follow-up of idiopathic thrombocytopenic purpura in 310 patients. Haematologica 2001;86:504-509.

112 Sarpatwari A, Provan D, Erqou S, Sobnack R, David Tai FW, Newland AC: Autologous ${ }^{111}$ In-labelled platelet sequestration studies in patients with primary immune thrombocytopenia (ITP) prior to splenectomy: a report from the United Kingdom ITP Registry. Br J Haematol 2010;151:477-487.

113 Cuker A, Cines DB: Evidence-based mini-review: Is indium-labeled autologous platelet scanning predictive of response to splenectomy in patients with chronic immune thrombocytopenia? Hematology Am Soc Hematol Educ Program 2010;2010:385-386.

114 Perotta A, Sunneberg TA, Scott J, Ratanatharaphorn V, Hook C, Attas L, Dason D, Kunkel LA: Rituxan ${ }^{\circledR}$ in the treatment of chronic idiopathic thrombocytopenia purpura (ITP). Blood 1999;94(suppl 1, Pt 1):14a, abstr 49.

115 Arnold DM, Heddle NM, Carruthers J, Cook DJ, Crowther MA, Meyer RM, Liu Y, Cook RJ, McLeod A, MacEachern JA, Mangel J, Anderson D, Vickars L, Tinmouth A, Schuh AC, Kelton JG: A pilot randomized trial of adjuvant rituximab or placebo for nonsplenectomized patients with immune thrombocytopenia. Blood 2012;119:1356-1362.

116 Ghanima W, Khelif A, Waage A, Michel M, Tjønnfjord GE, Romdhan NB, Kahrs J, Darne B, Holme PA; RITP study group: Rituximab as second-line treatment for adult immune thrombocytopenia (the RITP trial): a multicentre, randomised, double-blind, placebo-controlled trial. Lancet 2015;385:1653-1661.

117 Gudbrandsdottir S, Birgens HS, Frederiksen H, Jensen BA, Jensen MK, Kjeldsen L, Klausen TW, Larsen H, Mourits-Andersen HT, Nielsen CH, Nielsen OJ, Plesner T, Pulczynski S, Rasmussen IH, Rønnov-Jessen D, Hasselbalch HC: Rituximab and dexamethasone vs dexamethasone monotherapy in newly diagnosed patients with primary immune thrombocytopenia. Blood 2013;121:1976-1981. 
118 Li Z, Mou W, Lu G, Cao J, He X, Pan X, Xu K: Lowdose rituximab combined with short-term glucocorticoids up-regulates Treg cell levels in patients with immune thrombocytopenia. Int J Hematol 2011;93:9198.

119 Zaja F, Baccarani M, Mazza P, Bocchia M, Gugliotta L, Zaccaria A, Vianelli N, Defina M, Tieghi A, Amadori S, Campagna S, Ferrara F, Angelucci E, Usala E, Cantoni S, Visani G, Fornaro A, Rizzi R, De Stefano V, Casulli F, Battista ML, Isola M, Soldano F, Gamba E, Fanin R: Dexamethasone plus rituximab yields higher sustained response rates than dexamethasone monotherapy in adults with primary immune thrombocytopenia. Blood 2010;115:2755-2762.

120 Arnold DM, Dentali F, Crowther MA, Meyer RM, Cook RJ, Sigouin C, Fraser GA, Lim W, Kelton JG: Systematic review: Efficacy and safety of rituximab for adults with idiopathic thrombocytopenic purpura. Ann Intern Med 2007;146:25-33.

121 Stasi R, Stipa E, Forte V, Meo P, Amadori S: Variable patterns of response to rituximab treatment in adults with chronic idiopathic thrombocytopenic purpura. Blood 2002;99:3872-3873.

122 Nazi I, Kelton JG, Larché M, Snider DP, Heddle NM, Crowther MA, Cook RJ, Tinmouth AT, Mangel J, Arnold DM: The effect of rituximab on vaccine responses in patients with immune thrombocytopenia. Blood 2013;122:1946-1953.

123 Vesely SK, Perdue JJ, Rizvi MA, Terrell DR, George JN Management of adult patients with persistent idiopathic thrombocytopenic purpura following splenectomy: a systematic review. Ann Intern Med 2004;140: 112-120.

124 Audia S, Godeau B, Bonnotte B: Is there still a place for «old therapies» in the management of immune thrombocytopenia? Rev Med Interne 2016;37:43-49.

125 Cuker A, Neunert CE: How I treat refractory immune thrombocytopenia. Blood 2016;128:1547-1554.

126 Mahévas M, Gerfaud-Valentin M, Moulis G, Terriou L, Audia S, Guenin S, Le Guenno G, Salles G, Lambotte O, Limal N, Viallard JF, Cheze S, Tomowiak C, Royer B, Neel A, Debouverie O, Hot A, Durieu I, Perlat A, Cliquennois M, Deteix C, Michel M, Godeau B: Characteristics, outcome, and response to therapy of multirefractory chronic immune thrombocytopenia. Blood 2016;128:1625-1630.

127 Choi PY, Roncolato F, Badoux X, Ramanathan S, Ho SJ, Chong BH: A novel triple therapy for ITP using high-dose dexamethasone, low-dose rituximab, and cyclosporine (TT4). Blood 2015;126:500-503.

128 Veneri D, Soligo L, Pizzolo G, Ambrosetti A: The association of rituximab and a thrombopoietin receptor agonist in high-risk refractory immune thrombocytopenic purpura. Blood Transfus 2015;13:694-695.

129 Rashidi A, Blinder MA: Combination therapy in relapsed or refractory chronic immune thrombocytopenia: a case report and literature review. J Clin Pharm Ther 2016;41:453-458.

130 Mannucci PM: Hemostatic drugs. N Engl J Med 1998; 339:245-253.
131 Bussel JB, Buchanan GR, Nugent DJ, Gnarra DJ, Bomgaars LR, Blanchette VS, Wang YM, Nie K, Jun S: A randomized, double-blind study of romiplostim to determine its safety and efficacy in children with immune thrombocytopenia. Blood 2011;118:28-36.

132 Bussel JB, Hsieh L, Buchanan GR, Stine K, Kalpatthi R, Gnarra DJ, Ho RH, Nie K, Eisen M: Long-term use of the thrombopoietin-mimetic romiplostim in children with severe chronic immune thrombocytopenia (ITP). Pediatr Blood Cancer 2015;62:208-213.

133 Elalfy MS, Abdelmaksoud AA, Eltonbary KY: Romiplostim in children with chronic refractory ITP: randomized placebo controlled study. Ann Hematol 2011; 90:1341-1344.

134 Bundesärztekammer: Querschnitts-Leitlinien (B̈̈K) zur Therapie mit Blutkomponenten und Plasmaderivaten, ed 4. www.bundesaerztekammer.de/aerzte/medizinethik/wissenschaftlicher-beirat/veroeffentlichungen/ haemotherapie-transfusionsmedizin/querschnitt-leitlinie/, 2014 (letzter Aufruf 16. Januar 2018).

135 Wandt H, Schäfer-Eckart K, Greinacher A: Platelet transfusion in hematology, oncology and surgery. Dtsch Arztebl 2014;111:809-815.

136 Grimaldi-Bensouda L, Michel M, Aubrun E, Leighton P, Viallard JF, Adoue D, Magy-Bertrand N, Tisserand G, Khellaf M, Durand JM, Quittet P, Fain O, Bonnotte B, Morin AS, Limal N, Costedoat-Chalumeau N, Morel N, Pan-Petesch B, Decaux O, Mahevas M, Ruel M, Sacre K, Lefrere F, Abenhaim L, Godeau B; PGRx Immune Thrombocytopenia Study Group: A case-control study to assess the risk of immune thrombocytopenia associated with vaccines. Blood 2012;120:4938-4944.

137 Moulis G, Germain J, Comont T, Brun N, Dingremont C, Castel B, Arista S, Sailler L, Lapeyre-Mestre M, Beyne-Rauzy O, Godeau B, Adoue D; CARMEN Investigators Group: Newly diagnosed immune thrombocytopenia adults: clinical epidemiology, exposure to treatments, and evolution. Results of the CARMEN multicenter prospective cohort. Am J Hematol 2017; 92:493-500.

138 Gernsheimer T, James AH, Stasi R: How I treat thrombocytopenia in pregnancy. Blood 2013;121:38-47.

139 Koyama S, Tomimatsu T, Kanagawa T, Kumasawa K, Tsutsui T, Kimura T: Reliable predictors of neonatal immune thrombocytopenia in pregnant women with idiopathic thrombocytopenic purpura. Am J Hematol 2012;87:15-21.

140 van der Lugt NM, van Kampen A, Walther FJ, Brand A, Lopriore E: Outcome and management in neonatal thrombocytopenia due to maternal idiopathic thrombocytopenic purpura. Vox Sang 2013;105:236-243.

141 Myers B: Diagnosis and management of maternal thrombocytopenia in pregnancy. Br J Haematol 2012; 158:3-15.

142 Mahévas M, Michel M, Godeau B: How we manage immune thrombocytopenia in the elderly. Br J Haematol 2016;173:844-856.

143 Michel M, Rauzy OB, Thoraval FR, Languille L, Khellaf M, Bierling P, Godeau B: Characteristics and outcome of immune thrombocytopenia in elderly: results from a single center case-controlled study. Am J Hematol 2011;86:980-984.
144 Ekström Smedby K, Vajdic CM, Falster M, Engels EA, Martínez-Maza O, Turner J, Hjalgrim H, Vineis $\mathrm{P}$, Seniori Costantini A, Bracci PM, Holly EA, Willett E, Spinelli JJ, La Vecchia C, Zheng T, Becker N, De Sanjosé S, Chiu BC, Dal Maso L, Cocco P, Maynadié M, Foretova L, Staines A, Brennan P, Davis S, Severson R, Cerhan JR, Breen EC, Birmann B, Grulich AE, Cozen $\mathrm{W}$ : Autoimmune disorders and risk of non-Hodgkin lymphoma subtypes: a pooled analysis within the InterLymph Consortium. Blood 2008;111:4029-4038.

145 Feudjo-Tepie MA, Le Roux G, Beach KJ, Bennett D, Robinson NJ: Comorbidities of idiopathic thrombocytopenic purpura: a population-based study. Adv Hematol 2009;2009:963506.

146 Doobaree IU, Nandigam R, Bennett D, Newland A, Provan D: Thromboembolism in adults with primary immune thrombocytopenia: a systematic literature review and meta-analysis. Eur J Haematol 2016;97:321330 .

147 Langeberg WJ, Schoonen WM, Eisen M, Gamelin L, Stryker S:Thromboembolism in patients with immune thrombocytopenia (ITP): a meta-analysis of observational studies. Int J Hematol 2016;103:655-664.

148 Moulis G, Audemard-Verger A, Arnaud L, Luxembourger C, Montastruc F, Gaman AM, Svenungsson E, Ruggeri M, Mahévas M, Gerfaud-Valentin M, Brainsky A, Michel M, Godeau B, Lapeyre-Mestre M, Sailler L: Risk of thrombosis in patients with primary immune thrombocytopenia and antiphospholipid antibodies: a systematic review and meta-analysis. Autoimmun Rev 2016;15:203-209.

149 McMillan R, Bussel JB, George JN, Lalla D, Nichol JL: Self-reported health-related quality of life in adults with chronic immune thrombocytopenic purpura. Am J Hematol 2008;83:150-154.

150 Flores A, Klaassen RJ, Buchanan GR, Neunert CE: Patterns and influences in health-related quality of life in children with immune thrombocytopenia: a study from the Dallas ITP Cohort. Pediatr Blood Cancer 2017;64:e26045.

151 Brown TM, Horblyuk RV, Grotzinger KM, Matzdorff AC, Pashos CL: Patient-reported treatment burden of chronic immune thrombocytopenia therapies. BMC Blood Disord 2012;12:2

152 Kumar M, Lambert MP, Breakey V, Buchanan GR, Neier M, Neufeld EJ, Kempert P, Neunert CE, Nottage K, Klaassen RJ; ITP Consortium of North America: Sports participation in children and adolescents with immune thrombocytopenia (ITP). Pediatr Blood Cancer 2015;62:2223-2225.

153 Versorgungsmedizin-Verordnung vom 10. Dezember 2008 (BGBl. I S. 2412), die durch Artikel 18 des Gesetzes vom 17. Juli 2017 (BGBl. I S. 2541) geändert worden ist (www.gesetze-im-internet.de/versmedv/ BJNR241200008.html)

154 Lozano ML, Revilla N, Gonzalez-Lopez TJ, Novelli S, González-Porras JR, Sánchez-Gonzalez B, Bermejo N, Pérez S, Lucas FJ, Álvarez MT, Arilla MJ, Perera M, do Nascimento J, Campos RM, Casado LF, Vicente V: Real-life management of primary immune thrombocytopenia (ITP) in adult patients and adherence to practice guidelines. Ann Hematol 2016;95:1089-1098. 